\title{
The primary vascular dysregulation syndrome: implications for eye diseases
}

\author{
Josef Flammer $^{1 *}$, Katarzyna Konieczka ${ }^{1}$ and Andreas J Flammer ${ }^{2}$
}

\begin{abstract}
Vascular dysregulation refers to the regulation of blood flow that is not adapted to the needs of the respective tissue. We distinguish primary vascular dysregulation (PVD, formerly called vasospastic syndrome) and secondary vascular dysregulation (SVD). Subjects with PVD tend to have cold extremities, low blood pressure, reduced feeling of thirst, altered drug sensitivity, increased pain sensitivity, prolonged sleep onset time, altered gene expression in the lymphocytes, signs of oxidative stress, slightly increased endothelin-1 plasma level, low body mass index and often diffuse and fluctuating visual field defects. Coldness, emotional or mechanical stress and starving can provoke symptoms. Virtually all organs, particularly the eye, can be involved. In subjects with PVD, retinal vessels are stiffer and more irregular, and both neurovascular coupling and autoregulation capacity are reduced while retinal venous pressure is often increased. Subjects with PVD have increased risk for normal-tension glaucoma, optic nerve compartment syndrome, central serous choroidopathy, Susac syndrome, retinal artery and vein occlusions and anterior ischaemic neuropathy without atherosclerosis. Further characteristics are their weaker blood-brain and blood-retinal barriers and the higher prevalence of optic disc haemorrhages and activated astrocytes. Subjects with PVD tend to suffer more often from tinnitus, muscle cramps, migraine with aura and silent myocardial ischaemic and are at greater risk for altitude sickness. While the main cause of vascular dysregulation is vascular endotheliopathy, dysfunction of the autonomic nervous system is also involved. In contrast, SVD occurs in the context of other diseases such as multiple sclerosis, retrobulbar neuritis, rheumatoid arthritis, fibromyalgia and giant cell arteritis. Taking into consideration the high prevalence of PVD in the population and potentially linked pathologies, in the current article, the authors provide recommendations on how to effectively promote the field in order to create innovative diagnostic tools to predict the pathology and develop more efficient treatment approaches tailored to the person.
\end{abstract}

Keywords: Primary vascular dysregulation, Endothelial dysfunction, Vasospasm, Glaucoma, Retinal venous pressure, Risk factors, Molecular targets, Predictive diagnostics, Targeted prevention, Integrative medical approach

\section{Table of contents}

1. Introduction

2. Regulation of blood flow

2.1. Function of blood flow

2.2. Regulation of blood flow in general

2.2.1. Global blood circulation

2.2.2. Blood supply to the individual organs

2.2.3. The role of vascular endothelial cells

2.3. Regulation of ocular blood flow

\footnotetext{
* Correspondence: joseffflammer@usb.ch

'Department of Ophthalmology, University of Basel, Mittlere Strasse 91, Basel $\mathrm{CH}-4031$, Switzerland

Full list of author information is available at the end of the article
}

2.3.1. Anatomy of ocular blood supply

2.3.2. Regulation of retinal blood flow

2.3.3. Regulation of choroidal blood flow

2.3.4. Regulation of optic nerve head blood flow

3. Vascular dysregulation

3.1. Primary vascular dysregulation (PVD)

3.1.1. Risk factors for PVD

3.1.2. Pathomechanisms of PVD

3.1.3. Trigger factors for PVD

3.1.4. PVD and Raynaud's disease

3.2. Secondary vascular dysregulation

3.2.1. Mechanism of SVD

3.2.2. Causes of SVD

4. General symptoms and signs of PVD

\section{Ciomed Central}


4.1. General symptoms of PVD

4.1.1. PVD and temperature sensation

4.1.2. PVD and thirst

4.1.3. PVD and sleep behaviour

4.1.4. PVD and physical activity

4.1.5. PVD and professional activity

4.1.6. PVD and sensitivity

4.1.7. PVD and psychological stress

4.1.8. PVD and pain

4.1.9. PVD and migraine

4.1.10. PVD and altitude sickness

4.1.11. PVD, tinnitus and sudden hearing loss

4.1.12. PVD and thyroid dysfunction

4.2. General signs of PVD

4.2.1. PVD and temperature

4.2.2. PVD and Endothelin-1

4.2.3. PVD and blood pressure

4.2.4. PVD and the heart

4.2.5. PVD and the autonomic nervous system

4.2.6. PVD and circadian rhythm

4.2.7. PVD and gene expression in lymphocytes

4.2.8. PVD and oxidative stress

5. Visual signs and symptoms of PVD

5.1. PVD and visual function

5.2. PVD and ocular blood flow

5.3. PVD and retinal vascular spatial irregularities

5.4. PVD and stiffness of retinal vessels

5.5. PVD and neurovascular coupling

5.6. PVD and blood-brain barrier

5.7. PVD and activation of astrocytes

5.8. PVD and autoregulation

5.9. PVD and the relation between peripheral and ocular circulation

5.10. PVD and retinal venous pressure

5.11. PVD and optic disc haemorrhages

6. PVD and ophthalmic diseases

6.1. PVD and glaucoma

6.2. PVD and other eye diseases

6.2.1. Retinal arterial occlusion

6.2.2. Retinal vein occlusion

6.2.3. Anterior ischaemic optic neuropathy

6.2.4. Susac syndrome

6.2.5. PVD and optic nerve compartment syndrome

6.2.6. Central serous chorioretinopathy

6.2.7. Leber hereditary optic neuropathy

6.2.8. Retinitis pigmentosa

7. Therapy

7.1. Lifestyle

7.2. Nutrition

7.3. Magnesium

7.4. Calcium channel blockers

7.5. Endothelin-antagonists

7.6. Fludrocortisone
7.7. Carboanhydrase inhibitors

7.8. Ginkgo biloba

7.9. Other drugs

8. Conclusion

\section{Introduction}

The amount of blood needed in various organs and tissues varies greatly over time, which is why there is a demand for a sophisticated blood flow (BF) regulation. This is achieved by adapting perfusion pressure and local resistance to flow; resistance, thereby, is a function of the vessel diameter. The term vasospasm denotes an inappropriate constriction of an artery [1]. If such spasms occur in several organs simultaneously or sequentially, the condition is referred to as vasospastic syndrome [2]. The term vascular dysregulation, however, is a broader term that embraces arterial spasms and also inappropriate constrictions and/or dilatation of arteries, veins or capillaries, often accompanied by a barrier dysfunction $[3,4]$. Vascular dysregulation can lead to both over and under perfusion of a particular supply territory. If vascular dysregulation is associated with symptoms or signs, the term vascular dysregulation syndrome is used. This syndrome can be primary (primary vascular dysregulation syndrome, PVD syndrome) or secondary to another disease (secondary vascular dysregulation syndrome, SVD syndrome). Vascular dysregulation can involve any organ; however, the eye is particularly often affected. In this review, we summarise the basic aspects of vascular dysregulation and focus on its role in the pathogenesis of eye diseases.

\section{Regulation of blood flow}

\subsection{Function of blood flow}

One of the major functions of BF is its transport capability. It transports not only cells, ions and molecules but, importantly, also heat. In a nutshell, blood circulation connects organs, allowing the body to function as an integrative system.

Adequate and inadequate BF has a huge impact on human health and disease. The generally best known causes of disturbed BF are related to the consequences of advanced atherosclerosis and/or its secondary events like thrombosis and embolism. The risk factors for atherosclerosis have been studied extensively. Its medical and socio-economic impacts are most visible after a cerebrovascular insult or myocardial infarction. Vascular dysregulation is another, but far less well known, cause of a disturbed BF to organs, and its often-neglected role in the pathogenesis of several diseases will be discussed in detail in this review. 


\subsection{Regulation of blood flow in general}

There are two different regulatory components: the global circulation of the entire body and the distribution of $\mathrm{BF}$ to the individual organs or parts of them.

\subsubsection{Global blood circulation}

The heart pumps blood into the arteries, building up a pressure gradient from the arteries over the capillaries to the veins back to the heart. The global circulation equals the cardiac output, which is the amount of blood that is pumped by the heart per unit of time. This cardiac output is a function of heart rate and stroke volume. It is constantly adapted to the overall need of the body. During physical activity, for example, it can be four to five times larger than when at rest. Cardiac output is mainly controlled by the autonomic nervous system and circulating hormones.

Blood pressure results from the relationship between cardiac output and the overall resistance to flow. Blood pressure in itself, therefore, does not reflect the overall $\mathrm{BF}$ or the $\mathrm{BF}$ to the individual organs. In other words, a patient with systemic arterial hypertension or hypotension does not automatically have a higher or a lower overall perfusion.

\subsubsection{Blood supply to individual organs}

The demand of BF to different organs or parts of the organs varies partially independently. The distribution of cardiac output is therefore regulated by adapting the relative local resistance.

The BF to a tissue depends on the relationship between local perfusion pressure and local resistance to flow. Therefore, perfusion pressure alone is a weak parameter for the BF of an organ with autoregulation. If, however, the local regulation of BF in an organ is disturbed or absent, perfusion pressure becomes the dominant factor. Vascular resistance is regulated particularly in arteries and, to some extent, also in capillaries and veins. An increased resistance in the veins increases venous pressure and thereby reduces perfusion pressure and also increases transmural pressure in the capillaries. This leads potentially to higher extravasation of fluid.

The size of the vessels is regulated by contraction (vasoconstriction) or relaxation (vasodilatation) of the smooth muscle cells in arteries and veins and of pericytes in the capillaries. The smooth muscle cells get the corresponding information from different sources. They sense tension (myogenic regulation), and a large number of factors such as $\mathrm{K}^{+}, \mathrm{H}^{+}$or $\mathrm{CO}_{2}$ originating from the surrounding tissues influence smooth muscle cells either directly or indirectly via endothelial cells. In addition, smooth muscle cells get information from the autonomic nervous system and from molecules circulating in the blood.

\subsubsection{The role of vascular endothelial cells}

The endothelium is a thin layer of cells lining the inner parts of arteries, capillaries, veins and lymphatic vessels, thereby forming a structural barrier between the vascular space and the surrounding tissue. It is a dynamic organ, important in several housekeeping functions such as haemostasis, barrier function, immune and inflammatory responses, angiogenesis and particularly in the regulation of vascular tone. It has autocrine, paracrine and endocrine functions (Figure 1). It perceives mechanical information like sheer stress and traction as well as biochemical information, particularly via the circulating molecules [5-7]. Multiple factors, such as cardiovascular risk factors, genetic factors and inflammation, can influence the endothelium and predispose a subject to endothelial dysfunction [8]. A dysfunctional endothelium is involved in the pathogenesis of various diseases, which are called endotheliopathies [9]. A dysfunction of vascular endothelial cells (VEC) also plays a role in eye diseases. There is, for example, a relationship between reduced vascular endothelial progenitor cells and reduced flow-mediated dilation in glaucoma patients [10]. We also gain insight into the function of VEC from the analysis on neurovascular coupling in the retina. Stimulation with a flickering light leads to a quick dilatation of small vessels and, thereby, to a dilatation of larger retinal vessels by a mechanism called flowmediated vasodilatation. A prerequisite for this dilatation is a normal VEC function. Interestingly, reduced or even absent response, as quantified by the retinal vessel analyser, can be observed in both healthy PVD subjects [11] and in glaucoma patients progressing despite an intraocular pressure (IOP) in the normal range [12].

\subsection{Regulation of ocular blood flow \\ 2.3.1 Anatomy of ocular blood supply}

The eye is supplied by two vascular systems: the uveal and the retinal vessels. The uveal vascular system supplies the iris, the ciliary body and the choroid and also, by diffusion, the outer layers of the retina, including the photoreceptors. The retinal vessels supply the inner layers of the retina including the retinal ganglion cells.

Both the uveal and retinal vessels originate from the ophthalmic artery, which in turn is a branch of the internal carotid artery. The central retinal artery provides blood, and the central retinal vein drains the retina. The anterior choroid is supplied by the long ciliary arteries, whereas the posterior choroid is supplied by the short posterior ciliary arteries. The entire choroid drains into the vortex veins.

The retinal $\mathrm{BF}$ is characterised by a low perfusion rate, a high vascular resistance and a high oxygen extraction. By contrast, the choroid shows a high perfusion rate, a low vascular resistance and a low oxygen extraction. 


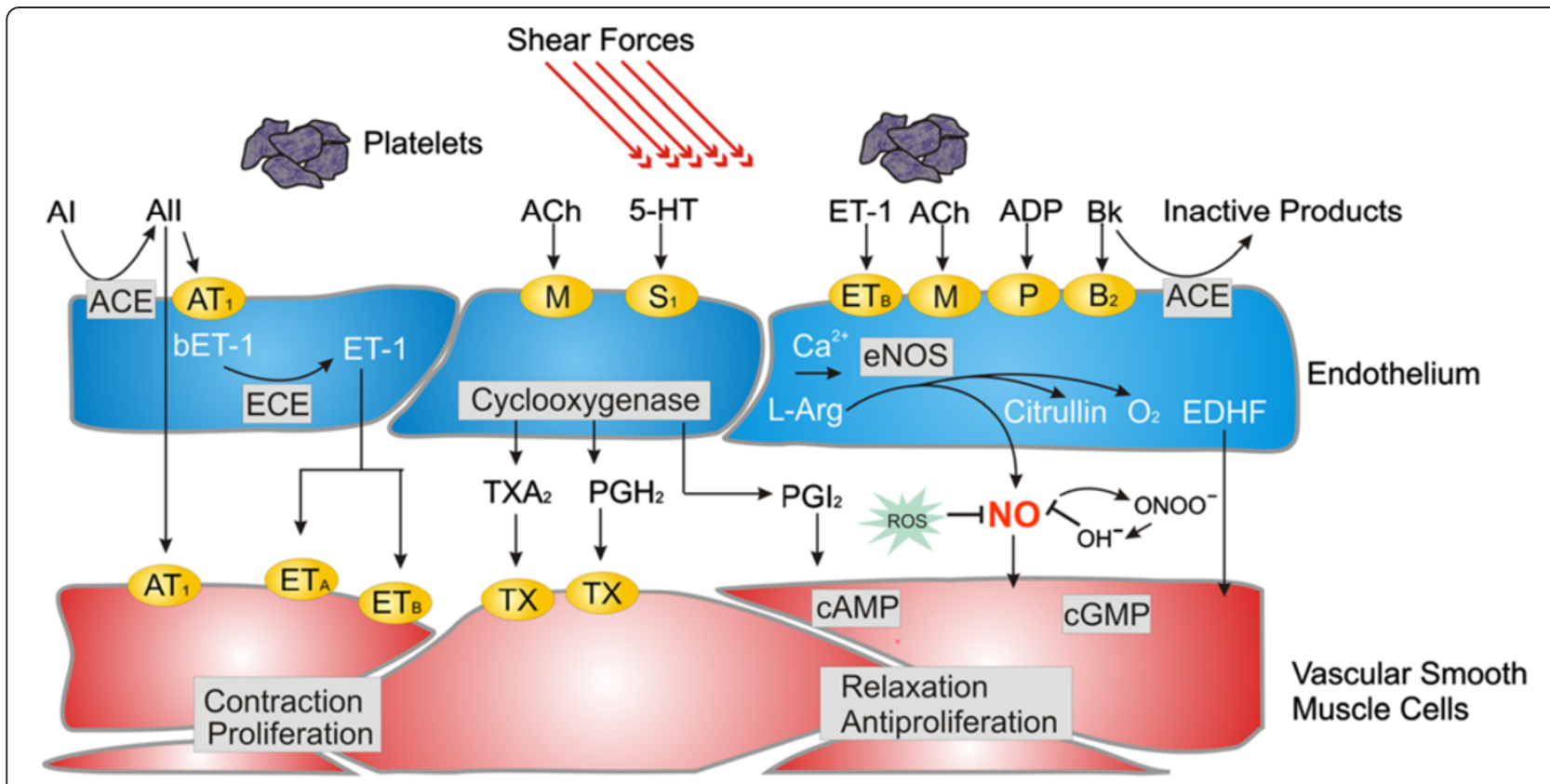

Figure 1 VEC receive physical and chemical information, integrate it and release vasoactive substances regulating vascular tone.

(From [5], with permission).

The $\mathrm{BF}$ in different tissues in the eye is regulated differently [13]. These regulations will therefore be discussed separately.

\subsubsection{Regulation of retinal blood flow}

Retinal vessels are very similar to brain vessels. However, only the extraocular part but not the intraocular part has autonomic innervation [14]. Proper retinal function requires the presence of a blood-retinal barrier. This physiological barrier regulates the flux of ions, proteins, hormones and water and also regulates infiltration of immune competent cells.

Retinal BF depends on the relationship between perfusion pressure and local resistance. Perfusion pressure is the difference between retinal arterial and retinal venous pressure. Under physiological conditions, retinal venous pressure is often more or less equal to the IOP. There are, however, a number of conditions in which retinal venous pressure is distinctly higher than the IOP [15].

Retinal BF, similar to brain BF, is autoregulated. Autoregulation is the intrinsic capacity to maintain constant flow despite changes in perfusion pressure. Autoregulation, however, is effective only within certain limits of perfusion pressure.

The size of retinal vessels and, thereby, the retinal circulation are also influenced by retinal activity. This connection is called neurovascular coupling. Neuronal activity in the central nervous system (including the retina) evokes localised changes in BF. The magnitude and the spatial location of these changes are tightly linked to changes in neural activity through a complex sequence of coordinated events involving neurons, glia and the vascular walls. The neurovascular coupling also provides a basis for functional imaging. If flickering light hits the retina, blood vessels dilate within seconds. The direct visual accessibility of fundus blood vessels allows direct monitoring of this response in vivo.

\subsubsection{Regulation of choroidal blood flow}

Choroidal BF regulation is distinctly different from the regulation of retinal BF $[16,17]$. The choroidal vessels are extensively innervated [18,19] (Figure 2). In addition to

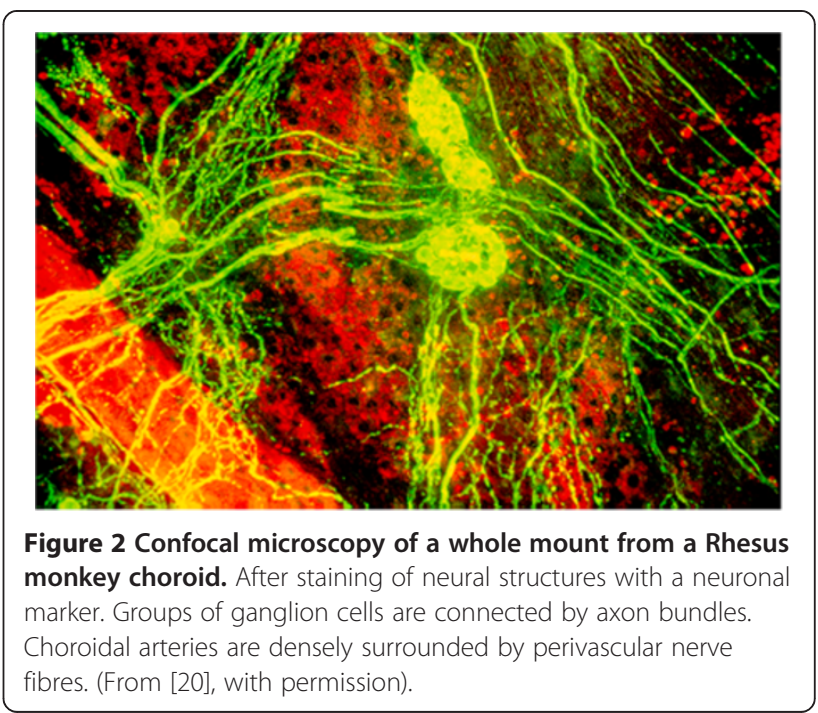


providing oxygen and other molecules, choroidal circulation also regulates eye temperature and most likely contributes to the fine-tuning of accommodation by regulating choroid thickness. This vascular bed is only partly autoregulated. The capillaries are fenestrated. Therefore, there is no or only little oncotic pressure gradient between intra- and extravascular spaces. The lack of oncotic pressure together with the absence of lymphatic vessels explains the choroidal effusion if IOP drops below a certain level.

Ciliary BF is similar to choroidal BF. Blood supply to the ciliary body is a prerequisite for the formation of aqueous humour [21]. A major drop of ciliary body BF therefore leads to a reduction of aqueous humour formation and, thereby, to a reduction of IOP.

\subsubsection{Regulation of optic nerve head blood flow}

Blood supply to the optic nerve head $(\mathrm{ONH})$ is very unique by any standard. The superficial layer of the $\mathrm{ONH}$ receives its blood supply via small branches of the central retinal artery. The prelaminar region (a small area anterior to the lamina cribrosa), however, is mainly supplied by branches from the choroidal arteries and directly from the short posterior ciliary arteries. The prelaminar area contains no arterioles, but has capillaries that are exceptionally long. In contrast to the arterial supply, venous drainage of the $\mathrm{ONH}$ is through the central retinal vein. The autoregulation in this area is less efficient than in the retina but better than in the choroid [22,23]. The ONH seems to be the only part of the central nervous system that has no proper blood-brain barrier. This is due to a lack of a proper blood-brain barrier of its capillaries [24] and to the fact that molecules can diffuse into the $\mathrm{ONH}$ from the surrounding choroid [25]. The diffusing vasoactive substances influence both size and barrier function of the vessels in the $\mathrm{ONH}$ and the adjacent retina. This is exemplified by endothelin-1 (ET-1) in Figure 3. Increased plasma concentrations of ET-1 reach the vascular endothelial cells and exert a more or less neutral effect on the vessel size, as long as the blood-brain barrier is intact. If, however, the blood-brain barrier is disrupted, ET-1 gets direct access to the vascular smooth muscle cells. If the proximate retina is hypoxic, hypoxia-inducible factor- $1 \alpha \quad(\mathrm{HIF}-1 \alpha)$ is increased and acts as a transcription factor, stimulating (among other molecules) the production of vascular endothelial growth factor (VEGF) or ET-1. This leads to both vasoconstriction and weakening of the blood-brain barrier in the corresponding area. Circulating ET-1 can also

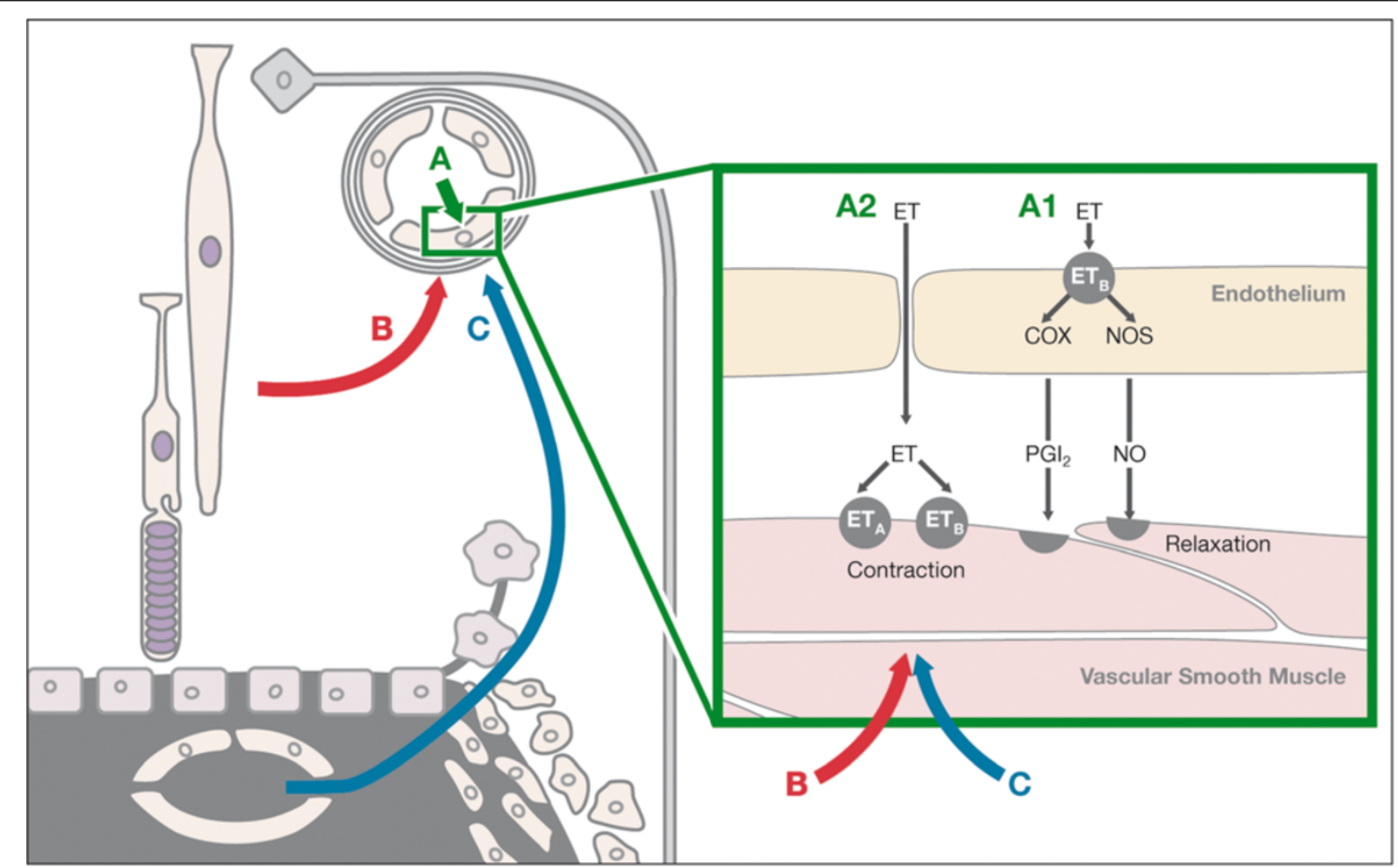

Figure 3 Influence of ET-1 on blood vessels in the optic nerve head and adjacent retina. (A) Circulating ET-1 reaches the endothelial cells (A1) and has a more or less neutral effect. If the blood-brain barrier is disrupted, it reaches directly the vascular smooth muscle cells (A2) and induces vasoconstriction. (B) Hypoxic retina produces ET-1 diffusing to neighbouring vessels. (C) ET-1 diffuses from fenestrated capillaries into the optic nerve head and adjacent retina, leading to vasoconstriction and, thereby, also to increased retinal venous pressure. (Modified from [26], with permission). 
diffuse from the fenestrated choriocapillaries directly into the $\mathrm{ONH}$ and adjacent retina bypassing the blood-brain barrier. Therefore, both local pathologies and systemic changes have a potential impact on $\mathrm{ONH}$ vessels, both arteries and veins (Figure 3).

\section{Vascular dysregulation}

The need for BF to different organs varies, and this is adapted by local vascular regulation. Such an adaption can be insufficient or improper. A patient with intermittent claudication, for example, cannot - due to atherosclerosis properly increase blood supply to the muscles of the legs while walking. The adaption of BF, however, can also be insufficient, despite anatomically normal vessels, due to a dysfunctional regulation of vascular tone $[1,4]$. This may be illustrated by red and white blotches on the face and neck of certain people when they are stressed. This is harmless but illustrates the basic characteristics of vascular dysregulation: the blood supply to a given organ is, for a period of time, not properly adapted to the need of this organ. Vascular dysregulation stands for an inadequate constriction or insufficient dilatation, as well as excessive dilatation of arteries, capillaries or veins. Such vascular dysregulation is often associated with other vascular dysfunctions, such as weakening of the blood-brain barrier [26] and also with seemingly independent signs and symptoms [27].

Global vascular dysregulation syndromes can be divided into primary vascular dysregulation and secondary vascular dysregulation syndromes. PVD is a predisposition to respond differently to a variety of stimuli like coldness or emotional stress. SVD is a dysfunction of anatomically healthy vessels, induced secondarily by an underlying disease [28].

\subsection{Primary vascular dysregulation}

Because PVD is an important risk factor for several eye diseases [1,3], we will discuss this entity in more detail. As outlined above, the PVD syndrome is a general predisposition to respond differently than unaffected persons do to a variety of stressors and stimuli, such as coldness, emotional stress and others. The most prominent aspect is the dysregulation of the vascular tone, giving the syndrome its name. However, other clinical signs and symptoms are often associated as well. Due to the lack of a gold standard for diagnosis and differences among populations, we do not know the exact prevalence of PVD. While in Switzerland 31\% of women and 7\% of men complain of cold extremities [29], only about $10 \%$ of women and $3 \%$ of men show the classic symptoms of PVD [30]. The term PVD should not be confused with the term posterior vitreous detachment.

\subsubsection{Risk factors for PVD}

Most of the subjects with PVD indicate that a parent suffered from the same syndrome. It is therefore likely an inherited disposition.

The syndrome manifests itself at, or shortly after, puberty and mitigates or even disappears with older age, particularly in females after menopause. The prevalence is much higher in women than in men [29]. Like migraine [31], PVD symptoms can recur if females take oestrogen replacement therapy after menopause. Therefore, oestrogen most likely plays a role as well.

Based on clinical experience, the syndrome occurs more often in academics than in blue-collar workers and more in Asians than in Caucasians. Although all these associations are obvious, the causal relationship is still unclear. The gender difference may partly be explained by differences in distribution of adrenergic receptors [32]. PVD is much more prevalent in slim people than in obese people [33]. Interestingly, patients with normal-tension glaucoma (NTG) also tend to be slim [34], and progression of NTG is often faster in patients with low body mass index (BMI) $[35,36]$.

\subsubsection{Pathomechanisms of PVD}

The exact pathogenesis for the development of PVD is still unclear. On the one hand, the autonomic nervous system is involved and contributes to the symptoms $[37,38]$, but on the other hand, the un-innervated retinal vessels are also involved. Therefore, PVD cannot be explained by the dysfunction of the autonomic nervous system only. Importantly, endothelial dysfunction is also involved; however, it is unclear what mechanism leads to such a type of endotheliopathy. An imbalance of ET-1 and nitric oxide (NO) production is most likely a major player and has been observed in glaucoma patients [39]. The mitochondria are also involved, although it is difficult to know whether they play a primary role or if they are involved secondarily $[40,41]$.

\subsubsection{Trigger factors for PVD}

Subjects with a predisposition for PVD have only minor symptoms, as long as they are not challenged. A classical challenge is coldness [2,42]. Subjects report more often the feeling of freezing, and they exhibit cooler extremities [43] and even cooler corneas than others when exposed to coldness [44]. Another trigger factor is psychological stress [45]. The way our body responds to this stress seems to be individually different [46] and also gender dependent [47]. Subjects with PVD often respond with redistribution of BF. These persons may get cold hands during stressful periods. To give an example, we performed a nailfold capillary microscopy test on a female musician suffering from NTG, a condition associated with PVD. While baseline BF in the capillaries was normal and 
her cold-induced BF stop lasted only a few seconds, the $\mathrm{BF}$ in the nailfold capillaries stopped for about $3 \mathrm{~min}$ when she started to talk about problems with her husband. Additionally, we observed a more heterogeneous distribution of temperature during psychological stress in thermography of the face as well.

In addition to cold and emotional stress, there are many other trigger factors. While some PVD subjects respond more to one particular trigger, others respond to multiple triggers. Vibration is another stimulus leading to vasoconstriction in some people [48], interestingly not only in the exposed but also in the unexposed hand [49]. Such people cannot work with a compressor [50]. Workers with hand-arm vibration syndrome also suffer from cold-induced vasospasm [51], indicating an underlying predisposition. Rarely do subjects with PVD respond to physical exercise. We made the observation that PVD subjects tend to suffer longer and stronger from whiplash traumata than others. Indeed, reduced cold pain threshold (cold hyperalgesia) predicted a worse outcome after whiplash traumata $[52,53]$.

\subsubsection{PVD and Raynaud's disease}

PVD [1] and Raynaud's disease [54] have certain similarities, which is why they are often confused with each other. In his thesis, written in 1892, Raynaud described an illness involving local ischaemic of the hands. This led to the term Raynaud's disease. In Raynaud's disease, the fingers turn white, which is why it is sometimes called the 'white finger disease' or 'corpse finger disease' (Figure 4). In addition, Raynaud's disease leads to morphological changes in the fingertips. Raynaud's disease is therefore distinctly different from PVD. Later, the term Raynaud's phenomenon was coined to describe a similar but clearly weaker entity than Raynaud's disease. Raynaud's phenomenon can also be primary or secondary [55]. The symptoms of Raynaud's phenomenon are to some extent similar to those of PVD [54]. The hands of PVD subjects indeed are also cool, but in contrast to Raynaud's syndrome, they almost never turn totally white and are not numb. In addition, the onset of

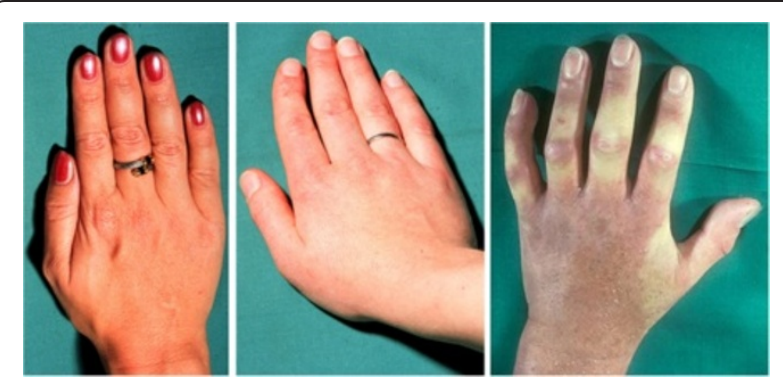

Figure 4 Raynaud's disease versus PVD. (Left) Hand of a healthy person. (Middle) Hand of a PVD subject. (Right) Hand of a patient with Raynaud's disease. (From [57], with permission). symptoms is not so abrupt and lasts longer than in Raynaud's phenomenon. PVD patients also suffer from a variety of other symptoms which do not occur in Raynaud's phenomenon. Therefore, PVD syndrome should not be confused with Raynaud's disease or with Raynaud's phenomenon. Additionally, both Raynaud's disease and Raynaud's phenomenon, in contrast to PVD, are only weakly related to glaucoma. Furthermore, PVD is also not identical with the so-called purple digit syndrome [56].

\subsection{Secondary vascular dysregulation}

$\mathrm{BF}$ to an organ can be dysregulated in diseases affecting the corresponding organ and also in diseases affecting remote organs. If a vascular dysregulation is secondary to such a disease, it is called secondary vascular dysregulation [1]. SVD in this context should not be confused with small vessel diseases.

\subsubsection{Mechanism of SVD}

In various conditions, particularly in inflammatory diseases, there is a release of molecules into the corresponding tissue and partially also into the blood stream, leading to changes of molecule concentration in the circulating blood that affects remote organs. Well known is the release of tumour necrosis factor-alpha which, among many effects, influences temperature control in the hypothalamus, thereby inducing fever. In a similar way, other molecules influence vascular tone; among these molecules, the most important is ET-1. ET-1 is produced by the vascular endothelium cells and is released predominantly abluminally and only partially intraluminally [58]. Under stress conditions, however, other cells also start to produce ET-1 [59] and thereby influence its concentration in the circulating blood. An increase in ET-1 has little or no effect on brain or retinal circulation as long as the blood-brain or blood-retinal barrier is intact [60]. In case of blood-brain or blood-retinal barrier breakdown, ET-1 gets direct access to smooth muscle cells or pericytes, thereby leading to vasoconstriction. As no such barrier exists in the choroid, an increase in ET-1 reduces choroidal BF. There is also a 'physiological barrier defect' in the $\mathrm{ONH}$ because molecules can diffuse from the choroid into the $\mathrm{ONH}$ [25] (see Figure 3). This explains $\mathrm{ONH}$ $\mathrm{BF}$ reduction in all conditions with increased ET-1 plasma levels.

\subsubsection{Causes of SVD}

We will discuss a few diseases which can lead to increased ET-1 plasma levels.

Multiple sclerosis. In patients with multiple sclerosis (MS), monocytes produce ET-1, thereby increasing its concentration in the cerebrospinal fluid (CSF). ET-1 levels are significantly elevated in the CSF of relapsing remitting MS patients with an acute clinical attack in 
comparison with those in a stable phase [61]. In some MS patients, ET-1 in the circulating blood [62] is increased, and therefore, ocular blood flow (OBF) decreased (Figure 5). This might contribute to the loss of retinal ganglion cells and their axons [63], to subclinical visual field defects [64], to narrower retinal arterioles and wider venules [65] and to increased rigidity of the retinal vessels [66]; furthermore, it may partially be the reason the $\mathrm{ONH}$ can turn slightly pale. Red wine can reduce ET-1 concentration which therefore explains why certain symptoms like visual disturbances in MS patients are reduced by red wine for a limited period of time [67]. The observed breakdown of the blood-brain barrier in these patients might also partly be due to ET-1 [68].

Optic neuritis. During optic neuritis, the blood ET-1 level rises quickly and then drops slowly during the next weeks but often remains slightly above normal values [70]. The reason for this increase during optic neuritis is not clear. Most likely, it is due to an increased production of ET-1 by monocytes. Whether ET-1 contributes to the symptoms is not clear at present.

Rheumatoid arthritis. Patients with rheumatoid arthritis have moderately increased plasma levels of ET-1 [71] produced, partly, by activated synovial cells [72]. ET-1 lowers the threshold of pain sensation. The mechanical hyperalgesia lasts longer in females [73], and ET-1 receptor blockade reduces pain [74].

Fibromyalgia. Some patients with fibromyalgia have increased levels of ET-1, although we do not know why [75]. It is also not known whether this plays any role. Nevertheless, by influencing the pain sensation threshold, the increased level of ET-1 presumably contributes to the pain sensation of these patients.

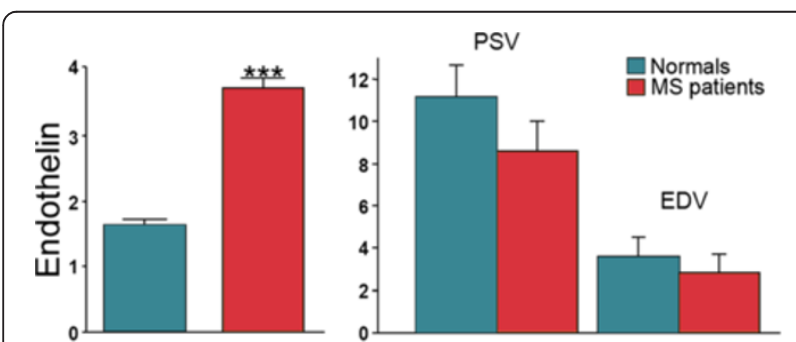

Figure 5 Endothelin-1 in multiple sclerosis patients. In some patients with multiple sclerosis, the plasma level of ET-1 (mean \pm SEM) is increased (left; modified from [62]). This leads to a decrease of OBF. Peak systolic and end diastolic velocity $(\mathrm{cm} / \mathrm{s})$ in the medial posterior ciliary arteries (mean \pm SEM) in the corresponding MS patients (right; from [69], with permission).
Giant cell arteritis. Giant cell arteritis is a systemic vasculitis affecting large and medium-sized arteries. The arteritic lesions lead to ischaemic symptoms such as cephalgia, masseter pain and mental depression. The acute loss of visual function is most often due to anterior ischaemic optic neuropathy and less frequently due to a central artery occlusion. Giant cell arteritis patients with involvement of the visual system have increased ET-1 plasma levels $[76,77]$. In inflamed temporal arteries, not only is the ET-1 level increased but also the expression of ET receptor B is upregulated both in vascular smooth muscle cells and multinucleated giant cells [78]. The involvement of the endothelin system explains why BF is reduced to a greater extent in the choroid than in the retina [79], why infarctions occur more often in the $\mathrm{ONH}$ than in the retina and also why amaurosis fugax-like symptoms often precede the major event [80]. The increased levels of ET-1 may be partly due to the matrix metalloproteinases (MMP2) released during inflammation. MMP2 converts the precursor molecule Big ET-1 to the active ET-1.

Retinal vein occlusion. Most patients with retinal vein occlusions have increased plasma levels of ET-1 during the acute phase. Weeks or months later, the concentration decreases, but rarely normalises totally $[81,82]$. The cause is unclear. The fact that the majority of patients suffer from other diseases such as systemic hypertension, diabetes or glaucoma makes it probable that these diseases may have caused or at least contributed to the increase of ET-1 plasma levels. PVD is another cause. For this reason, vein occlusions will be discussed in the section on PVD. The occlusion of the retinal vein seems to be often a secondary consequence of a retinal hypoperfusion due to an arterial disease. This leads to tissue hypoxia and thereby to an increase in HIF-1 $\alpha$ (Figure 6).

HIF- $1 \alpha$ then increases the expression of several factors like VEGF, erythropoietin and ET-1. An increased concentration of ET-1, both in the circulating blood and locally in the retinal tissue, can induce venous constriction and thereby increase retinal venous pressure [84]. If this pressure increases further, a prestasis syndrome and eventually the clinical picture of retinal vein occlusion (also called retinal venous thrombosis) develop. Indeed, ET-1 injection into the vitreous occludes the veins [85].

Others. Secondary vascular dysregulation may occur also in patients with antiphospholipid syndrome, pre-eclampsia, Susac syndrome and 


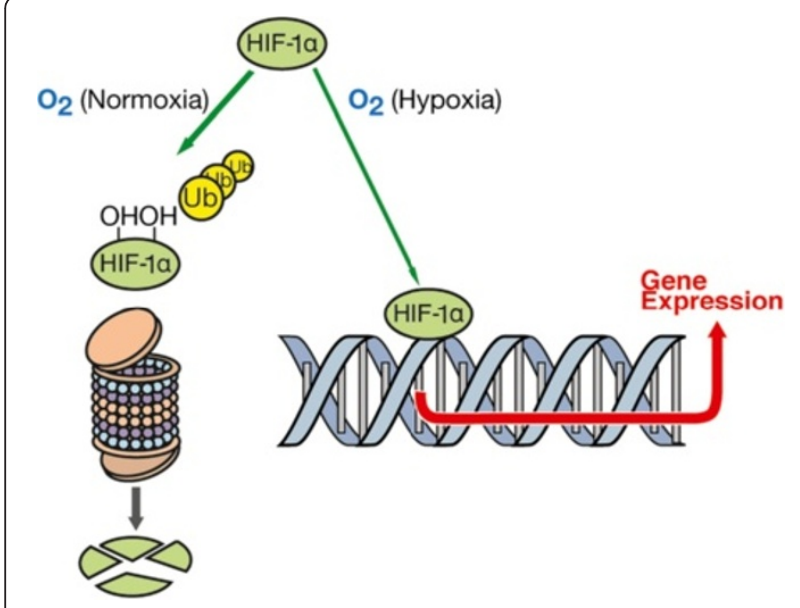

Figure 6 Hypoxia-inducible factor-1a. If oxygen concentration in a cell is lowered, less HIF-1a is oxidised and degraded. Thus, stabilised HIF-1a moves into the nucleus of the cell, where it acts as a transcription factor, stimulating the production of ET-1 or VEGF. (From [83], with permission.)

central serous chorioretinopathy. However, based on their medical history, these subjects also often suffer from PVD syndrome before they get sick; therefore, some of these diseases will be discussed in the context of PVD.

\section{General symptoms and signs of PVD}

Although the most striking signs and symptoms in PVD subjects are directly related to the dysregulation of $\mathrm{BF}$, these subjects often have additional signs and symptoms only indirectly related or seemingly even unrelated to BF. These signs and symptoms are not specific for PVD subjects but occur significantly more often in PVD subjects than in non-PVD subjects. The knowledge on these signs and symptoms helps in understanding these subjects better and might influence recommendations for behaviour as well as treatment of such patients.

\subsection{General symptoms of PVD}

\subsubsection{PVD and temperature sensation}

Classically, PVD patients indicate that they often feel cold, particularly in the hands or feet. Cold hands can be provoked not only by coldness but also by emotional stress, by vibration or via vasoconstrictive drugs; interestingly, the sensitivities to these trigger factors are interrelated. For example, emotional stress increases drug sensitivity, and patients that respond to vibration also have higher probability to respond to coldness $[51,86,87]$. An epidemiological study analysed thermal discomfort with cold extremities in a Swiss urban population. Younger subjects suffered more intensively from cold extremities than elderly subjects, women suffered more often than men, and slim subjects suffered more often than those with higher body mass index [33]. Psychological stress leads to vascular dysfunction, even in animals $[88,89]$. Subjects with PVD, however, seem to respond stronger to psychological stress than non-PVD subjects. There is also a relationship between cold extremities and sleep behaviour, which will be discussed in the section 4.1.3.

\subsubsection{PVD and thirst}

The desire to drink is significantly lower in subjects with PVD, while estimated daily fluid intake is only slightly lower [27]. However, PVD subjects tend to forget to drink. The concentration of ET-1 in the circulating blood is slightly increased [27], and this (among other effects) suppresses - via the prostaglandin-E2 axes - the centre of thirst in the brain. Reduced feeling of thirst, however, occurs also in patients with other diseases in which ET-1 concentration in the circulating blood is increased. For example, MS patients typically indicate that they are not thirsty and drink simply because they know they have to drink.

\subsubsection{PVD and sleep behaviour}

PVD subjects often indicate that they require a long time to fall asleep, particularly when their feet are cold. Indeed, studies have shown that body temperature and sleep are interrelated [90]. Sleep is typically initiated when central body temperature is declining and body heat loss on the extremities is maximal. This indicates that we fall asleep only after our extremities, particularly our feet, are warmed up, and this takes longer on average in subjects with PVD (Figure 7). Melatonin is one factor involved in the fine-tuning of vascular tone in selective vascular beds [91], and PVD subjects have circadian phase delay of dimlight melatonin onset [92].

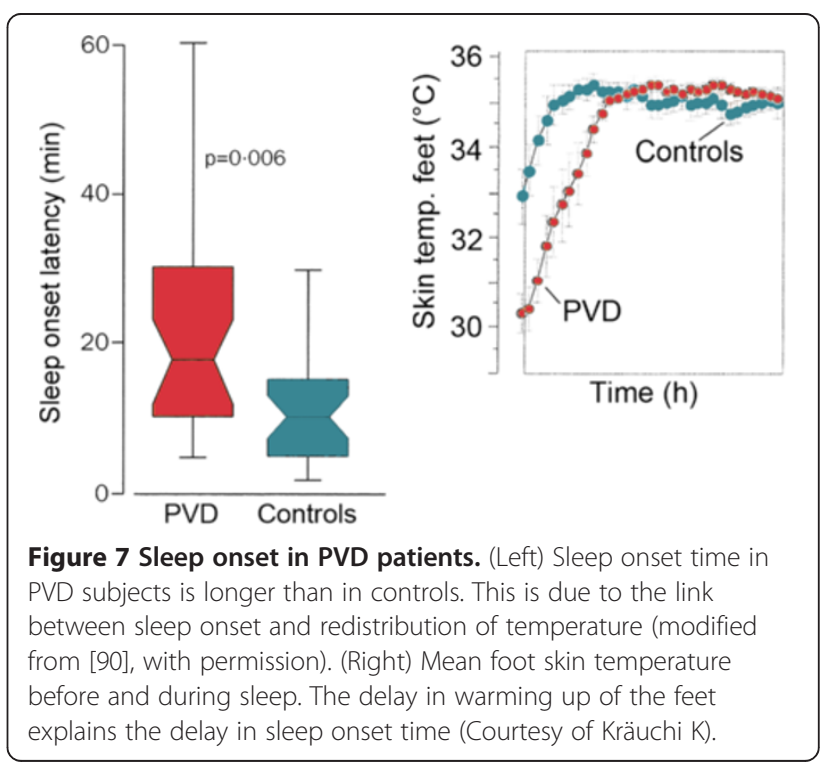




\subsubsection{PVD and physical activity}

Physical activity and mechanical stimuli can, in some PVD subjects, provoke local vasospasm. Examples are algodystrophy or acute posttraumatic ischaemic of the limbs [93], exercise-induced amaurosis fugax-like symptoms [94] due to vasospasm of the retinal arteries, painful and ischaemic mammilla provoked by nursing $[95,96]$ or orgasmic headache due to transient vasospasm [97-99]. All these symptoms fortunately occur infrequently. Most PVD subjects tolerate physical activities and are physically even more active than non-PVD subjects, particularly in endurance sports like cycling or running.

\subsubsection{PVD and professional activity}

Subjects with PVD are generally very meticulous. They tend to be very exact and diligent, particularly at work. They are often successful in their careers. Interestingly, there are more PVD subjects amongst the academics than amongst blue-collar workers. We observed only very few farmers or gardeners with PVD syndrome. Furthermore, we made the observation that black Africans developed the symptoms of PVD only after moving from Africa to Europe. At present, we do not have an explanation for this relationship. One hypothetical explanation is light exposure. Vitamin D may play a role, but has not yet been studied.

\subsubsection{PVD and sensitivity}

Based on clinical experience, PVD subjects are generally more sensitive. PVD subjects, for example, are able to smell odours that others cannot [100] (Figure 8), and they do have a higher pain sensation. Some PVD subjects perceive thunderstorms as well as foehn

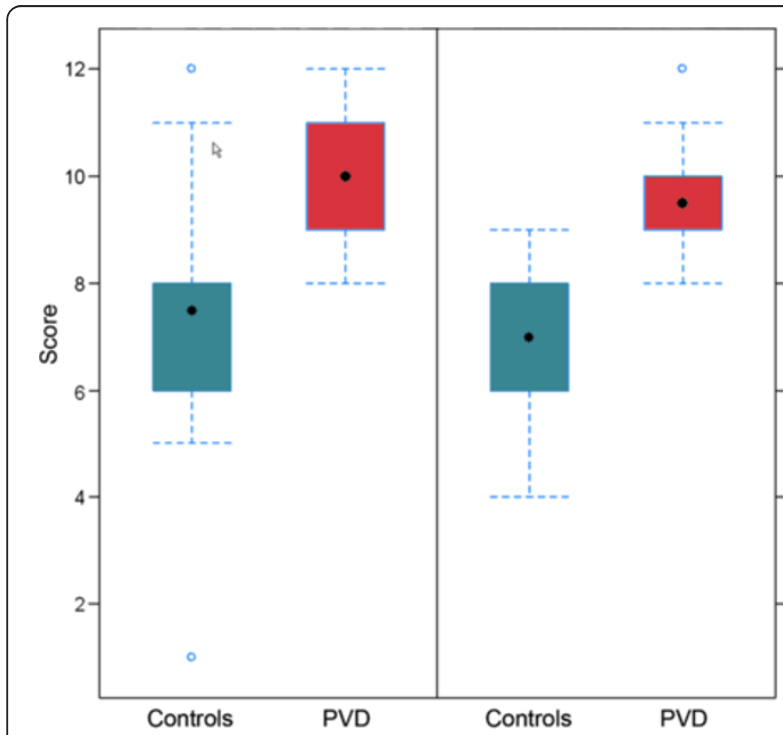

Figure 8 PVD subjects are good smellers. 'Sniffin' Sticks' score in healthy (left) and normal-tension glaucoma patients (right) with and without PVD. (Modified from [100], with permission). weather situations stronger than non-PVD subjects. It is our clinical experience that PVD subjects also have a higher sensitivity to certain drugs. They tolerate these drugs well but often only when given at much lower doses. This might partly be explained by the different expressions of certain ATP binding cassette (ABC) transporter proteins [101] (Figure 9).

The vascular response to nicotinates is increased [102]. We observed a young PVD patient who lost the tips of his fingers and nose after receiving an infusion containing adrenalin to treat arterial hypotension, which occurred in the context of an infection. Although the clinical observations are quite consistent, all these aspects have not yet been studied sufficiently.

\subsubsection{PVD and psychological stress}

Not much is known about the stress level of people with PVD. However, they tend to react differently to stress, particularly by reducing BF to the extremities and to the eyes [103]. In extreme situations, this can even lead to an infarction (e.g. an infarction of the $\mathrm{ONH}$ ). We observed $\mathrm{ONH}$ infarctions in two stock market traders when share values dropped dramatically and in one student who failed an exam. A schoolgirl suffered from a retinal arterial branch occlusion after a major stress. We often observed retinal venous occlusion in PVD subjects after major psychological stress (see 'Retinal vein occlusion'). In some subjects with PVD, an increased heterogeneity of skin perfusion, e.g. in the face, can be observed by eye but even better with the help of a thermal camera. Emotions can also provoke reversible cerebral vasoconstrictions [104].

\subsubsection{PVD and pain}

We already discussed pain sensitivity. Some PVD subjects also suffer from muscle cramps and other

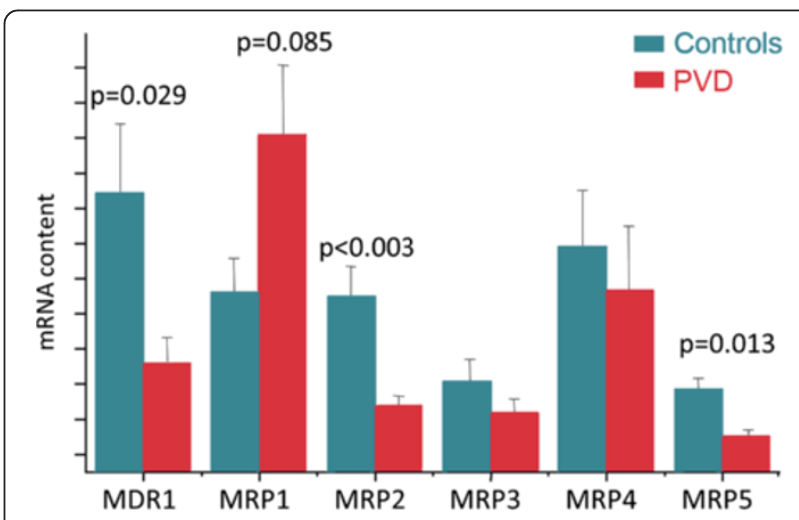

Figure 9 The role of transport proteins: MDRI (P-glycoprotein) and MRP (multidrug resistance-associated protein). The mean expression of these genes is significantly different in PVD subjects in relation to healthy controls. (Modified from [101], with permission). 
pain. Sometimes they feel pain deep in their eyes (behind the upper eyelid), which most likely is due to ischaemic of the ciliary muscle. These eye pains vanish quickly after treatment with a calcium channel blocker (CCB) such as nifedipine.

\subsubsection{PVD and migraine}

PVD and migraine are not identical and should not be confounded. Although PVD subjects suffer more often from migraine and vice versa, the two entities are principally independent [105]. While patients with migraine often have thermal hypersensitivity between attacks [106], a migraine attack can trigger the symptoms in a PVD subject, such as cold hands in the phase of aura. A reduction of neurovascular coupling during the acute phase has also been reported, potentially explaining why migraine patients avoid both intensive light and noises $[107,108]$.

PVD subjects sometimes - but not often - suffer from retinal migraine, also called 'presumed retinal vasospasm' [109]. Retinal 'angiospasm' during migraine has already been described in 1910 [110]. In 1939, a relationship between retinal vasospasm and alterations in the nailfold capillaries was described [111]. Such focal retinal arteriolar vasospasm can be dynamic with spastic cycles of a few seconds [112] (Figure 10). The reversible vasoconstriction in the retina [113] indicates that there must exist stimuli for vasoconstriction other than the autonomic nervous system. Taking neurovascular coupling into consideration, it seems feasible that a spreading depression [114] acts as a trigger factor for the vasoconstriction.

\subsubsection{PVD and altitude sickness}

Altitude sickness is a general term encompassing a spectrum of disorders that occur at higher altitudes. Most individuals suffer from altitude sickness to some extent when they reach high altitudes within a short time without giving their body enough time to adapt. Potential symptoms are as follows: headaches, lack of appetite, nausea, vomiting, fatigue, dizziness, sleep disturbances and peripheral oedema. The eyes are often involved. BF disturbances and retinal bleeding may occur. There is evidence for a genetic basis for altitude sickness [115].

The major cause of altitude sickness is the low oxygen level at higher elevations that leads to tissue hypoxia and thereby to an increase of HIF- $1 \alpha$. This induces increased expression of several hormones, including erythropoietin and also ET-1. Carbonic anhydrase inhibitors, endothelin antagonists and CCBs alleviate the symptoms. In the long term, our body acclimates to this situation, for example, by building more red blood cells. Based on our still-ongoing studies, we can state that the symptoms of altitude sickness are more pronounced in PVD subjects. We observed a young female subject with a known PVD syndrome who lost consciousness on a hot air balloon ride over the Alps. At high altitude, we also observed an increase in the retinal venous pressure, which is most likely a consequence of the rise of ET-1 [116].

\subsubsection{PVD, tinnitus and sudden hearing loss}

PVD subjects with NTG often indicate suffering from tinnitus and remarkably often indicate a history of sudden (mostly reversible) hearing loss [117]. Hearing problems in the context of migraine have been described [118], but the relationship between hearing and PVD needs to be studied. Nevertheless, the presence of ET receptors in the spiral modiolar artery makes a relationship probable [119]. The majority of patients with sudden hearing loss, despite apparent good health, have signs of disturbed microcirculation in the eye [120]. In addition, auditory processing deficits occur more often in individuals with primary open-angle

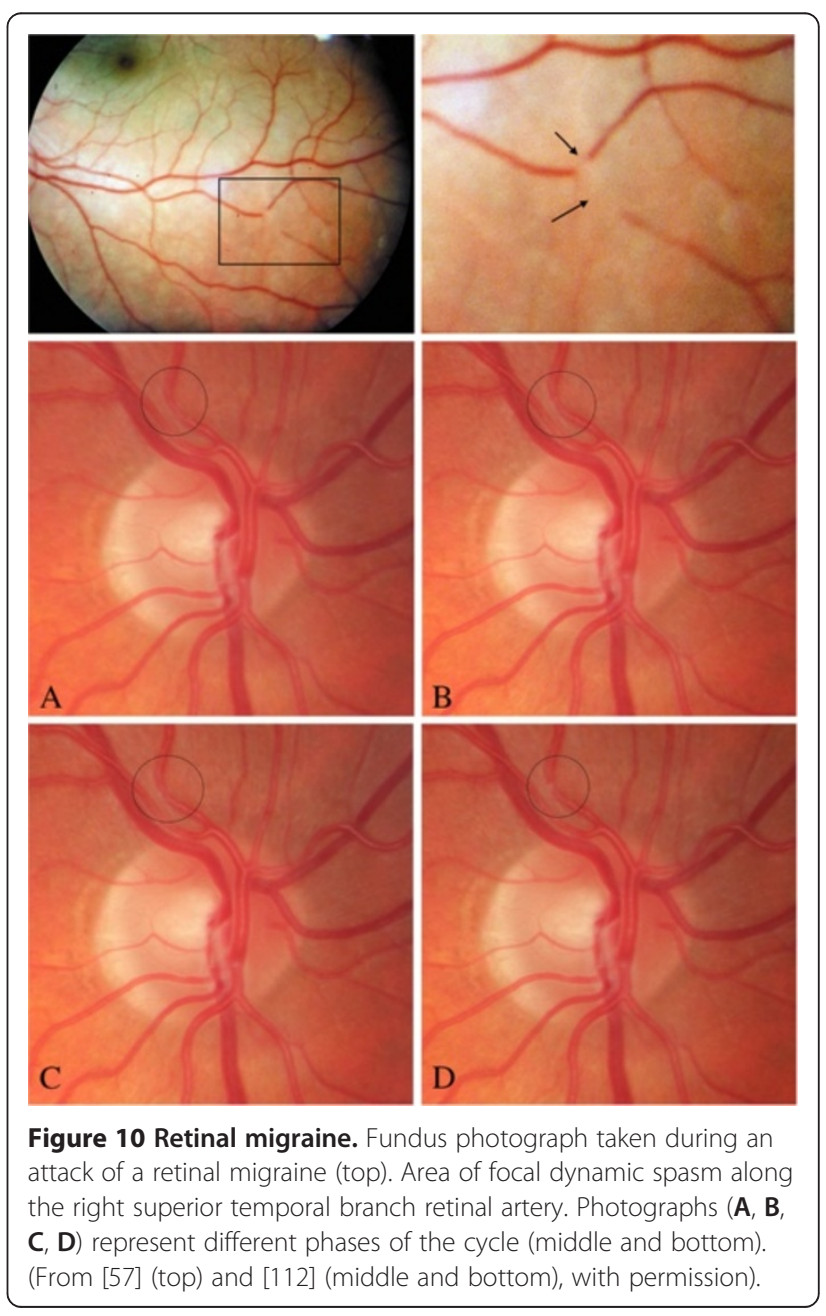


glaucoma [121], supporting the concept of glaucoma as a sick eye in a sick body [122].

\subsubsection{PVD and thyroid dysfunction}

Hyperthyroidism may induce coronary vasoconstriction $[123,124]$, and treatment with L-thyroxine can induce coronary spasm [125]. Hypothyroidism also can be associated with vascular dysfunction such as impaired endothelial- and non-endothelial-mediated vasodilation [126]. Hypothyroidism is associated with NTG [127], and interestingly, we find thyroid antibodies in most of these NTG patients. The vast majority of such patients are PVD subjects. An association between Raynaud's phenomenon and hypothyroidism was also described [128]. The causal relationship is not yet clear. Theoretically, ischaemic lesions in the thyroid gland may stimulate an autoimmune process or, conversely, autoimmunity may cause secondary vascular dysfunction.

\subsection{General signs of PVD}

In addition to the above illustrated symptoms, several signs characterise PVD subjects. These signs, which can be quantified objectively, will be summarised in the following paragraphs.

\subsubsection{PVD and temperature}

The sensation of cold extremities, a leading PVD symptom, is confirmed by finger skin temperature measurements $[29,87]$. PVD subjects are characterised by a lower distal (hands and feet) skin and corneal temperature (Figure 11). In some PVD subjects, the temperatures are asymmetric (Figure 12).

However, proximal skin temperatures of PVD subjects do not differ significantly from other subjects. Furthermore, in the circadian rhythm, PVD subjects also show a phase delay in foot skin temperature in comparison to non-PVD subjects [129]. Reduction of temperature due to vasospasm can occur anywhere on the body surface, not only on the hands, feet or nose but also at the scrotum [130] or the mammillae [131]. Interestingly, corneal temperature correlates well with BF of the ophthalmic artery $[132,133]$ and with finger temperature even after adjusting for environmental and tympanic temperatures and for age and sex [44].

\subsubsection{PVD and endothelin-1}

ET-1 is a peptide produced mainly, but not only, by endothelial cells. It is secreted abluminally to regulate local vascular tone. A small part is secreted intraluminally, leading to a certain concentration of ET-1 in the circulating blood (Figure 13). Production of ET-1 in other cells, particularly under pathological conditions (see 'Secondary vascular dysregulation'), further contributes to the plasma level. After the

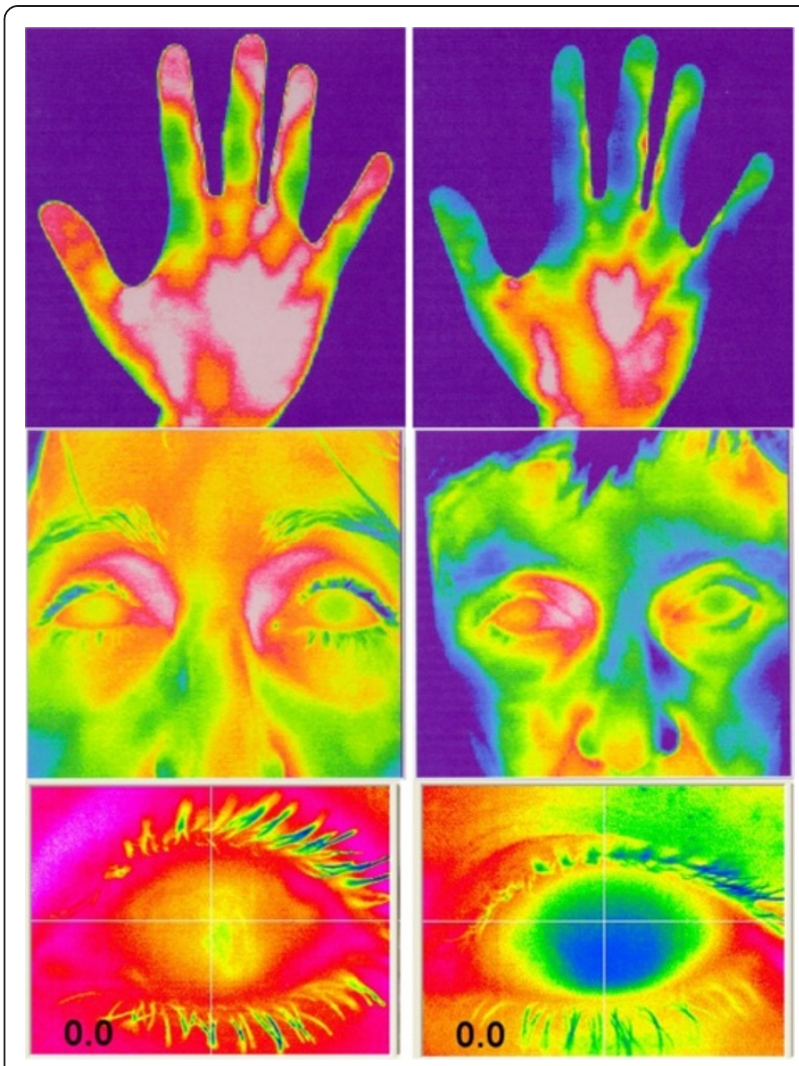

Figure 11 Examples of thermography of the hands, faces and eyes of controls (left) and PVD subjects (right). (From [57], with permission).

binding of ET-1 to its receptor, the complex is internalised into the cell. A major stimulation by ET-1 is therefore followed by a refractory phase (Figure 14).

Circulating ET-1 is mainly eliminated in the lung. Plasma level of ET-1 therefore reflects the balance between production and elimination of ET-1 and thus represents, to some extent, local activities. In healthy

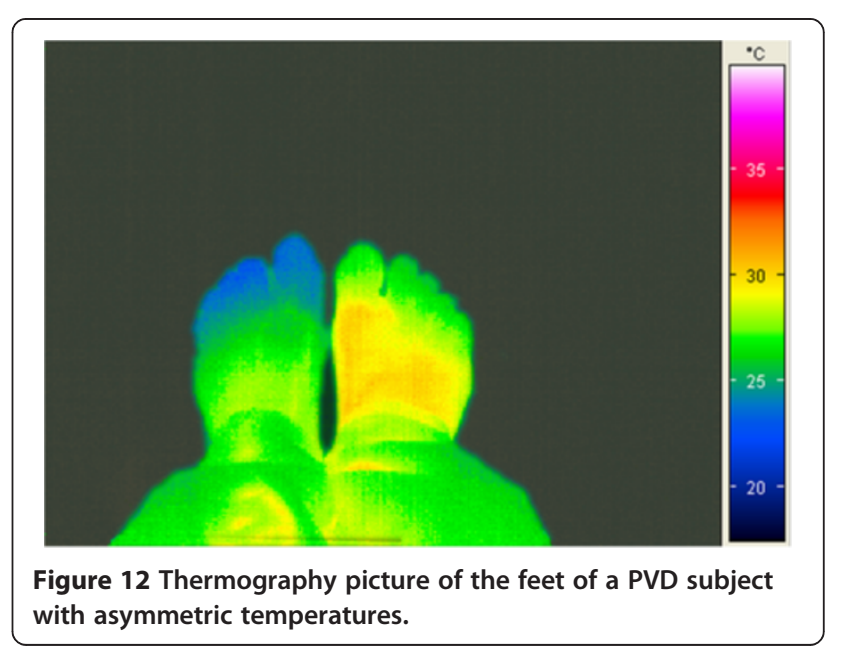




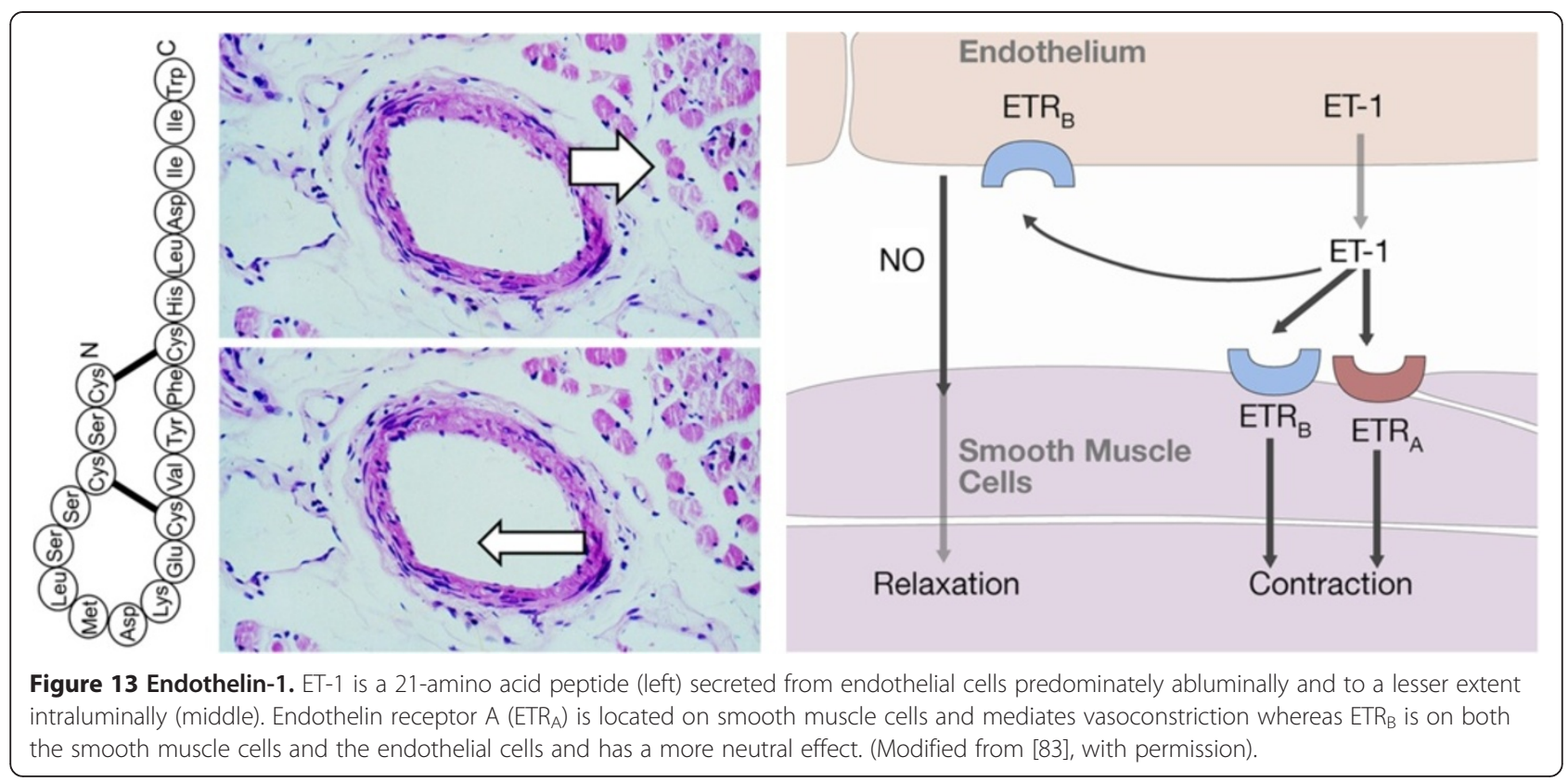

PVD subjects, ET-1 is slightly increased [27]. Both increased [135-138] and normal circulating ET-1 plasma levels [139] have been described in NTG patients. In one study, ET-1 was higher in those with progressive $\mathrm{ONH}$ damage than in those in which the damage has stabilised [140]. Other authors found a normal ET-1 level at baseline, but an abnormal response with changing body position [141] or after cold provocation [142]. There are conditions in which

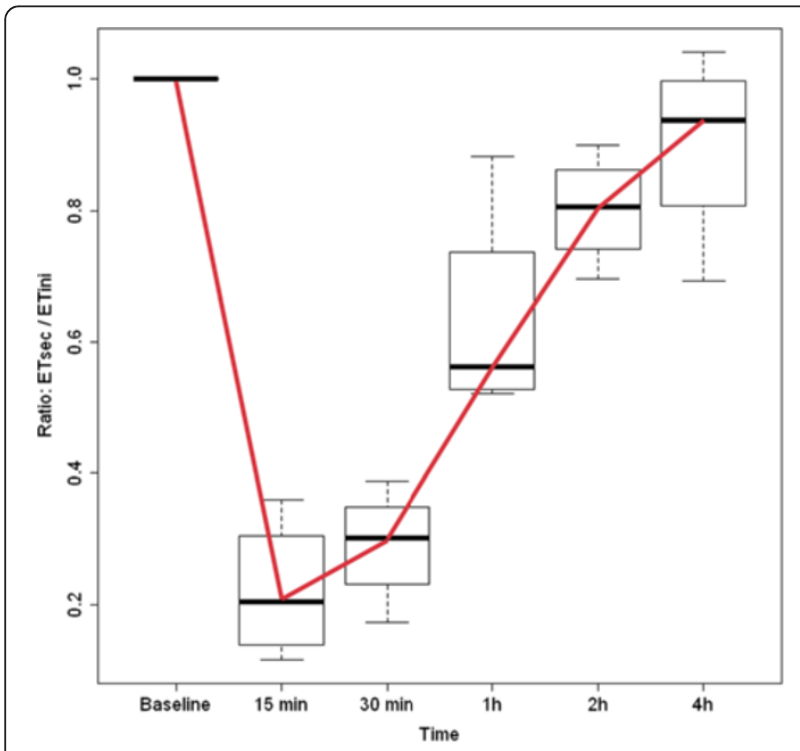

Figure 14 Refractoriness to ET-1. After the first stimulation by ET-1, subsequent stimulations lead to a smaller response. The first response is arbitrarily defined as 1 , while subsequent responses are less than 1. The vessels recover within about $4 \mathrm{~h}$. (From [134], with permission). local ET-1 concentrations do not correspond to the plasma level, for example, in the aqueous humour of glaucoma patients [139]. Notably, ET-1 in the aqueous humour correlates with IOP but not with systemic ET-1 plasma level [143]. Thus, in NTG patients, ET-1 may have a local as well as a systemic role, while in high-tension glaucoma (HTG) patients ET-1 may be dominantly increased to ocular tissue. Overall, for an adequate vascular function, the balance between vasoconstrictors (particularly ET-1) and vasodilators (particularly NO) [39] is of importance. In addition to the local concentration of ET-1, the local sensitivity to ET-1, which in turn depends on the number of ET receptors, is of importance as well [134,144]. Receptor density is locally increased in patients with giant cell arteritis. Interestingly, ET sensitivity is also dependent on blood pressure (BP). PVD subjects with low BP have higher ET-1 sensitivity [145]. Polymorphism of the ET receptor A seems to be associated with NTG [146]. A variant of the ET receptor A gene also modulates the risk for migraine [147]. Corresponding studies with healthy PVD subjects have not been done yet.

\subsubsection{PVD and blood pressure}

Aside from cold extremities, low BP is a characteristic of PVD subjects, especially when they are young. The diurnal pattern of the mean arterial pressure nearly mirrors the distal minus the proximal skin temperature gradient, providing a measure for distal skin BF. In other words, diurnal BP variations are associated with changes in distal-proximal skin temperature gradients. Therefore, subjects with cold extremities (particularly PVD subjects) mostly have lower BP than control subjects [148]. 
Glaucoma patients with PVD also have lower mean daytime BP (Figure 15).

BF standstill in the nailfold capillaries is often used as the gold standard for the diagnosis of PVD (Figure 16). Interestingly, BF standstill in the nailfold capillaries after cold provocation was negatively correlated with the lowest systolic BP at night (dipping) [149]. Conversely, patients with nocturnal over-dipping had reduced retrobulbar BF with increased resistivity [150]. Systemic hypotension and PVD occur more often in young females than in postmenopausal women or in men. It was suggested that local $\beta$-adrenergic vasodilatation may offset $\alpha$-adrenergic vasoconstriction in women to a greater extent than it does in men [151]. NTG patients have reduced sodium reabsorption in the proximal tubule, in spite of a low BP [152], probably also influenced by the slightly increased ET-1 level [153].

\subsubsection{PVD and the heart}

The role of vascular dysfunction in the development, progression and prognosis of atherosclerosis has been well documented [8]; however, vascular dysfunction is not pathognomonic for atherosclerosis. Chest pain or ischemia despite structurally normal, non-atherosclerotic coronary arteries is quite common, particularly in women, and may represent local dysregulations of the epicardial or the microcirculatory coronary vessels. Coronary vasospasms of apparently healthy arteries were described by Prinzmetal in 1959 [154]. Such spasms of the epicardial arteries occur at rest or after certain provocations, sometimes triggered by psychological stress [155]. Interestingly, the typical reduction or even stop in BF in the nailfold capillaries of PVD subjects in response to local cooling is also seen in patients with vasospastic angina [54]. Furthermore,

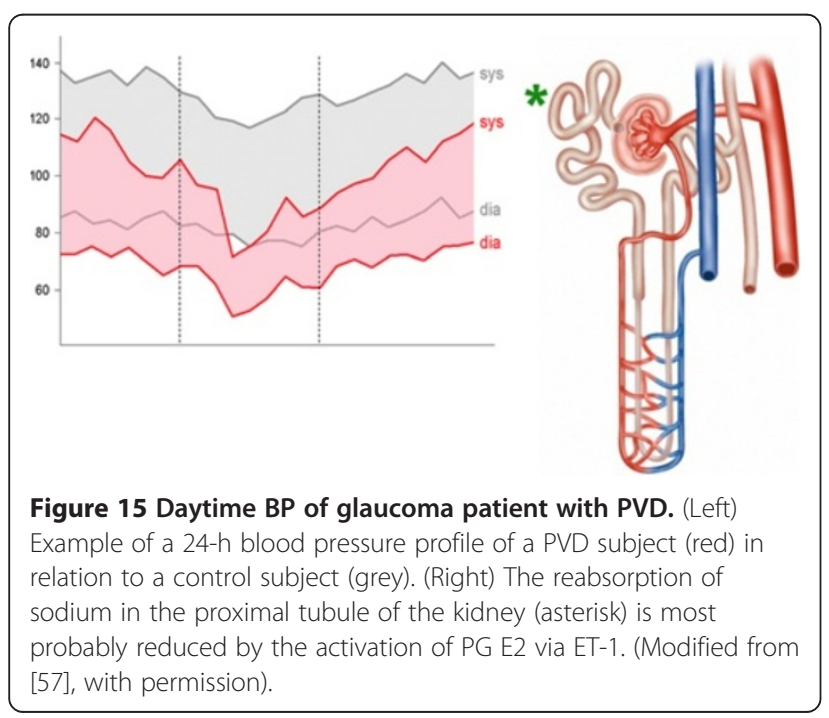

vasospastic angina is far more common in Asian countries [156], a pattern similar to both PVD and NTG [157]. Microvascular angina, particularly present in women, is another entity associated with dysfunctional vessels, particularly in the microcirculation [158]. However, it more likely affects elderly women with cardiovascular risk factors, thus a population different from those with PVD. However, microvascular angina may be an umbrella term for several vascular diseases, and PVD may be responsible for symptoms in a subset of these patients, especially in those where an abnormal increased pain sensitivity is proposed to be the pathomechanism [159]. An interesting observation in PVD patients is that electrocardiogram changes typical for myocardial ischemia occur frequently when patients are monitored over $24 \mathrm{~h}$, thus silent ischemia could take place in these patients, particularly at night $[160,161]$. Interestingly, disorders associated with secondary elevation of ET-1 and SVD, such as rheumatoid arthritis or psoriasis, show endothelial dysfunction and a significantly higher cardiovascular mortality $[162,163]$.

\subsubsection{PVD and the autonomic nervous system}

Vascular dysregulation is often explained by autonomic nervous dysfunctions. Indeed, analysis of heart rate variability revealed an autonomic imbalance in healthy PVD subjects with sympathetic predominance [164] (Figure 17). This is in agreement with the observation of a shift in the sympathovagal balance of the autonomic nervous system of NTG patients towards sympathetic activity [165].

Furthermore, PVD subjects show an increased reactivity in the well-innervated choroid [166]. PVD subjects also show a temperature dysregulation in the extremities and in the sympathetically innervated skin. This also explains the influence of emotions (including anxiety) on skin perfusion $[37,167]$. This was indirectly confirmed by a study comparing slow and normal hand re-warmers. Slow rewarmers demonstrated less activity in the parasympathetic nervous system during the cold provocation protocol compared to normal re-warmers [168]. Dysfunction of the autonomic nervous system in NTG patients [169] was related to ET-1 levels [170].

The exact causal relationship between autonomic nervous dysfunction and vascular dysfunction is unclear. A dysfunction of the autonomic nervous system can induce dysregulation of vessels. On the other hand, vascular dysregulation leads to chronic intermittent hypoxia, and this in turn increases sympathetic nervous activity chronically [171]. The involvement of the non-innervated retinal vessel, however, demonstrates that although the autonomic nervous system is involved, it cannot be the only player in the pathophysiology of PVD. 


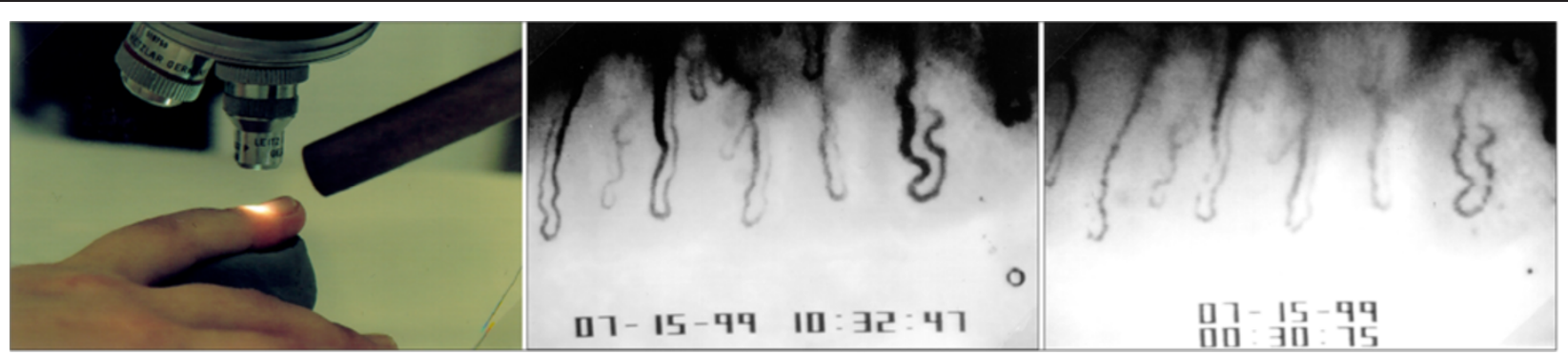

Figure 16 Nailfold capillary microscopy with a cooling device. The nailfold is made transparent by a drop of oil and is then videotaped (left). Normal blood flow (middle) and flow stopping after cold provocation (right). (Modified from [57], with permission).

\subsubsection{PVD and circadian rhythm}

Circadian rhythm and thermoregulation are interconnected phenomena [172]. The human body consists of two compartments, the heat-producing core and the heat-losing regulating shell. Even in a comfortable thermo-neutral environment, heat produced by the core is transferred to the peripheral parts of the body, which serve the function of heat loss. These parts are distal skin regions - fingers and toes. Heat loss is autonomically regulated and occurs via constriction or dilatation of peripheral blood vessels [173].

There is a close link between body heat loss and sleep induction. When falling asleep, the core body temperature declines, while distal skin temperature increases, indicating heat redistribution from the core to the shell. The degree of peripheral blood vessel dilatation of the skin of the hands and feet is a good physiological predictor for the rapid onset of sleep [174]. There is a strong association between thermal discomfort from cold extremities and sleep onset latency in the general population [29]. It has been shown that PVD subjects with sleep onset insomnia exhibit a phase delay of the circadian system (circadian

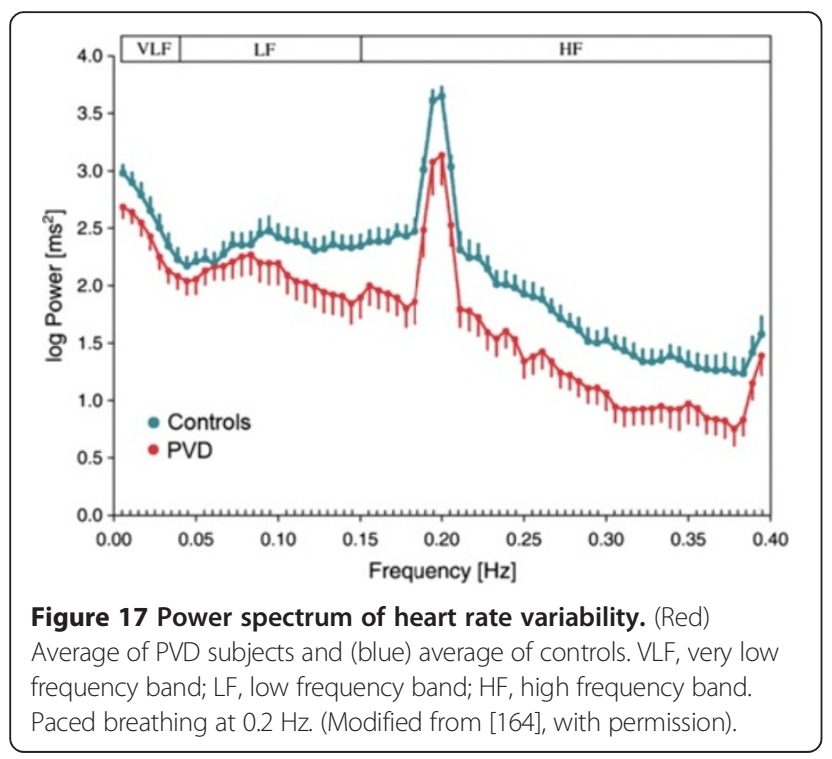

rhythms of distal and proximal skin temperatures, core body temperature and salivary melatonin secretion) by approximately $1 \mathrm{~h}$, but no differences in overall sleep times [92] (Figure 18).

\subsubsection{PVD and gene expression in lymphocytes}

Cells adapt their gene expression depending on internal and external information. Gene expression therefore reflects, at least to some extent, the environment in

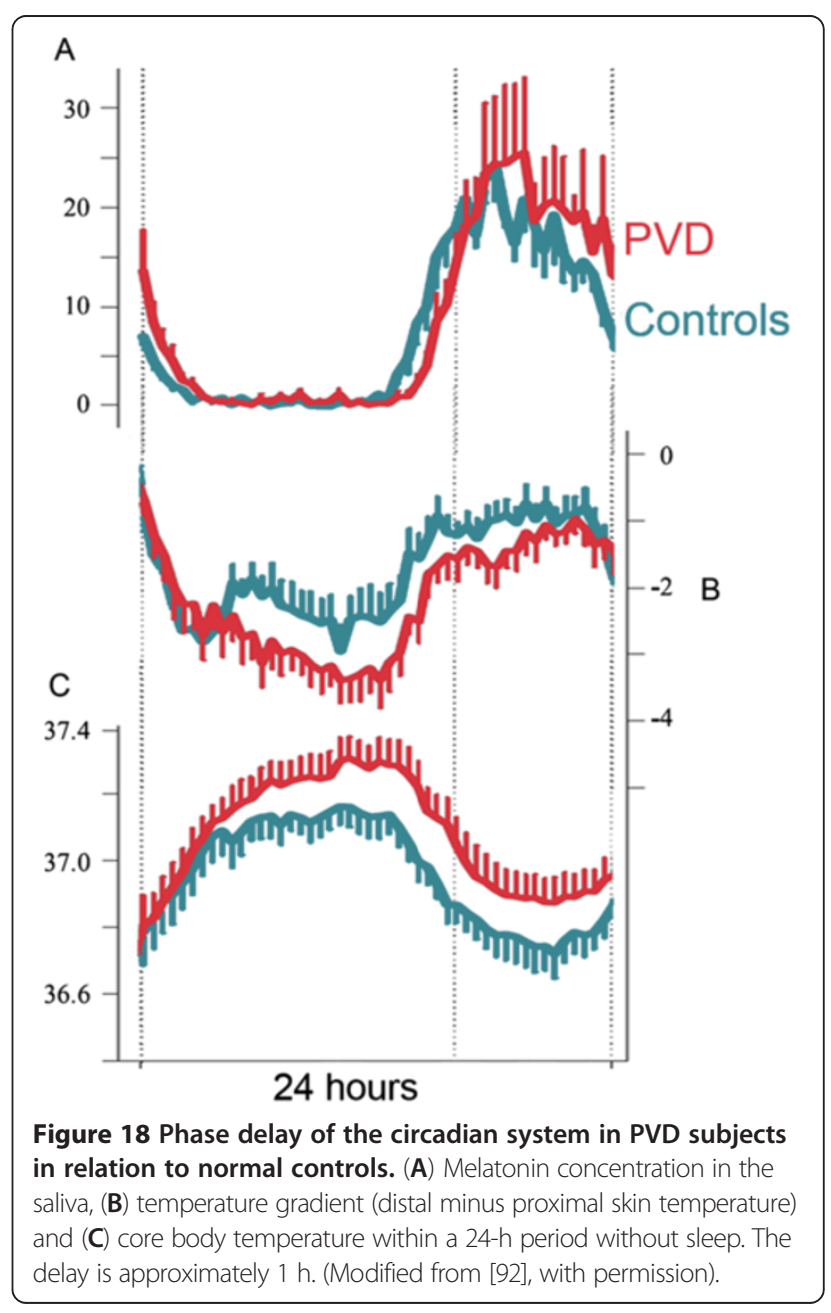


which these cells live. Circulating lymphocytes are not only easily accessible but also circulate through the whole body and are therefore good candidates to compare populations. Indeed, the gene expression profiling of PVD subjects revealed significant differences from non-PVD subjects but is very similar to that of glaucoma patients [175,176] (Figure 19). The genes and gene products of interest as potential diagnostic and drug targets have been summarised in other review articles $[177,178]$.

\subsubsection{PVD and oxidative stress}

Reactive oxygen species (ROS) play a major role in both physiology and pathophysiology. If production of ROS exceeds its elimination capacity, oxidative stress results. Oxidative stress can be local or more generalised. Because PVD leads to unstable BF and thus to an unstable oxygen supply in certain organs, ROS productions may be triggered (Figure 20).

The majority of PVD subjects, especially when they are young, can cope with oxidative stress and do not develop tissue damage. Patients suffering from both PVD and glaucoma show a higher number of DNA breaks in their circulating lymphocytes (quantified by comet assay), indicating that oxidative stress is present even systemically [179,180] (Figure 21). In glaucoma, oxidative stress occurs mostly in the mitochondria of the retinal ganglion cells and their axons. Research, therefore, is focused on developing strategies to maintain mitochondrial function [181].

\section{Visual signs and symptoms of PVD}

\subsection{PVD and visual function}

Most healthy subjects with PVD do not complain of visual disturbances, though some rarely indicate scintillation. In

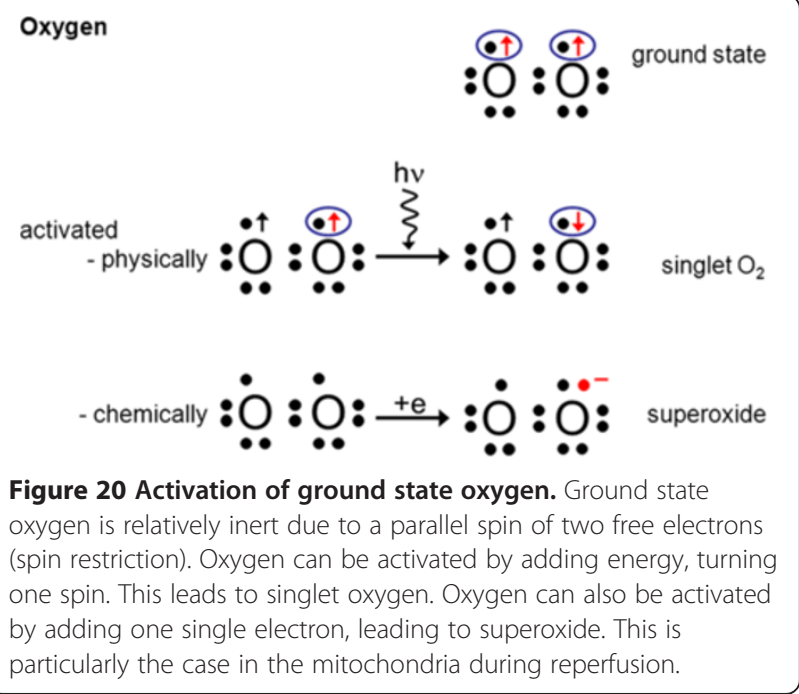

contrast to this perception, quantitative perimetry shows fluctuating visual defects in many subjects with PVD $[30,45,182,183]$. These are commonly diffuse defects best visualised by the Bebie curve [184] (Figure 22).

However, some researchers have first questioned whether changes in OBF lead to changes in visual function. Experimental studies in a pressure chamber then revealed that mean visual sensitivity is indeed directly and quickly influenced by oxygen saturation [185]. Although not felt, the differential light sensitivity decreased as oxygen concentration dropped. Visual fields reveal short- [186] and long-term [187] fluctuations. Certainly, long-term fluctuation is increased in PVD subjects [188]. Interestingly, if glaucoma patients with PVD show visual field defects, then only the diffuse component of the defect fluctuates [1,189].

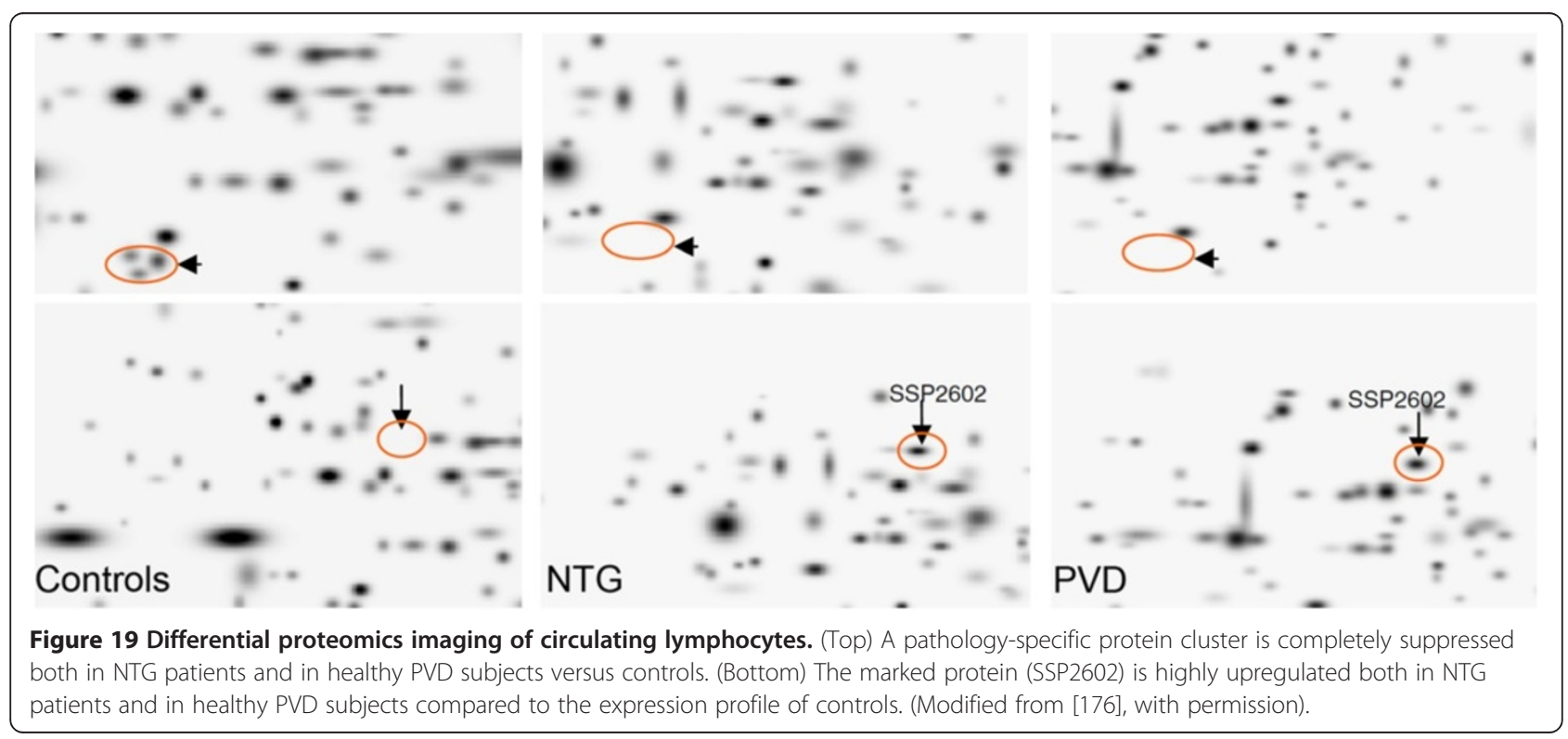



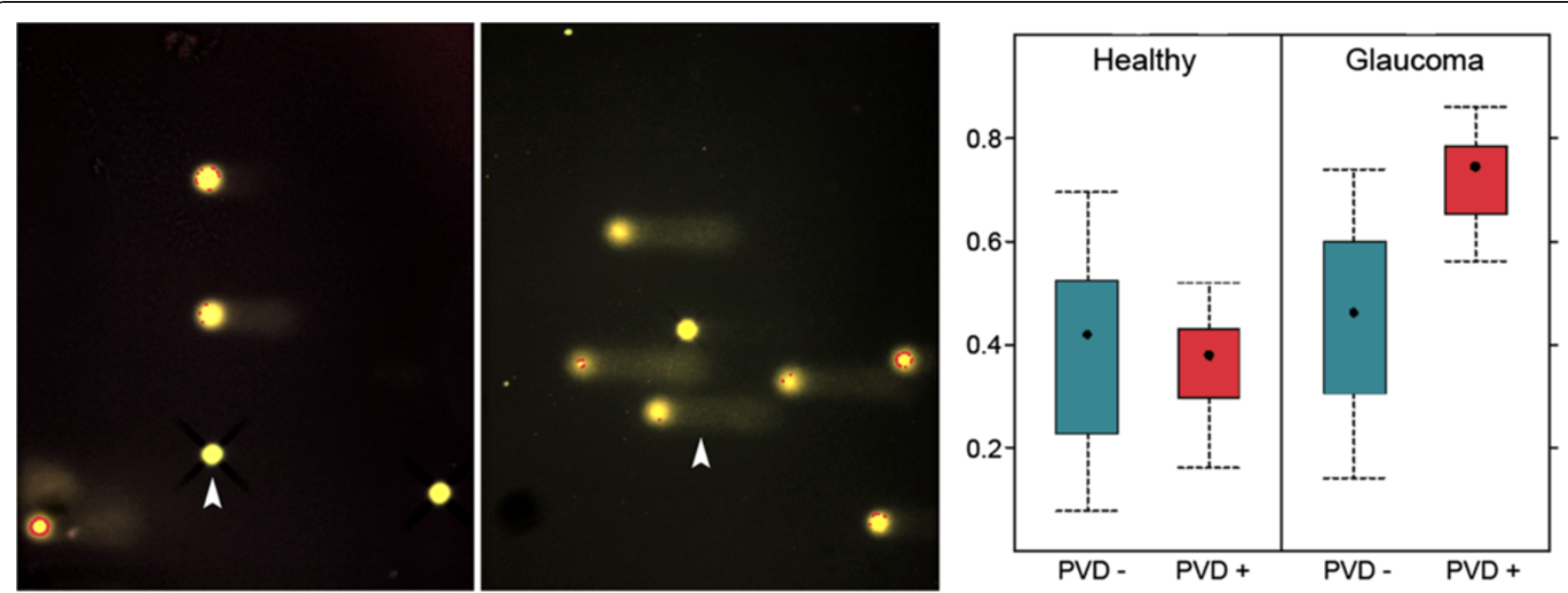

Figure 21 One possibility to estimate oxidative stress is DNA break quantification by comet assay analysis. (Left) Example of lymphocytes of a healthy subject. (Middle) Lymphocytes of a patient with glaucoma and PVD. (Right) Mean number of the breaks (quantified as tail moment) demonstrating an increase of DNA breaks in subjects suffering from both glaucoma and PVD. (From [180], with permission).

\subsection{PVD and ocular blood flow}

It is known that the circulation in the extremities or the heart may react with vasospasm [156]. Rather surprising is the fact that the eye can react with inadequate vasoconstrictions as well. In 1910, Blessing and Amburger described retinal angiospasms during migraine [110]. In 1939, Lisch described functional vascular dysregulations of the eye and recognised a relationship with a dysregulation of the finger capillaries [111]. In 1948, Traquair observed spasm in the central retinal artery [190]. Incidentally, at that time, the visual symptoms of Adolf Hitler were interpreted by his physician as being of vasospastic origin [191]. In 1986, we described an involvement of the eye in primary vasospastic syndrome (we call it PVD today) $[182,183]$. We also described the assumption that vasospasm might be involved in the pathogenesis of glaucomatous damage [192] and discussed the potential role of CCBs to treat this condition [193].

At that time, it was difficult to measure $\mathrm{OBF}$ in humans, and our suppositions therefore were mainly based on the quantitative relationship between visual function and peripheral BF. The measurement of OBF is still challenging [194], and reliable methods have been made available only recently $[4,195]$. From a historical prospective, it is interesting that the hypothesis of PVD affecting OBF was based on the analogy of nailfold capillaries [2] and visual field behaviour $[188,196]$. In PVD subjects (but not in others), there was a significant correlation between nailfold capillary $\mathrm{BF}$ and visual fields. After cold provocation, both the nailfold capillary BF and the visual field deteriorated; likewise, after an intake of CCBs [197], both nailfold capillary BF and the visual fields improved.

It was debated as to what extent the observed visual field improvement in PVD subjects after treatment with a CCB may be due to the improved OBF or rather a direct effect of these drugs on neural tissue [198]. However, a similar visual field improvement has been observed with other OBF-improving drugs, such as with carbonic anhydrase inhibitors [199] and even with $\mathrm{CO}_{2}$ breathing [200]. It has also been shown that the same people responding well to $\mathrm{CO}_{2}$ also respond well to CCBs;

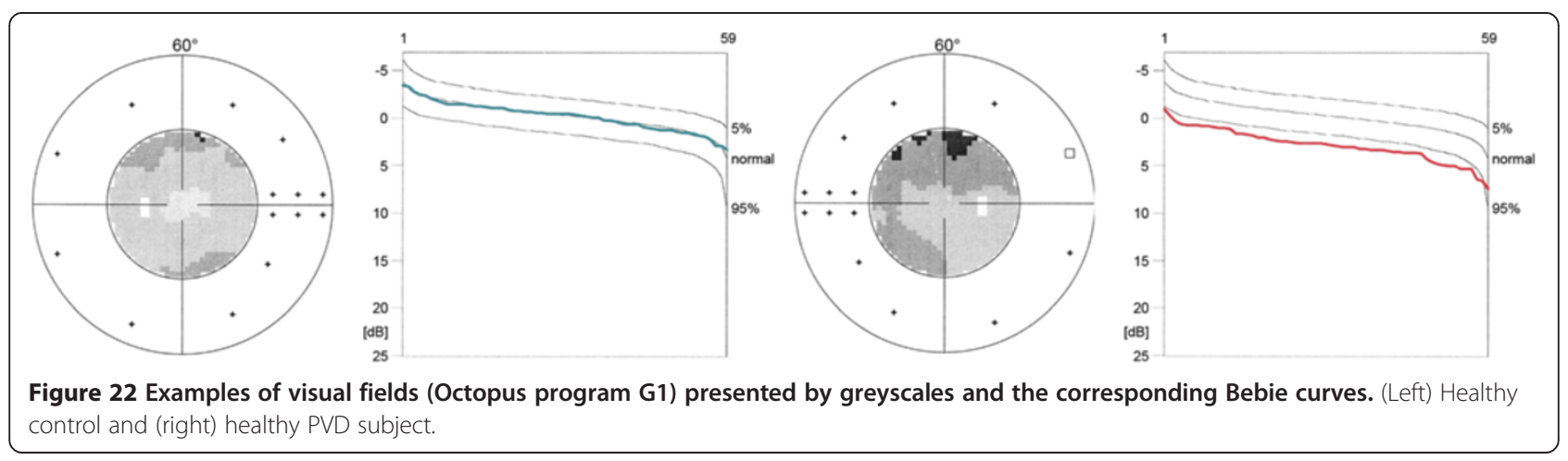


additionally, subjects responding well to CCBs in the short term also respond well in the long term [201]. In contrast to non-PVD subjects, in PVD subjects, OBF is directly related to ocular perfusion pressure [202,203], indicating a disturbed autoregulation [204] of ocular perfusion in PVD subjects. Although BF velocity in the periphery [2] and in the ocular circulation is decreased on average, BF in individual PVD subjects can be normal under baseline conditions. However, a cutaneous cold provocation induces an immediate decrease in retinal and $\mathrm{ONH}$ perfusion, and this decrease diminishes or disappears quickly when the hand is immersed in warm water [205]. In PVD subjects examined with colour Doppler imaging, the peak systolic and end diastolic velocities and the resistivity index of the central retinal artery significantly correlated with the mean ocular perfusion pressure [206]. In glaucoma patients with PVD, BF in the choroid and $\mathrm{ONH}$ is reduced compared to glaucoma patients without PVD [207]. More details will be discussed in the section 6.1.

\subsection{PVD and retinal vascular spatial irregularities}

Healthy PVD subjects showed higher spatial irregularities in retinal vessels than non-PVD subjects [208]; in other words, retinal vessels of vasospastic subjects are less smooth. This indicates that the mechanism of dysregulation (particularly endothelium dysfunction) is not homogenous along the vessels. It rather affects different parts of the same vessel stronger than other parts. This irregularity is not identical to overall retinal arteriolar narrowing, which, interestingly, is an important risk factor for open-angle glaucoma [209].

\subsection{PVD and stiffness of retinal vessels}

Vessels become stiffer when they become sclerotic. Interestingly, pulse wave propagation in the retinal vessels of PVD subjects is faster, indicating that they are stiffer without recognisable morphological alterations [210]. This is also the case in untreated NTG patients [211].

\subsection{PVD and neurovascular coupling}

Flickering light to the retina leads to a dilation of both retinal arteries and veins within seconds (Figure 23). This response is reduced in healthy PVD subjects [11]. The cause of this is not yet clear. Most probably, it is mainly due to an altered function of the vascular endothelial cells in PVD subjects (see 'The role of vascular endothelial cells'). Interestingly, the general vessel response to flickering light was also decreased in POAG patients [12].

\subsection{PVD and the blood-brain barrier}

The central nervous system (including the retina) is a very sensitive system. Specialised structures, such as tight junctions between endothelial cells, are required to maintain a stable environment and to ensure appropriate neuronal activities [212]. The barrier in the $\mathrm{ONH}$, however, is physiologically incomplete as a result of (a) diffusion from the fenestrated capillaries of the choroid into the $\mathrm{ONH}$ (see Figure 3) and (b) a nonspecific permeability of the capillaries, possibly mediated by vesicular transport [24]. The blood-retinal barrier is highly regulated, and this involves molecules such as ET-1 that are also involved in the regulation of vascular tone [213]. Expression of ET-1 is increased under hypoxic conditions, either locally in the retina, affecting retinal vessels, or systemically, thereby influencing the barrier in the $\mathrm{ONH}$ and adjacent retina by diffusion from the choroid. PVD can lead to hypoxia and thereby indirectly to barrier dysfunction. This is of special interest for glaucoma $[26,178]$.

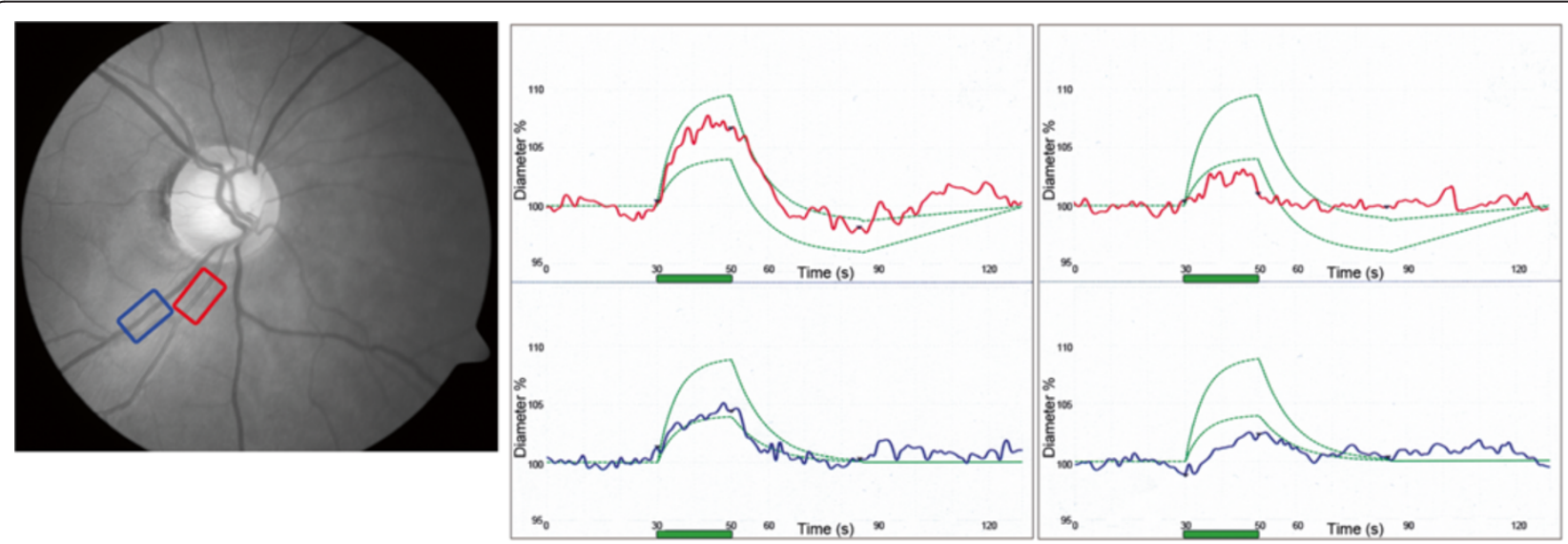

Figure 23 Retinal vessel analyser registers the size of a selected retinal artery and vein. Flickering light (green bar) leads to vasodilation of arteries (red) and veins (blue) in healthy subjects (middle) and to a lesser extent in subjects with vascular dysregulation (right). The green curves indicate the normal range. (Modified from [83], with permission). 


\subsection{PVD and activation of astrocytes}

Glial cell activation is a typical response to injuries of the central nervous system including the retina. The activation of glial cells, well demonstrated by increased glial fibrillary acidic protein staining, has been described in the retina in response to light damage or mechanical stress and also to hypoxia. Retinal astrocytes and Mueller cells also become activated in glaucoma. This includes a change of both the function and the morphology of these cells (Figure 24).

We have first described the clinical correlate of astrocytes activation in the retina [215]. Activated astrocytes change not only gene expression but also their morphology, leading to an increased backscatter [83]. Therefore, glinting spots can be recognised in red-free photos or by time domain optical coherence tomography [217]. Interestingly, activated astrocytes can be particularly observed in glaucoma patients with PVD [216].

\subsection{PVD and autoregulation}

Autoregulation describes the capacity to keep BF in an organ within a certain range independently of perfusion pressure. This is also the case for the eye, particularly for the retina, slightly less for the $\mathrm{ONH}$ and only limited

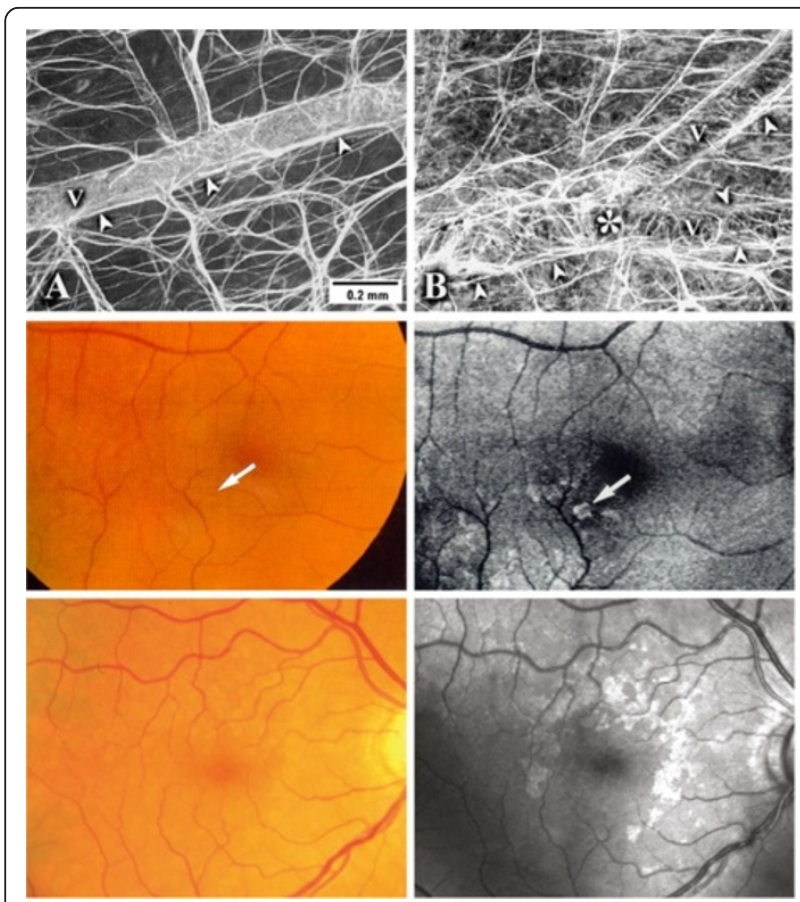

Figure 24 Glial cell activation. (Top) Activation of glial cells in the retina. Astrocytes connecting vessels with neurons (left) and irregular pattern of activated astrocytes (right). (Middle and bottom) Activated astrocytes increase light scattering, visible in red-free light (right), but not visible in colour photos (left). (From [214] (top), [215] (middle) and [216] (bottom), with permission). for the choroid. A disturbed autoregulation has been described both for healthy PVD subjects [206] and for glaucoma patients with progressive disease [202]. The main impact of such a deficient autoregulation is unstable oxygen supply with the consequences of oxidative stress [204]. The dysfunctional autoregulation in PVD subjects is the major link between PVD and glaucoma [28].

\subsection{PVD and the relation between peripheral and ocular circulation}

$\mathrm{ONH} \mathrm{BF}$ was correlated to both finger BF and finger temperature in PVD subjects but not in others [218]. This can be explained by deficient autoregulation allowing systemic factors such as perfusion pressure to dominate. The situation is different in the choroid, which is less autoregulated and highly innervated. Here, the BF was higher in patients with PVD, probably to keep the temperature at the back of the eye constant despite a reduced $\mathrm{BF}$ in the peripheral environment [219]. Corneal temperature in an unselected population correlates with finger temperature [44]. Interestingly, $\mathrm{OBF}$ and finger BF changes induced by cold provocation were correlated in glaucoma patients but not in others [220]. Additionally, retrobulbar BF in glaucoma patients is also correlated with ONH BF [221].

\subsection{PVD and retinal venous pressure}

Retinal venous pressure (RVP) was once assumed to be more or less equal to IOP [222], except in patients with increased intracranial pressure [223]. After ophthalmodynamometry was introduced to measure RVP, this assumption could no longer be made [224]. RVP is increased [15], and spontaneous venous pulsations occur less often in glaucoma, especially in NTG patients than in healthy controls [225]. RVP is also increased in other conditions such as diabetic retinopathy or in the fellow eye of patients with retinal vein occlusion. In PVD subjects, RVP can be normal (equal to IOP); most often, however, it is slightly or sometimes even markedly increased.

\subsection{PVD and optic disc haemorrhages}

Optic disc haemorrhages $(\mathrm{ODH})$ in the context of glaucoma were first described more than 100 years ago by Bjerrum in 1889, but studied in detail much later [226,227]. ODH are associated with morphological and functional progression of disease [228-230]. Interestingly, the presence of ODH is strongly associated with nail bed haemorrhages [231], indicating systemic factors involved in the pathogenesis of ODH. The fact that $\mathrm{ODH}$ occur more often in NTG [232] than in HTG patients and that they often precede damage and occur more often in females than in males provoked the question of a potential 
relationship between $\mathrm{ODH}$ and PVD. Indeed, $\mathrm{ODH}$ also occur in PVD subjects without glaucoma [233]. Furthermore, ODH occur in the contra-lateral eye of patients with retinal vein occlusion. We hypothesise that $\mathrm{ODH}$ are not a consequence of a disrupted vessel but rather of a dysfunctional blood-retinal barrier [26] (Figure 25). ET-1 seems to be involved not only in the pathogenesis of ODH but also in the pathogenesis of the increase of retinal venous pressure and retinal vein occlusion [84].

\section{PVD and ophthalmic diseases}

\subsection{PVD and glaucoma}

The pathogenesis of glaucomatous optic neuropathy and particularly the role of OBF has been discussed controversially [234] since the first description of optic nerve excavation by von Graefe in the nineteenth century. In addition to an increased IOP, the main risk factors for glaucomatous damage are IOP fluctuations $[235,236]$, low BP $[237,238]$, reduced perfusion pressure

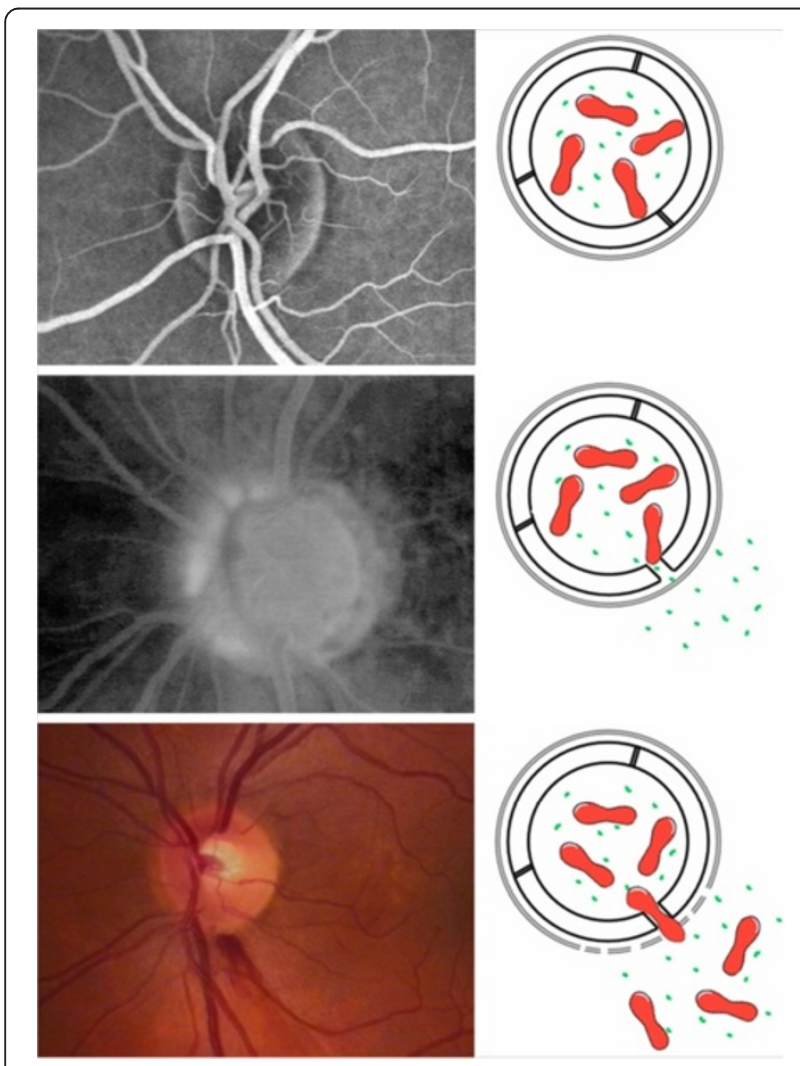

Figure 25 Pathogenesis of optic disc splinter haemorrhages.

Under normal conditions, the vessels in and around the optic nerve head are watertight (top). If the barrier is opened at the level of the endothelial cells (e.g. by ET-1), small molecules such as water and fluorescein can leak out (middle). If at the same time the basal membrane in the same area is also weakened (e.g. by MMP-9), erythrocytes can also escape (bottom). (Modified from [26], with permission).
[239] and fluctuation of perfusion pressure [240]. While it was difficult to measure OBF in the past, the present methods clearly reveal that OBF is reduced in glaucoma patients, particularly if the damage is progressing despite a normal IOP [241,242]. The reduction of OBF was often interpreted as being only secondary to the glaucomatous damage. This assumption was also supported by the fact that there is only a weak relationship between glaucomatous optic neuropathy (GON) and atherosclerosis. Today, we know that a reduction in OBF predicts future GON progression [243-245]. Furthermore, vascular dysfunction in glaucoma is not limited to the eyes [246]. These facts argue in favour of a primary component of BF reduction in glaucoma. In addition, it has become evident that OBF regulation is more important than the OBF at baseline condition and that fluctuations in OBF are particularly damaging [4,234]. Indeed, glaucoma patients react with an altered OBF response when challenged by changes in perfusion pressure [202], hypercapnia [247,248], hyperoxia, flicker light stimulation [12] or cold provocation [220,249]. These patients also have altered vasoreactivity to ET-1 [250] and an imbalance between the vasoconstrictor ET-1 and vasodilator $\mathrm{NO}$ in both plasma and aqueous humour $[39,251]$. The prevalence of silent myocardial ischaemic was also higher [160,161].

But what exactly is the cause of vascular dysfunction in glaucoma, and how does this contribute to damage? We postulated that PVD is the major cause of vascular dysfunction and formulated a concept of the pathogenesis of GON (Figure 26).

While hypoxia per se may lead to some optic nerve atrophy, it is the instability of the oxygen supply, leading to oxidative stress, that contributes to glaucomatous atrophy [252]. Oxygen supply fluctuates if either the oxygen saturation of the blood fluctuates (e.g. in patients with severe sleep apnoea) or the OBF is unstable. OBF is unstable if either IOP fluctuates above or BP fluctuates below the capacity of autoregulation. However, even normal IOP and normal BP fluctuation lead to OBF fluctuation if the autoregulation itself is disturbed. This explains why PVD is a major risk factor for GON [3]. PVD is associated with (a) low BP, (b) increased retinal venous pressure and (c) disturbed autoregulation. Although these three conditions are interrelated [150], each can also contribute to the damage independently [253]. Figure 27 shows examples of optic nerve heads of (a) a normal healthy subject, (b) a healthy PVD subject, (c) an HTG patient and (d) an NTG patient. We abstain from a detailed description of the role of OBF in glaucoma in this review. For readers with interest in this field, we refer to the following literature: We summarised the role of vasospasm [1], systemic diseases [122], OBF [4] and autoregulation [204] in the pathogenesis of GON and presented our pathogenetic concept 


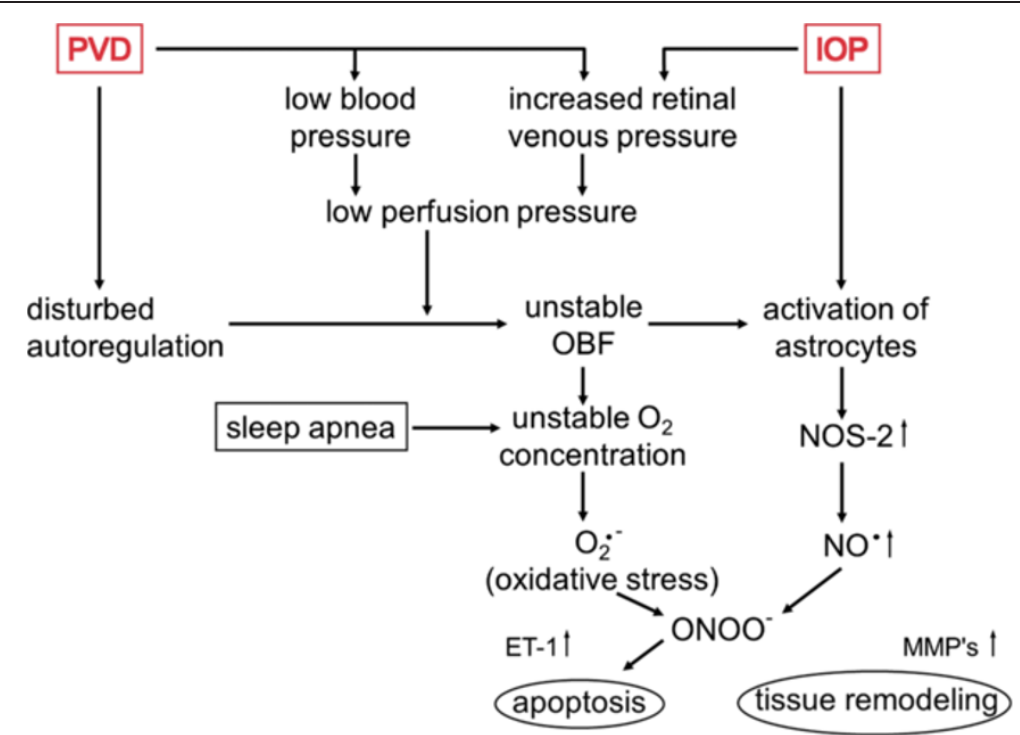

Figure 26 There are two major risk factors for GON: PVD and IOP. PVD decreases perfusion pressure by lowering blood pressure and by increasing retinal venous pressure. Increased IOP also reduces perfusion pressure and activates the astrocytes. PVD also leads to disturbed autoregulation and therefore to an unstable OBF. This in turn leads to oxidative stress. Oxidative stress together with activated astrocytes leads to the damaging peroxynitrite and cell death.

[254]. In a recent review, we further summarised the relationship between OBF and cardiovascular diseases [163]. The vascular aspects are also included in our glaucoma book [57]. Finally, the relationship between $\mathrm{BF}$ and glaucoma was described in detail in a pocketbook [255].

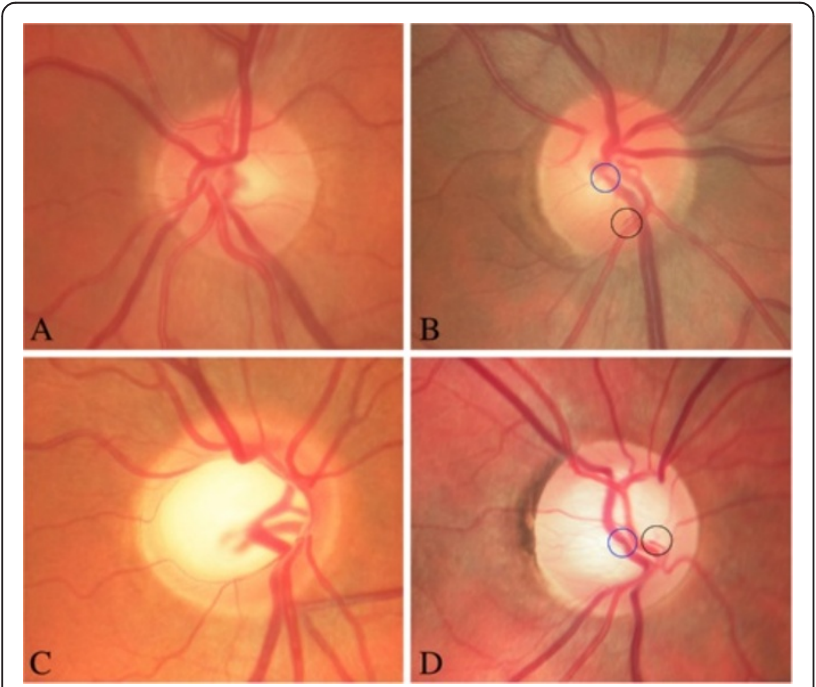

Figure 27 Typical examples of optic nerve heads. Taken from (A) a healthy subject, (B) a healthy subject with PVD, (C) an HTG patient (vessels are pushed towards the nasal quarter of the excavation) and (D) an NTG patient with PVD (vessels are not pushed to the nasal side, and the remaining neuroretinal rim is slightly pale). The rings highlight the local manifestations of vascular dysregulations.

\subsection{PVD and other eye diseases}

\subsubsection{Retinal arterial occlusion}

Retinal arterial occlusions normally occur in elderly patients with risk factors for atherosclerosis. Rarely, such occlusions occur also in young subjects without any signs of atherosclerosis [256]. It is sometimes explained by factors such as hyperhomocysteinemia [257], although the causal relationship remains unclear. Occlusions rarely occur during a migraine attack [258]. Most of these young and otherwise healthy patients with arterial occlusion suffer from PVD [1] and have slightly increased plasma level of ET-1 [81]; often, the occlusion is reversible [259].

\subsubsection{Retinal vein occlusion}

Retinal vein occlusion (RVO) occurs most often in elderly patients with vascular risk factors such as systemic hypertension and in patients with glaucoma. $\mathrm{RVO}$, however, can sometimes occur in relatively young subjects without risk factors for atherosclerosis and without glaucoma. Most of these patients suffer from PVD [260]. We made the clinical observation that RVO in such PVD subjects most often occurred after a major stress episode. An association with both a cilioretinal artery occlusion [261] and with retinal arterial vasospasm has been described [262]. As in the older and more classical RVO patients [82], these young subjects also have increased ET-1 plasma levels [81]. We know from experimental studies that ET-1 injection in the vitreous body leads to transient complete obstruction of retinal vessels [85]. We hypothesised that RVO may primarily be caused by a local ET-1-induced constriction of the vein, either at 
the arterio-venous crossing in the retina or at the level of the lamina cribrosa. ET-1 diffuses either from the fenestrated capillaries of the choroid, from diseased arteries or from hypoxic retinal tissue to the vein [84] (Figure 28).

In contrast to what is often assumed, veins are not passive tubes but respond very sensitively to vasoactive hormones. Impaired generalised endothelial function in patients with RVO [263] has been reported, and this is compatible both with atherosclerosis of older patients and with PVD of younger subjects.

\subsubsection{Anterior ischaemic optic neuropathy}

As with all arterial occlusions, atherosclerosis and its risk factors also play a major role for anterior ischaemic optic neuropathy (AION). Like retinal arterial occlusion and RVO, AION can occur in young subjects without any risk factors for atherosclerosis as well. We made the observations that the vast majority of these patients are PVD subjects and that the occlusions occur in most cases after major psychological stress [264,265] or, alternatively, are drug induced [266]. AION, however, can also be observed secondarily to other diseases (see 'Secondary vascular dysregulation') such as autoimmune diseases [267].

\subsubsection{Susac syndrome}

The syndrome was named after J.O. Susac, who first described it in 1979 [268]. It is characterised by the clinical triad of encephalopathy, branch retinal artery occlusion [269] and sensorineural hearing loss. Like PVD, it mainly occurs in young women. It is generally assumed that an autoimmune process leads to damage and inflammationrelated occlusion of the microvessels in the brain, retina and inner ear. Indeed, anti-endothelial cell antibodies could be detected in some patients [270]. It remains, however, unclear whether this is a primary or secondary event as, on the one hand, autoimmunity can lead to ischemia and, on the other hand, ischaemic lesions can induce autoimmunity. All patients we had the opportunity to examine suffered from the classical symptoms and signs of PVD [271] (Figure 29). As discussed with multiple sclerosis, further studies are necessary to sort out what came first in these Susac patients: the dysregulation or the autoimmunity (see 'Causes of SVD').

\subsubsection{PVD and optic nerve compartment syndrome}

Cerebrospinal fluid normally communicates freely throughout all CSF compartments. CSF sampled during lumbar puncture is therefore considered to be representative for all CSF compartments in terms of pressure and composition. However, in optic nerve compartment syndrome, there is proven segregation of CSF between the intracranial subarachnoid space and the subarachnoid space surrounding the optic nerve [272]. This compartment [273] is characterised by measurable differences of fluid composition [274], comparable to the composition of the subretinal fluid [275], reduced CSF exchange [273] (Figure 30) and extension of the optic nerve sheath diameter due to increased pressure [276,277]. These patients are often referred because of visual field defects. The visual field can be concentric constricted or more glaucoma-like, while visual acuity is often but not always reduced. The $\mathrm{ONH}$ is mostly more or less atrophic, sometimes glaucoma-like excavated [278] as we see in NTG [279] and rarely swollen [280]. The retinal venous pressure is nearly always increased.

The increase of CSF pressure leads to proliferation of meningothelial cells [281,282]. These cells participate in immunological processes in the CSF [283]. The change in the concentration of CSF proteins such as lipocalin-like prostaglandin-D- synthase could harm the neurons [284].

The pathogenesis of the compartment syndrome is not yet clear. A reduced outflow of the CSF through the lymphatic vessels may contribute [285-287]. It is our clinical experience that the majority of patients with optic nerve compartment syndrome are PVD patients. We have also observed that a treatment of PVD very often reduces the extension of the optic nerve sheath diameter and reduces retinal venous pressure in patients
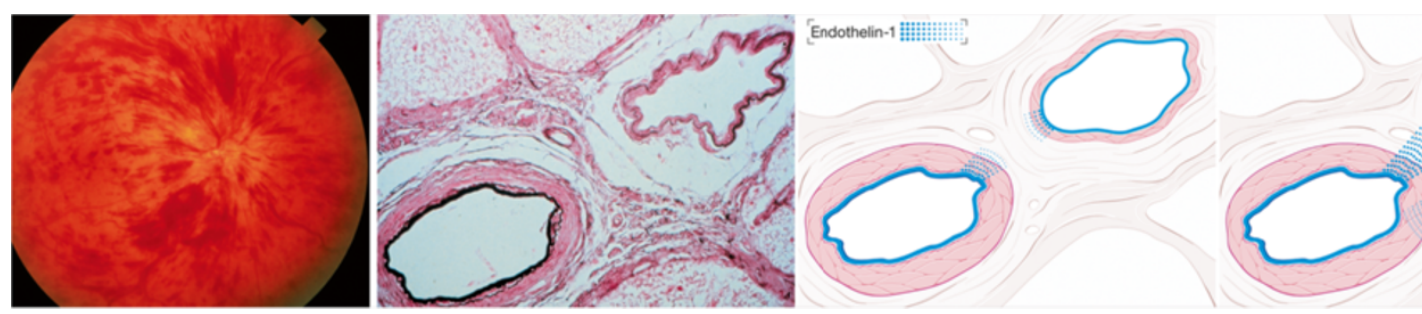

Figure 28 Pathogenesis of retinal vein occlusion. At the lamina cribrosa, the central retinal artery and central retinal vein are topographically very close and share a common adventitia (middle). This enables a molecular crosstalk between the two vessels (right). ET-1 (blue), for example, can diffuse from the ailing artery as well as from the adjacent hypoxic tissue to the very sensitive vein, leading to venous constriction. (Modified from [84], with kind permission from Springer Science + Business Media B.V.). 

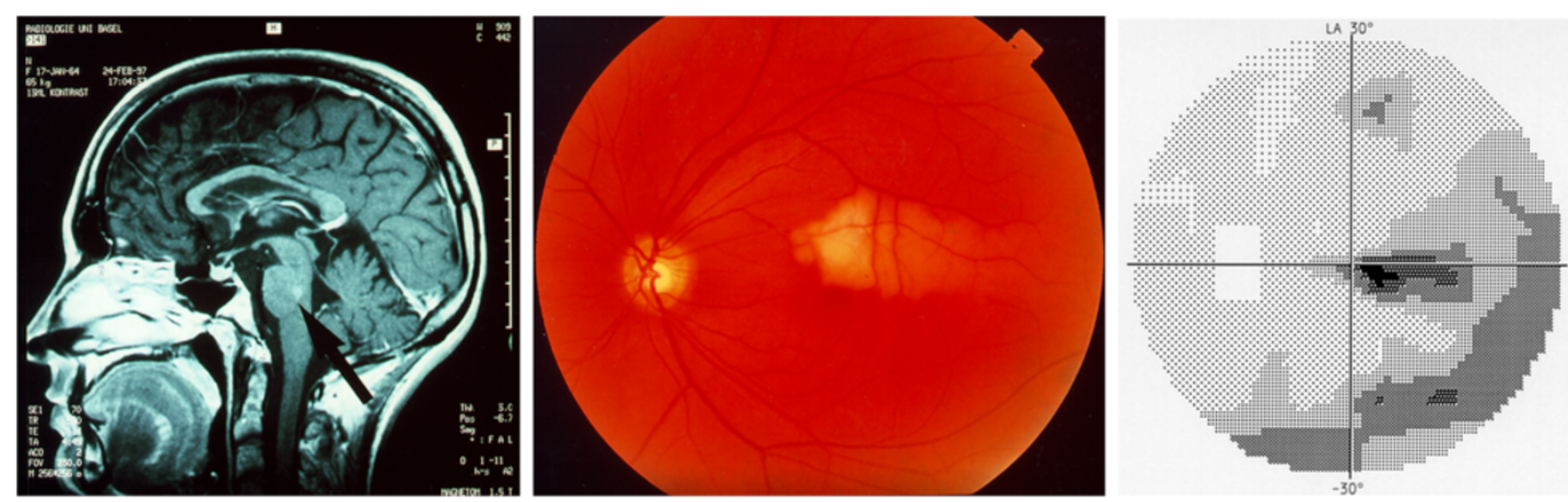

Figure 29 Susac syndrome in a patient with severe PVD. (Left) MRI of the pons with a hyperintensive lesion. (Middle) Localised retinal infarction. (Right) Corresponding visual field defects. (From [271], with permission).

that had recently developed a compartment syndrome. In more advanced cases, steroids sometimes help, whereas in very advanced cases, only optic nerve sheath fenestration is helpful. We assume that the unstable oxygen supply due to PVD may lead to chronic inflammation via oxidative stress. This in turn could induce swelling and proliferation of the arachnoid trabeculae leading to a kind of valve allowing CSF to enter in the optic nerve compartment but hindering the backflow.

\subsubsection{Central serous chorioretinopathy}

Central serous chorioretinopathy is a common disorder characterised by accumulation of serous fluid under the neurosensory retina secondary to a localised defect of the outer blood-retinal barrier. The pathogenesis is

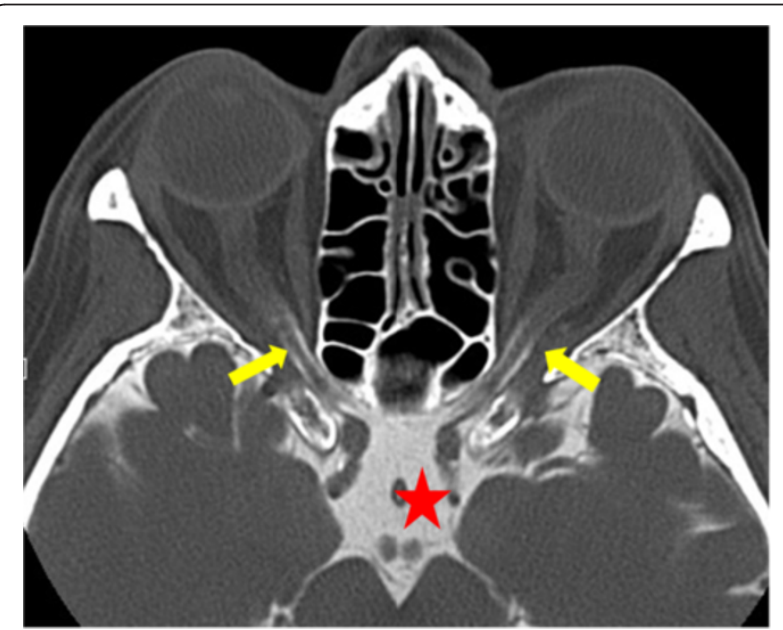

Figure $\mathbf{3 0}$ Cisternography of a patient with optic nerve compartment syndrome. Normal contrast-loaded cerebrospinal fluid in the pituitary cistern is indicated by a star. Stopping of the contrast-loaded cerebrospinal fluid in the posterior portion of the intraorbital subarachnoid space in both optic nerves is indicated by arrows (Courtesy of Killer HE) controversial. We hypothesised that local vascular dysregulation in the choroidal BF plays a major role [288]. This assumption is based on the following observations: (a) indocyanine green angiography done during the acute phase revealed delayed filling and venous congestion in the corresponding area of the choroid most likely induced by venous constriction (Figure 31), (b) it is most often preceded by a major psychological stress and occurs more often in subjects with so-called type-A behaviour, and (c) it can be provoked by intravenous injection of epinephrine. The resulting hypoxia in the area of the corresponding lobulus may then secondarily break down the outer blood-retinal barrier.

We further observed that these patients were mostly PVD subjects and had increased ET-1 plasma level during the acute phase; in addition, they often showed increased retinal venous pressure. Interestingly, it occurs particularly often in young men. Male hormones most likely play a role. Once, a 45-year-old woman with a history of metamorphopsia was referred to our institution, and we diagnosed a classical central serous chorioretinopathy in a PVD subject under major professional stress. We told her that she was suffering from a disease we most often see in young men. On her second visit, she mentioned that she had been taking $40 \mathrm{mg}$ of oral testosterone a day for the previous 2 months for better professional performance. Plasma testosterone level was markedly increased. We stopped testosterone treatment, and she recovered quickly and remained free of symptoms the following years [289].

\subsubsection{Leber hereditary optic neuropathy}

Leber hereditary optic neuropathy (LHON) is a maternally inherited disorder resulting from point mutations in mitochondrial DNA (mtDNA) [290]. Ophthalmologic findings in $\mathrm{LHON}$ patients are variable, but classical LHON cases exhibit vascular tortuosity of the central retinal vessels, swelling of the retinal nerve fibre layer, a circumpapillary 


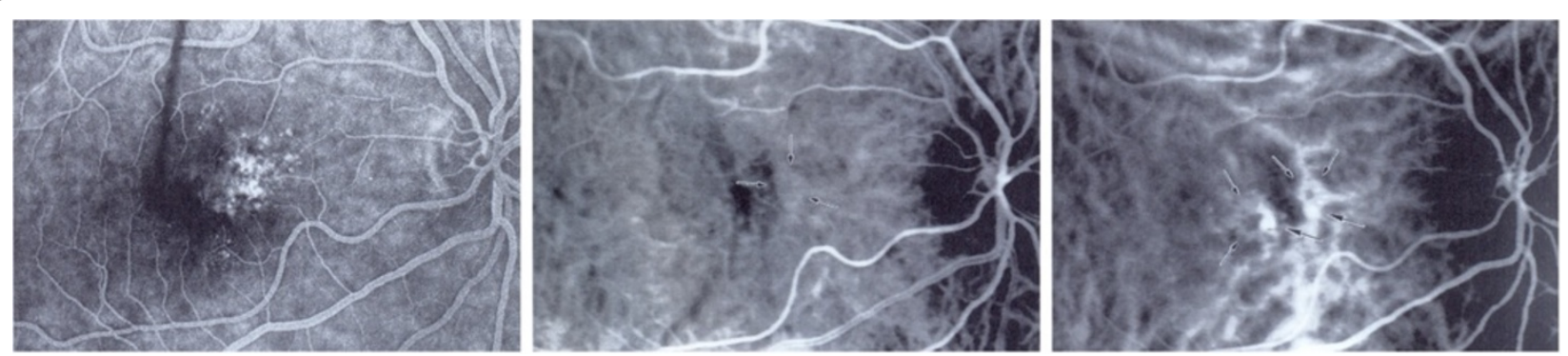

Figure 31 Angiography of a 46-year-old female subject with recurrent central serous chorioretinopathy. (Left) Disorder of the retinal pigment epithelium with leakage. (Middle) Slight congestion in the early capillary filling phase in indocyanine green angiography. (Right) Congestion of the draining veins clearly visible in the venous filling phase. (From [288], with permission).

telangiectatic microangiopathy and a cecocentral scotoma with variable preservation of peripheral vision. The disease finally leads to optic disc atrophy. Despite a clear genetic background, other factors play a role in manifestation and progression for the following reasons: (a) not all patients harbouring a pathogenic LHON mtDNA mutation develop the disease, (b) patients live free of symptoms many years before the onset of the disease, and (c) only a few organs and particularly the visual system get sick. It is likely that internal or external factors additionally damaging mitochondria are contributing factors, such as smoking, excessive alcohol, light exposure [291] and age. We made the clinical observation that the majority of patients we saw with LOHN were PVD subjects. There are many possible interpretations of this: (a) it could be referral bias, (b) subjects with mitochondrial mutations have higher risk for PVD, or (c) PVD subjects have unstable OBF leading to oxidative damage of the mitochondria and thereby increasing the probability that mitochondria with pre-existing mutations decompensate. The relationship between LOHN and NTG is unclear, but the majority of NTG patients have no mtDNA mutations [292]. However, we saw a young man with PVD and acute unilateral LOHN in his right eye, who developed NTG in his unaffected left eye over the following 10 years.

\subsubsection{Retinitis pigmentosa}

Retinitis pigmentosa (RP) encompasses a large group of hereditary diseases of the posterior segment of the eye characterised by degeneration, atrophy and, finally, loss of photoreceptors and retinal pigment epithelium, leading to progressive visual loss. Even though the disease has a genetic background, we assume that additional factors influence the manifestation of the disease. One potential modifying factor is disturbed OBF. Indeed, reduced OBF in $\mathrm{RP}$ patients has been described. BF is more or less always reduced in atrophic tissue, secondary to a decreased demand for supply. However, there are indications of an additional primary component mainly caused by PVD. We refer to a recent review [293].

\section{Therapy}

Although vascular dysregulation is frequent, often cumbersome and sometimes damaging, little research has been conducted to develop treatments. The present therapeutic armamentarium therefore is very limited and mainly based on clinical experience. The majority of PVD subjects do not need any treatment because they are healthy. Treatment should be considered if these subjects are bothered by signs and symptoms or if they show PVD-related disease like progressive NTG.

\subsection{Lifestyle}

To some extent, PVD subjects can reduce their symptoms by lifestyle modification. They should avoid, as far as this is possible, major emotional stress. In glaucoma patients with PVD, we often observed very fast progression of visual field defects during a major stress event, for example, in the context of a divorce. It has recently been shown that women who commonly suppress anger experience more thermal discomfort from cold extremities and have prolonged sleep onset latency [47]. Furthermore, PVD subjects should avoid extensive cold. We observed two PVD subjects that acquired sudden and irreversible bundle-shaped visual field defects during skiing. One woman with PVD repeatedly lost consciousness after jumping in cold water. PVD subjects are mostly slim, but we recommend that PVD subjects keep their BMI not too low and avoid major fasting periods. PVD subjects should not exaggerate with sport. We observed a fast progressive NTG in a young man bicycling every day for several hundred kilometres in a mountainous area. After he stopped doing this, his NTG stabilised. Daily mild physical activity, however, is helpful. PVD subjects should be careful climbing high mountains too quickly. Altitude sickness seems to be stronger in these subjects. We observed a young female ophthalmologist with marked PVD symptoms who lost her fingers and toes at high altitude. We further recommend avoiding strong light and wearing 
sunglasses. Similar to an unstable oxygen supply, light induces oxidative stress and damages the mitochondria [294-296]. We examined a gastroenterologist who had performed more than 22,000 endoscopies with his preferred left eye (this was before the advent of video monitors). In this left eye, he acquired colour vision deficiency, reduced contrast sensitivity and inhomogeneity of the pigment in the macular area, whereas the other eye remained normal [297].

\subsection{Nutrition}

We recommend a diet containing fruits and vegetables, particularly if they are rich in antioxidants such as anthocyanosides or flavonoids. Black currant anthocyanins have been shown to normalise abnormal levels of serum concentrations of ET-1 in patients with glaucoma [298]. Food rich in flavanols, particularly cocoa, may improve endothelial function in general [299]. Food rich in omega-3 fatty acids improves vascular regulation [300]. We also recommend green tea [301]. If BP is very low, salt intake should be increased [302]. For a more detailed description of our recommendation on nutrition, we refer to the book Ocular Blood Flow and Glaucomatous Optic Neuropathy [255].

\subsection{Magnesium}

Magnesium is cheap and has few side effects. In ex vivo studies, it reduces the vasoconstrictive effect of ET-1 (Figure 32) [303] and potentially has a positive effect on visual fields [304].

\subsection{Calcium channel blockers}

CCBs are the classical anti-vasospastic drugs at present $[197,305]$. They reduce the effect of ET-1 [306,307] and

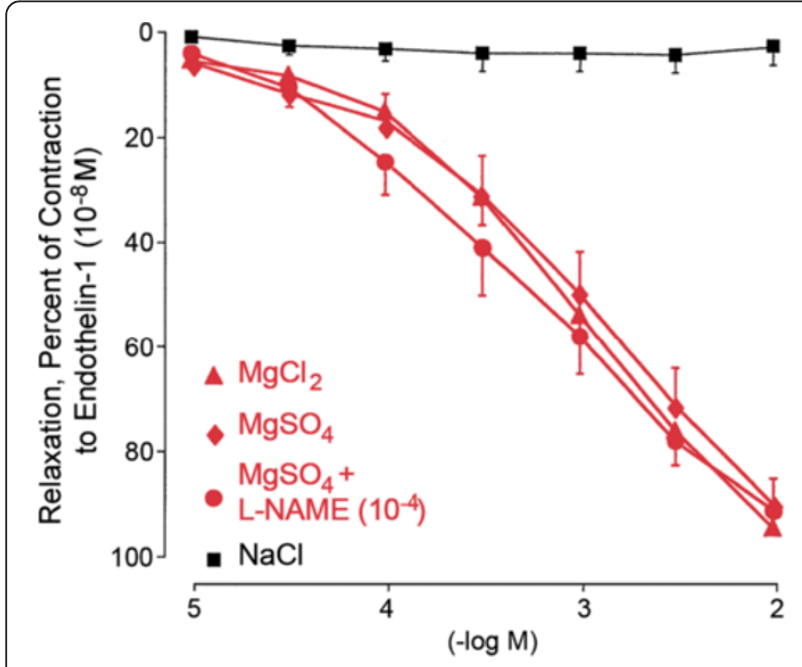

Figure 32 Similar relaxing effect of increasing $\mathrm{MgSO}_{4}$ and $\mathrm{MgCl}_{2}$ concentrations added to ET-1 precontracted ciliary arteries. (Modified from [303], with permission). improve visual fields of PVD patients [265]. It is not clear yet which of the CCBs is best and whether watersoluble or fat-soluble CCBs should be used. We use water-soluble CCBs like nifedipine for glaucoma and fat-soluble $\mathrm{CCBs}$ like nimodipine for retinal diseases. To reach the $\mathrm{ONH}$ of glaucoma patients, the drugs do not need to cross the blood-brain barrier. It is important to use very low doses [60] for the following reasons: (1) already low doses show efficient anti-vasospastic effects, (2) the drug sensitivity of PVD subjects is increased, and (3) in most cases, we do not want to further decrease BP. Nifedipine improves capillary BF in PVD subjects [308]. In a placebo-controlled 3-year study, nilvadipine slowed the visual field progression, maintained the optic disc rim and increased choroidal circulation in patients with NTG [309]. The better visual field preservation effect of betaxolol over timolol is most likely also due to the calcium antagonising side effect of betaxolol [310]. Topical flunarizine reduces IOP and protects the retina against ischaemic-excitotoxicity [311]. The use of CCBs in glaucoma has recently been reviewed $[198,312]$.

\subsection{Endothelin antagonists}

Bosentan, a dual endothelin receptor antagonist, reduces coronary vasospasm [313], cerebral vasospasm [314] and pulmonary vasoconstriction [315] and increases OBF in patients with glaucoma [316]. Avosentan, an ET(A)-endothelin receptor antagonist, relaxes ciliary arteries [317]. Sulfisoxazole, another ET receptor antagonist, protects retinal neurons from the insult of ischaemic/reperfusion [318]. Nevertheless, a routine use of ET blockers at present is not or not yet recommended for treatment of PVD due to potential side effects.

\subsection{Fludrocortisone}

The rare PVD patients who have extremely low BP, not responding to salt intake, we treat with the mineralocorticoid fludrocortisone [319] at very low doses (0.1 mg twice a week). Even when only a slight BP increase is achieved, haemodynamic parameters are improved [320].

\subsection{Carboanhydrase inhibitors}

In the early 1970s, Paterson [321] and Heilmann [322] described visual field reversibility in glaucoma patients after treatment with acetazolamide. We confirmed these findings [323] and postulated a relationship with an improvement of OBF. This effect occurred particularly in young female subjects [199]. Today, we know that both the systemically applied acetazolamide as well as the locally applied dorzolamide improve OBF [324]. 


\subsection{Ginkgo biloba}

Oxidative stress occurs particularly in the mitochondria, where it damages the inner membrane. While vitamins do not reach this area, G. biloba polyphenols may protect the mitochondria. For more details, we refer to a recent review [325].

\subsection{Other drugs}

A female patient with advanced NTG and PVD took sildenafil for better vision. Indeed, sildenafil increases BF in the choroid [326], and we observed dilatation of retinal arteries and veins in healthy subjects after intake [327]. Whether a long-term treatment with a phosphodiesterase- 5 inhibitor is helpful or counterproductive in PVD subjects is unclear as of now.

In ex vivo studies, dipyridamole dilated ciliary arteries, and pre-incubation with dipyridamole reduced contractions to ET-1 [328]. In clinical short-term studies, dipyridamole increased BF velocities in the extraocular vessels [329]. However, long-term studies are not available so far.

\section{Conclusions}

Although PVD syndrome is quite prevalent and mostly benign, it can be accompanied by bothering symptoms and may contribute to the occurrence and progression of potentially serious diseases such as NTG. Despite the emphasised importance, we are still in the infant stage of the research in this field. Taking into consideration the prevalence of PVD in the population, the authors strongly recommend the following steps to be undertaken in order to effectively promote the field:

- While in the past nailfold capillaroscopy was considered to be the gold standard for the diagnosis of PVD, we may need to redefine it. The proposed minimally invasive biomarker panels besides imaging by nailfold capillary microscopy with cold provocation are the dynamic retinal vessel imaging with flicker light stimulation or the pathologyspecific molecular profiles in circulating leukocytes.

- The phenomenology of the syndrome needs to be further qualitatively and quantitatively characterised to enable early diagnosis, pathology prediction and targeted prevention in groups at risk. This task is of particular value from the viewpoint of ethics and positive economy of medical services.

- The underlying pathophysiology should be studied in more detail. Concretely, the role of the autonomic nervous system, vascular endothelial cells or even that of the mitochondria needs to be clarified in order to develop highly sensitive diagnostic tools and to promote therapy approaches tailored to the person.
- The functional link between vascular dysregulation and the spectrum of related and downstream diseases needs to be established.

- The present treatment is of limited value and not yet based on well-controlled studies. Once the role of the syndrome is established and accepted by the scientific community, innovative diagnostic tools might be created and the pharmaceutical industry can get motivated to develop novel drug targets and more efficient treatment approaches.

\section{Competing interests}

The authors declare that they have no competing interests.

\section{Authors' contributions}

JF created the concept of the review, drafted the article and coordinated the writing. KK and AJF contributed to the drafting, writing and reviewing of the manuscript. All authors read and approved the final manuscript.

\section{Authors' information}

JF has worked in the field of glaucoma and microcirculation for decades. For more details see http://www.glaucomaresearch.ch. KK is an ophthalmologist and a glaucoma fellow with special interest in ocular blood flow. AJF is a cardiologist with special interest in vascular endothelial function.

\section{Acknowledgements}

The authors would like to express their gratitude to Daniela Hauenstein for her support and production of the figures.

\section{Author details}

${ }^{1}$ Department of Ophthalmology, University of Basel, Mittlere Strasse 91, Basel $\mathrm{CH}-4031$, Switzerland. ${ }^{2}$ Cardiovascular Center, Cardiology, University Hospital Zurich, Zurich $\mathrm{CH}-8091$, Switzerland.

Received: 23 April 2013 Accepted: 26 April 2013

Published: 7 June 2013

\section{References}

1. Flammer J, Pache M, Resink T: Vasospasm, its role in the pathogenesis of diseases with particular reference to the eye. Prog Retin Eye Res 2001, 20:319-349.

2. Saner H, Wurbel H, Mahler F, Flammer J, Gasser P: Microvasculatory evaluation of vasospastic syndromes. Adv Exp Med Biol 1987, 220:215-218.

3. Flammer J, Haefliger IO, Orgul S, Resink T: Vascular dysregulation: a principal risk factor for glaucomatous damage? J Glaucoma 1999, 8:212-219.

4. Flammer J, Orgul S, Costa VP, Orzalesi N, Krieglstein GK, Serra LM, Renard JP, Stefansson E: The impact of ocular blood flow in glaucoma. Prog Retin Eye Res 2002, 21:359-393.

5. Flammer AJ, Luscher TF: Human endothelial dysfunction: EDRFs. Pflugers Arch 2010, 459:1005-1013.

6. Haefliger IO, Meyer P, Flammer J, Luscher TF: The vascular endothelium as a regulator of the ocular circulation: a new concept in ophthalmology? Surv Ophthalmol 1994, 39:123-132.

7. Haefliger 10, Flammer J, Beny JL, Luscher TF: Endothelium-dependent vasoactive modulation in the ophthalmic circulation. Prog Retin Eye Res 2001, 20:209-225.

8. Flammer AJ, Anderson T, Celermajer DS, Creager MA, Deanfield J, Ganz P, Hamburg NM, Luscher TF, Shechter M, Taddei S, Vita JA, Lerman A: The assessment of endothelial function: from research into clinical practice. Circulation 2012, 126:753-767.

9. Senn B, Orgul S, Keller U, Dickermann D, Dubler B, Vavrecka J, Gasser P, Kaiser HJ, Flammer J: Retrobulbar and peripheral capillary blood flow in hypercholesterolemic subjects. Am J Ophthalmol 1999, 128:310-316.

10. Fadini GP, Pagano C, Baesso I, Kotsafti O, Doro D, de Kreutzenberg SV, Avogaro A, Agostini C, Dorigo MT: Reduced endothelial progenitor cells and brachial artery flow-mediated dilation as evidence of endothelial dysfunction in ocular hypertension and primary open-angle glaucoma. Acta Ophthalmol 2010, 88:135-141. 
11. Gugleta K, Zawinka C, Rickenbacher I, Kochkorov A, Katamay R, Flammer J, Orgul $\mathrm{S}$ : Analysis of retinal vasodilation after flicker light stimulation in relation to vasospastic propensity. Invest Ophthalmo/ Vis Sci 2006, 47:4034-4041.

12. Gugleta K, Kochkorov A, Waldmann N, Polunina A, Katamay R, Flammer J, Orgul $S$ : Dynamics of retinal vessel response to flicker light in glaucoma patients and ocular hypertensives. Graefes Arch Clin Exp Ophthalmol 2012, 250:589-594.

13. Kur J, Newman EA, Chan-Ling T: Cellular and physiological mechanisms underlying blood flow regulation in the retina and choroid in health and disease. Prog Retin Eye Res 2012, 31:377-406.

14. Bergua A, Kapsreiter M, Neuhuber WL, Reitsamer HA, Schrodl F: Innervation pattern of the preocular human central retinal artery. Exp Eye Res 2013, 110:142-147.

15. Stodtmeister $R$ : The pulsation and the pressure of the central retinal vein and their relation to glaucoma damage and therapy. Klin Monbl Augenheilkd 2008, 225:632-636.

16. Polska E, Simader C, Weigert G, Doelemeyer A, Kolodjaschna J, Scharmann $\mathrm{O}$, Schmetterer L: Regulation of choroidal blood flow during combined changes in intraocular pressure and arterial blood pressure. Invest Ophthalmol Vis Sci 2007, 48:3768-3774.

17. Portmann N, Gugleta K, Kochkorov A, Polunina A, Flammer J, Orgul S: Choroidal blood flow response to isometric exercise in glaucoma patients and patients with ocular hypertension. Invest Ophthalmol Vis Sci 2011, 52:7068-7073.

18. Neuhuber W, Schrodl F: Autonomic control of the eye and the iris. Auton Neurosci 2011, 165:67-79.

19. Lutjen-Drecoll E: Choroidal innervation in primate eyes. Exp Eye Res 2006, 82:357-361.

20. May CA, Hayreh SS, Furuyoshi N, Ossoinig K, Kaufman PL, Lutjen-Drecoll E: Choroidal ganglion cell plexus and retinal vasculature in monkeys with laser-induced glaucoma. Ophthalmologica 1997, 211:161-171.

21. Kiel JW, Hollingsworth M, Rao R, Chen M, Reitsamer HA: Ciliary blood flow and aqueous humor production. Prog Retin Eye Res 2011, 30:1-17.

22. Alm A, Bill A: Ocular and optic nerve blood flow at normal and increased intraocular pressures in monkeys (Macaca irus): a study with radioactively labelled microspheres including flow determinations in brain and some other tissues. Exp Eye Res 1973, 15:15-29.

23. Schmidl D, Boltz A, Kaya S, Werkmeister R, Dragostinoff N, Lasta M, Polska E, Garhofer G, Schmetterer L: Comparison of choroidal and optic nerve head blood flow regulation during changes in ocular perfusion pressure. Invest Ophthalmol Vis Sci 2012, 53:4337-4346.

24. Hofman P, Hoyng P, vanderWerf F, Vrensen GF, Schlingemann RO: Lack of blood-brain barrier properties in microvessels of the prelaminar optic nerve head. Invest Ophthalmol Vis Sci 2001, 42:895-901.

25. Sossi N, Anderson DR: Blockage of axonal transport in optic nerve induced by elevation of intraocular pressure. Effect of arteria hypertension induced by angiotensin I. Arch Ophthalmol 1983, 101:94-97.

26. Grieshaber MC, Flammer J: Does the blood-brain barrier play a role in glaucoma? Surv Ophthalmol 2007, 52(Suppl 2):S115-121.

27. Teuchner B, Orgul S, Ulmer H, Haufschild T, Flammer J: Reduced thirst in patients with a vasospastic syndrome. Acta Ophthalmol Scand 2004, 82:738-740

28. Grieshaber MC, Mozaffarieh M, Flammer J: What is the link between vascular dysregulation and glaucoma? Surv Ophthalmol 2007, 52(Suppl 2):S144-154.

29. Krauchi K, Gasio PF, Vollenweider S, Von Arb M, Dubler B, Orgul S, Flamme J, Stutz EZ: Cold extremities and difficulties initiating sleep: evidence of co-morbidity from a random sample of a Swiss urban population. J Sleep Res 2008, 17:420-426.

30. Gasser P, Flammer J, Guthauser U, Mahler F: Do vasospasms provoke ocular diseases? Angiology 1990, 41:213-220.

31. Kaiser HJ, Meienberg $\mathrm{O}$ : Deterioration or onset of migraine under oestrogen replacement therapy in the menopause. J Neurol 1993, 240:195-196.

32. Ludwig DA, Vernikos J, Wade CE, Convertino VA: Blood pressure changes during orthostatic stress: evidence of gender differences in neuroeffector distribution. Aviat Space Environ Med 2001, 72:892-898.

33. Mozaffarieh M, Fontana Gasio P, Schotzau A, Orgul S, Flammer J, Krauchi K: Thermal discomfort with cold extremities in relation to age, gender, and body mass index in a random sample of a Swiss urban population. Popul Health Metr 2010, 8:17

34. Gasser P, Stumpfig D, Schotzau A, Ackermann-Liebrich U, Flammer J: Body mass index in glaucoma. J Glaucoma 1999, 8:8-11.
35. Pasquale LR, Willett WC, Rosner BA, Kang JH: Anthropometric measures and their relation to incident primary open-angle glaucoma. Ophthalmology 2010, 117:1521-1529.

36. Ramdas WD, Wolfs RC, Hofman A, de Jong PT, Vingerling JR, Jansonius NM: Lifestyle and risk of developing open-angle glaucoma: the Rotterdam study. Arch Ophthalmol 2011, 129:767-772.

37. Brown R, James C, Henderson LA, Macefield VG: Autonomic markers of emotional processing: skin sympathetic nerve activity in humans during exposure to emotionally charged images. Front Physiol 2012, 3:394.

38. Hart EC, Joyner MJ, Wallin BG, Charkoudian N: Sex, ageing and resting blood pressure: gaining insights from the integrated balance of neural and haemodynamic factors. J Physiol 2012, 590:2069-2079.

39. Galassi F, Giambene B, Varriale R: Systemic vascular dysregulation and retrobulbar hemodynamics in normal-tension glaucoma. Invest Ophthalmol Vis Sci 2011, 52:4467-4471.

40. Abu-Amero KK, Morales J, Bosley TM: Mitochondrial abnormalities in patients with primary open-angle glaucoma. Invest Ophthalmol Vis Sci 2006, 47:2533-2541.

41. Fujimoto $H$, Kobayashi $H$, Ogasawara K, Yamakado M, Ohno M: Association of the manganese superoxide dismutase polymorphism with vasospastic angina pectoris. J Cardiol 2010, 55:205-210.

42. Pyykko I, Kolari P, Farkkila M, Starck J, Korhonen O, Jantti V: Finger peripheral resistance during local cold provocation in vasospastic disease. Scand J Work Environ Health 1986, 12:395-399.

43. Kavroulaki D, Gugleta K, Kochkorov A, Katamay R, Flammer J, Orgul S: Relation of body mass index and blood pressure to subjective and objective acral temperature. Klin Monbl Augenheilkd 2009, 226:328-331.

44. Girardin F, Orgul S, Erb C, Flammer J: Relationship between corneal temperature and finger temperature. Arch Ophthalmol 1999, 117:166-169.

45. Flammer J: Psychophysical mechanisms and treatment of vasospastic disorders in normal-tension glaucoma. Bull Soc Belge Ophtalmol 1992, 244:129-134.

46. Schiffer F, Hartley LH, Schulman CL, Abelmann WH: Evidence for emotionally-induced coronary arterial spasm in patients with angina pectoris. Br Heart J 1980, 44:62-66.

47. von Arb M, Gompper B, Meyer AH, Stutz EZ, Orgul S, Flammer J, Krauchi K: Relationship between gender role, anger expression, thermal discomfort and sleep onset latency in women. Biopsychosoc Med 2009, 3:11.

48. Ye Y, Mauro M, Bovenzi M, Griffin MJ: Association between vasoconstriction during and following exposure to hand-transmitted vibration. Int Arch Occup Environ Health 2012. http://www.ncbi.nlm.nih.gov/pubmed/23238880.

49. Thompson AJ, Griffin MJ: Effect of the magnitude and frequency of handtransmitted vibration on finger blood flow during and after exposure to vibration. Int Arch Occup Environ Health 2009, 82:1151-1162.

50. Bovenzi M, D'Agostin F, Rui F, Negro C: A longitudinal study of finger systolic blood pressure and exposure to hand-transmitted vibration. Int Arch Occup Environ Health 2008, 81:613-623.

51. House R, Jiang D, Thompson A, Eger T, Krajnak K, Sauve J, Schweigert M: Vasospasm in the feet in workers assessed for HAVS. Occup Med (Lond) 2011, 61:115-120.

52. Sterling $M$, Jull G, Kenardy J: Physical and psychological factors maintain long-term predictive capacity post-whiplash injury. Pain 2006, 122:102-108

53. Sterling M, Hendrikz J, Kenardy J, Kristjansson E, Dumas JP, Niere K, Cote J, Deserres S, Rivest K, Jull G: Assessment and validation of prognostic models for poor functional recovery 12 months after whiplash injury: a multicentre inception cohort study. Pain 2012, 153:1727-1734.

54. Mahler F, Saner H, Wurbel H, Flammer J: Local cooling test for clinical capillaroscopy in Raynaud's phenomenon, unstable angina, and vasospastic visual disorders. Vasa 1989, 18:201-204.

55. Herrick AL: The pathogenesis, diagnosis and treatment of Raynaud phenomenon. Nat Rev Rheumatol 2012, 8:469-479.

56. Brown PJ, Zirwas MJ, English JC 3rd: The purple digit: an algorithmic approach to diagnosis. Am J Clin Dermatol 2010, 11:103-116.

57. Flammer J: Glaucoma. 3rd edition. Bern: Hogrefe \& Huber; 2006.

58. Haefliger IO, Flammer J, Luscher TF: Nitric oxide and endothelin-1 are important regulators of human ophthalmic artery. Invest Ophthalmol Vis Sci 1992, 33:2340-2343

59. Dallinger S, Dorner GT, Wenzel R, Graselli U, Findl O, Eichler HG, Wolzt M, Schmetterer L: Endothelin-1 contributes to hyperoxia-induced vasoconstriction in the human retina. Invest Ophthalmol Vis Sci 2000, 41:864-869. 
60. Strenn K, Matulla B, Wolzt M, Findl O, Bekes MC, Lamsfuss U, Graselli U, Rainer G, Menapace R, Eichler HG, Schmetterer L: Reversal of endothelin-1 -induced ocular hemodynamic effects by low-dose nifedipine in humans. Clin Pharmacol Ther 1998, 63:54-63.

61. Speciale L, Sarasella M, Ruzzante S, Caputo D, Mancuso R, Calvo MG, Guerini FR, Ferrante P: Endothelin and nitric oxide levels in cerebrospinal fluid of patients with multiple sclerosis. J Neurovirol 2000, 6(Suppl 2):S62-66.

62. Haufschild T, Shaw SG, Kesselring J, Flammer J: Increased endothelin-1 plasma levels in patients with multiple sclerosis. J Neuroophthalmol 2001, 21:37-38.

63. Gugleta K, Mehling M, Kochkorov A, Grieshaber M, Katamay R, Flammer J, Orgul S, Kappos L: Pattern of macular thickness changes measured by ocular coherence tomography in patients with multiple sclerosis. Klin Monbl Augenheilkd 2008, 225:408-412.

64. Mienberg O, Flammer J, Ludin HP: Subclinical visual field defects in multiple sclerosis. Demonstration and quantification with automated perimetry, and comparison with visually evoked potentials. J Neurol 1982, 227:125-133.

65. Gugleta K, Kochkorov A, Kavroulaki D, Katamay R, Weier K, Mehling M, Kappos L, Flammer J, Orgul S: Retinal vessels in patients with multiple sclerosis: baseline diameter and response to flicker light stimulation. Klin Monbl Augenheilkd 2009, 226:272-275.

66. Kochkorov A, Gugleta K, Kavroulaki D, Katamay R, Weier K, Mehling M, Kappos L, Flammer J, Orgul S: Rigidity of retinal vessels in patients with multiple sclerosis. Klin Monbl Augenheilkd 2009, 226:276-279.

67. Haufschild T, Kaiser HJ, Preisig T, Pruente C, Flammer J: Influence of red wine on visual function and endothelin-1 plasma level in a patient with optic neuritis. Ann Neurol 2003, 53:825-826.

68. Reijerkerk A, Lakeman KA, Drexhage JA, van Het Hof B, van Wijck Y, van der Pol SM, Kooij G, Geerts D, de Vries HE: Brain endothelial barrier passage by monocytes is controlled by the endothelin system. J Neurochem 2012, 121:730-737.

69. Pache M, Kaiser HJ, Akhalbedashvili N, Lienert C, Dubler B, Kappos L, Flammer J: Extraocular blood flow and endothelin-1 plasma levels in patients with multiple sclerosis. Eur Neurol 2003, 49:164-168.

70. Haufschild T, Shaw SG, Kaiser HJ, Flammer J: Transient raise of endothelin1 plasma level and reduction of ocular blood flow in a patient with optic neuritis. Ophthalmologica 2003, 217:451-453.

71. Pache M, Schwarz HA, Kaiser HJ, Wuest P, Kloti M, Dubler B, Flammer J: Elevated plasma endothelin-1 levels and vascular dysregulation in patients with rheumatoid arthritis. Med Sci Monit 2002, 8:CR616-619.

72. Yoshida H, Imafuku Y, Ohhara M, Miyata M, Kasukawa R, Ohsumi K, Horiuchi J: Endothelin-1 production by human synoviocytes. Ann Clin Biochem 1998, 35(Pt 2):290-294

73. Joseph EK, Levine JD: Sexual dimorphism in endothelin-1 induced mechanical hyperalgesia in the rat. Exp Neurol 2012, 233:505-512.

74. Matwyshyn GA, Bhalla S, Gulati A: Endothelin ETA receptor blockade potentiates morphine analgesia but does not affect gastrointestinal transit in mice. Eur J Pharmacol 2006, 543:48-53.

75. Pache M, Ochs J, Genth E, Mierau R, Kube T, Flammer J: Increased plasma endothelin-1 levels in fibromyalgia syndrome. Rheumatology (Oxford) 2003, 42:493-494.

76. Lozano E, Segarra M, Corbera-Bellalta M, Garcia-Martinez A, Espigol-Frigole G, Pla-Campo A, Hernandez-Rodriguez J, Cid MC: Increased expression of the endothelin system in arterial lesions from patients with giant-cell arteritis: association between elevated plasma endothelin levels and the development of ischaemic events. Ann Rheum Dis 2010, 69:434-442.

77. Pache M, Kaiser HJ, Haufschild T, Lubeck P, Flammer J: Increased endothelin-1 plasma levels in giant cell arteritis: a report on four patients. Am J Ophthalmol 2002, 133:160-162.

78. Dimitrijevic I, Andersson C, Rissler P, Edvinsson L: Increased tissue endothelin-1 and endothelin-B receptor expression in temporal arteries from patients with giant cell arteritis. Ophthalmology 2010, 117:628-636.

79. Valmaggia $C$, Speiser $P$, Bischoff $P$, Niederberger $H$ : Indocyanine green versus fluorescein angiography in the differential diagnosis of arteritic and nonarteritic anterior ischemic optic neuropathy. Retina 1999, 19:131-134.

80. Schmidt WA, Moll A, Seifert A, Schicke B, Gromnica-Ihle E, Krause A: Prognosis of large-vessel giant cell arteritis. Rheumatology (Oxford) 2008, 47:1406-1408
81. Haufschild T, Prunte C, Messerli J, Flammer J: Increased endothelin-1 plasma level in young adults with retinal vascular occlusive diseases. Klin Monbl Augenheilkd 2004, 221:357-359.

82. Iannaccone A, Letizia C, Pazzaglia S, Vingolo EM, Clemente G, Pannarale MR: Plasma endothelin-1 concentrations in patients with retinal vein occlusions. Br J Ophthalmol 1998, 82:498-503.

83. Flammer J, Mozaffarieh M, Bebie H: Basic Sciences in Ophthalmology - Physics and Chemistry. Berlin: Springer; 2013.

84. Fraenkl SA, Mozaffarieh M, Flammer J: Retinal vein occlusions: the potential impact of a dysregulation of the retinal veins. EPMA J 2010, 1:253-261

85. Takei K, Sato T, Nonoyama T, Miyauchi T, Goto K, Hommura S: A new model of transient complete obstruction of retinal vessels induced by endothelin-1 injection into the posterior vitreous body in rabbits. Graefes Arch Clin Exp Ophthalmol 1993, 231:476-481.

86. Coughlin PA, Chetter IC, Kent PJ, Kester RC: The analysis of sensitivity, specificity, positive predictive value and negative predictive value of cold provocation thermography in the objective diagnosis of the hand-arm vibration syndrome. Occup Med (Lond) 2001, 51:75-80.

87. Ishitake $\mathrm{T}$, Ando $\mathrm{H}$ : Significance of finger coldness in hand-arm vibration syndrome. Environ Health Prev Med 2005, 10:371-375.

88. d'Audiffret AC, Frisbee SJ, Stapleton PA, Goodwill AG, Isingrini E, Frisbee JC: Depressive behavior and vascular dysfunction: a link between clinical depression and vascular disease? J Appl Physiol 2010, 108:1041-1051.

89. Neves VJ, Moura MJ, Almeida BS, Costa R, Sanches A, Ferreira R, Tamascia ML, Romani EA, Novaes PD, Marcondes FK: Chronic stress, but not hypercaloric diet, impairs vascular function in rats. Stress 2012, 15:138-148.

90. Pache M, Krauchi K, Cajochen C, Wirz-Justice A, Dubler B, Flammer J, Kaiser $\mathrm{HJ}$ : Cold feet and prolonged sleep-onset latency in vasospastic syndrome. Lancet 2001, 358:125-126.

91. Krauchi K, Cajochen C, Pache M, Flammer J, Wirz-Justice A: Thermoregulatory effects of melatonin in relation to sleepiness. Chronobiol Int 2006, 23:475-484

92. Vollenweider S, Wirz-Justice A, Flammer J, Orgul S, Krauchi K: Chronobiological characterization of women with primary vasospastic syndrome: body heat loss capacity in relation to sleep initiation and phase of entrainment. Am J Physiol Regul Integr Comp Physiol 2008, 294:R630-638.

93. Pistorius MA, Connault J, Kalassy C, Goueffic Y, Planchon B: Acute posttraumatic ischaemic of the limbs: algodystrophy or related syndrome? A prospective study on a series of 25 patients. Angiology 2008, 59:301-305.

94. Jehn A, Frank Dettwiler B, Fleischhauer J, Sturzenegger M, Mojon DS: Exercise-induced vasospastic amaurosis fugax. Arch Ophthalmol 2002, 120:220-222.

95. Anderson JE, Held N, Wright K: Raynaud's phenomenon of the nipple: a treatable cause of painful breastfeeding. Pediatrics 2004, 113:e360-364.

96. Page SM, McKenna DS: Vasospasm of the nipple presenting as painful lactation. Obstet Gynecol 2006, 108:806-808.

97. Hu CM, Lin YJ, Fan YK, Chen SP, Lai TH: Isolated thunderclap headache during sex: orgasmic headache or reversible cerebral vasoconstriction syndrome? J Clin Neurosci 2010, 17:1349-1351.

98. Schlegel D, Cucchiara B: Orgasmic headache with transient basilar artery vasospasm. Headache 2004, 44:710-712

99. Valenca MM, Valenca LP, Bordini CA, da Silva WF, Leite JP, Antunes-Rodrigues J, Speciali JG: Cerebral vasospasm and headache during sexual intercourse and masturbatory orgasms. Headache 2004, 44:244-248.

100. Mozaffarieh M, Hauenstein D, Schoetzau A, Konieczka K, Flammer J: Smell perception in normal tension glaucoma patients. Mol Vis 2010, 16:506-510

101. Wunderlich K, Zimmerman C, Gutmann H, Teuchner B, Flammer J, Drewe J: Vasospastic persons exhibit differential expression of ABC-transport proteins. Mol Vis 2003, 9:756-761.

102. Roussaki-Schulze AV, Zafiriou E, Nikoulis D, Klimi E, Rallis E, Zintzaras E: Objective biophysical findings in patients with sensitive skin. Drugs Exp Clin Res 2005, 31(Suppl):17-24.

103. Kaiser HJ, Erb C, Flammer J: Auge und Psyche. In Uexküll-Psychosomatische Medizin. 6th edition. Edited by Adler RH, Herrmann JM, Köhle K, Langewitz W, Schonecke OW, Uexküll T, Wesiak W. München: Urban \& Fischer; 2003:1169-1177. 
104. Whyte CA, Calabrese LH: Reversible cerebral vasoconstriction syndrome. Headache 2009, 49:597-598.

105. Hegyalijai T, Meienberg O, Dubler B, Gasser P: Cold-induced acral vasospasm in migraine as assessed by nailfold video-microscopy: prevalence and response to migraine prophylaxis. Angiology 1997, 48:345-349.

106. Schwedt TJ, Krauss MJ, Frey K, Gereau RW: Episodic and chronic migraineurs are hypersensitive to thermal stimuli between migraine attacks. Cephalalgia 2011, 31:6-12.

107. Chang JC, Shook LL, Biag J, Nguyen EN, Toga AW, Charles AC, Brennan KC: Biphasic direct current shift, haemoglobin desaturation and neurovascular uncoupling in cortical spreading depression. Brain 2010, 133:996-1012.

108. Wolf ME, Held VE, Forster A, Griebe M, Szabo K, Gass A, Hennerici MG, Kern R: Pearls \& oy-sters: dynamics of altered cerebral perfusion and neurovascular coupling in migraine aura. Neurology 2011, 77:e127-128.

109. Hill DL, Daroff RB, Ducros A, Newman NJ, Biousse V: Most cases labeled as "retinal migraine" are not migraine. J Neuroophthalmol 2007, 27:3-8.

110. Blessig E, Amburger N: Ein Fall von schwerer Flimmermigräne mit retinalen Angiospasmen. St Petersburger Medizinische Wochenschrift 1910, 45:1-15.

111. Lisch K. Ueber Vasopathie und Auge. Klin Monbl Augenheilkd 1939, 102:228-231.

112. Abdul-Rahman AM, Gilhotra JS, Selva D: Dynamic focal retinal arteriolar vasospasm in migraine. Indian J Ophthalmol 2011, 59:51-53.

113. Killer HE, Forrer A, Flammer J: Retinal vasospasm during an attack of migraine. Retina 2003, 23:253-254.

114. Wiedemann M, de Lima VM, Hanke W: Effects of antimigraine drugs on retinal spreading depression. Naunyn Schmiedebergs Arch Pharmacol 1996, 353:552-556.

115. Maclnnis MJ, Koehle MS, Rupert JL: Evidence for a genetic basis for altitude illness: 2010 update. High Alt Med Biol 2010, 11:349-368.

116. Morganti A, Giussani M, Sala C, Gazzano G, Marana I, Pierini A, Savoia MT, Ghio F, Cogo A, Zanchetti A: Effects of exposure to high altitude on plasma endothelin-1 levels in normal subjects. J Hypertens 1995, 13:859-865.

117. Palmer KT, Griffin MJ, Syddall HE, Pannett B, Cooper C, Coggon D: Raynaud's phenomenon, vibration induced white finger, and difficulties in hearing. Occup Environ Med 2002, 59:640-642.

118. Lee H, Whitman GT, Lim JG, Yi SD, Cho YW, Ying S, Baloh RW: Hearing symptoms in migrainous infarction. Arch Neurol 2003, 60:113-116.

119. Scherer EQ, Wangemann P: ETA receptors in the gerbil spiral modiolar artery. Adv Otorhinolaryngol 2002, 59:58-65.

120. Erb C, Preyer S, Thiel HJ: [Ophthalmologic findings in patients with sudden deafness]. Ophthalmologe 1996, 93:433-439.

121. Rance G, O'Hare F, O'Leary S, Starr A, Ly A, Cheng B, Tomlin D, Graydon K, Chisari D, Trounce I, Crowston J: Auditory processing deficits in individuals with primary open-angle glaucoma. Int J Audiol 2012, 51:10-15.

122. Pache M, Flammer J: A sick eye in a sick body? Systemic findings in patients with primary open-angle glaucoma. Surv Ophthalmol 2006, 51:179-212.

123. Choi YH, Chung JH, Bae SW, Lee WH, Jeong EM, Kang MG, Kim BJ, Kim KW, Park JE: Severe coronary artery spasm can be associated with hyperthyroidism. Coron Artery Dis 2005, 16:135-139.

124. DeTommasi A, Rogge S, Houghton JL: Refractory vasomotor angina in subclinical hyperthyroidism demonstrating focal and segmental coronary vasoconstriction. J Invasive Cardiol 2003, 15:289-292.

125. Hiasa Y, Ishida T, Aihara T, Bando M, Nakai Y, Kataoka Y, Mori H: Acute myocardial infarction due to coronary spasm associated with L-thyroxine therapy. Clin Cardiol 1989, 12:161-163.

126. Napoli R, Guardasole V, Zarra E, D'Anna C, De Sena A, Lupoli GA, Oliviero U, Matarazzo M, Lupoli G, Sacca L: Impaired endothelial- and nonendothelialmediated vasodilation in patients with acute or chronic hypothyroidism. Clin Endocrinol (Oxf) 2010, 72:107-111.

127. Cartwright MJ, Grajewski AL, Friedberg ML, Anderson DR, Richards DW: Immune-related disease and normal-tension glaucoma. A case-control study. Arch Ophthalmol 1992, 110:500-502.

128. Shagan BP, Friedman SA: Raynaud's phenomenon and thyroid deficiency. Arch Intern Med 1980, 140:832-833.

129. Gompper B, Bromundt V, Orgul S, Flammer J, Krauchi K: Phase relationship between skin temperature and sleep-wake rhythms in women with vascular dysregulation and controls under real-life conditions. Chronobiol Int 2010, 27:1778-1796.
130. al-Awami M, Schillinger M, Minar E: Vasospasm of the scrotum - a manifestation of Raynaud's phenomenon? Vasa 2004, 33:87-88.

131. Stammler F, Lawall H, Diehm C: Repeated attacks of pain in the nipple of a pregnant woman. Unusual manifestation of Raynaud's phenomenon. Dtsch Med Wochenschr 2003, 128:1825-1828.

132. Galassi F, Giambene B, Corvi A, Falaschi G, Menchini U: Retrobulbar hemodynamics and corneal surface temperature in glaucoma surgery. Int Ophthalmol 2008, 28:399-405.

133. Gugleta K, Orgul S, Flammer J: Is corneal temperature correlated with blood-flow velocity in the ophthalmic artery? Curr Eye Res 1999, 19:496-501.

134. Konieczka K, Flammer AJ, Neutzner A, Schoetzau A, Binggeli T, Flammer J: Refractoriness to the effect of endothelin-1 in porcine ciliary arteries. J Ocul Pharmacol Ther 2013, 29:488-492.

135. Cellini M, Possati GL, Profazio V, Sbrocca M, Caramazza N, Caramazza R: Color Doppler imaging and plasma levels of endothelin-1 in low-tension glaucoma. Acta Ophthalmol Scand Supp/ 1997, 224:11-13.

136. Chen HY, Chang YC, Chen WC, Lane HY: Association between plasma endothelin-1 and severity of different types of glaucoma. J Glaucoma 2013, 22:117-122.

137. Sugiyama T, Moriya S, Oku H, Azuma I: Association of endothelin-1 with normal tension glaucoma: clinical and fundamental studies. Surv Ophthalmol 1995, 39(Suppl 1):S49-56

138. Young Lee N, Park HY, Park CK, Ahn MD: Analysis of systemic endothelin-1 , matrix metalloproteinase-9, macrophage chemoattractant protein-1, and high-sensitivity C-reactive protein in normal-tension glaucoma. Curr Eye Res 2012, 37:1121-1126.

139. Kunimatsu S, Mayama C, Tomidokoro A, Araie M: Plasma endothelin-1 level in Japanese normal tension glaucoma patients. Curr Eye Res 2006, 31:727-731.

140. Emre M, Orgul S, Haufschild T, Shaw SG, Flammer J: Increased plasma endothelin-1 levels in patients with progressive open angle glaucoma. Br J Ophthalmol 2005, 89:60-63.

141. Kaiser HJ, Flammer J, Wenk M, Luscher T: Endothelin-1 plasma levels in normal-tension glaucoma: abnormal response to postural changes. Graefes Arch Clin Exp Ophthalmol 1995, 233:484-488.

142. Nicolela MT, Ferrier SN, Morrison CA, Archibald ML, LeVatte TL, Wallace K Chauhan BC, LeBlanc RP: Effects of cold-induced vasospasm in glaucoma: the role of endothelin-1. Invest Ophthalmol Vis Sci 2003, 44:2565-2572

143. Choritz L, Machert M, Thieme H: Correlation of endothelin-1 concentration in aqueous humor with intraocular pressure in primary open angle and pseudoexfoliation glaucoma. Invest Ophthalmol Vis Sci 2012, 53:7336-7342.

144. Wang J, Chiou WJ, Gagne GD, Wu-Wong JR: Internalization of type-A endothelin receptor. J Cardiovasc Pharmacol 2000, 36:S61-65.

145. Gass A, Flammer J, Linder L, Romerio SC, Gasser P, Haefeli WE: Inverse correlation between endothelin-1-induced peripheral microvascular vasoconstriction and blood pressure in glaucoma patients. Graefes Arch Clin Exp Ophthalmol 1997, 235:634-638.

146. Kim SH, Kim JY, Kim DM, Ko HS, Kim SY, Yoo T, Hwang SS, Park SS: Investigations on the association between normal tension glaucoma and single nucleotide polymorphisms of the endothelin-1 and endothelin receptor genes. Mol Vis 2006, 12:1016-1021.

147. Tzourio C, El Amrani M, Poirier O, Nicaud V, Bousser MG, Alperovitch A Association between migraine and endothelin type $A$ receptor (ETA -231 A/G) gene polymorphism. Neurology 2001, 56:1273-1277.

148. Krauchi K, Gompper B, Hauenstein D, Flammer J, Pfluger M, Studerus E, Schotzau A, Orgul S: Diurnal blood pressure variations are associated with changes in distal-proximal skin temperature gradient. Chronobiol Int 2012, 29:1273-1283.

149. Orgul S, Kaiser HJ, Flammer J, Gasser P: Systemic blood pressure and capillary blood-cell velocity in glaucoma patients: a preliminary study. Eur J Ophthalmol 1995, 5:88-91.

150. Gherghel D, Orgul S, Gugleta K, Flammer J: Retrobulbar blood flow in glaucoma patients with nocturnal over-dipping in systemic blood pressure. Am J Ophthalmol 2001, 132:641-647.

151. Kneale BJ, Chowienczyk PJ, Brett SE, Coltart DJ, Ritter JM: Gender differences in sensitivity to adrenergic agonists of forearm resistance vasculature. J Am Coll Cardiol 2000, 36:1233-1238.

152. Pechere-Bertschi A, Sunaric-Megevand G, Haefliger I, Panarello F, Maillard M, Burnier M: Renal sodium handling in patients with normal pressure glaucoma. Clin Sci (Lond) 2007, 112:337-344 
153. Kohan DE: Biology of endothelin receptors in the collecting duct. Kidney Int 2009, 76:481-486.

154. Prinzmetal M, Kennamer R, Merliss R, Wada T, Bor N: Angina pectoris. I. A variant form of angina pectoris; preliminary report. Am J Med 1959, 27:375-388

155. Yoshida K, Utsunomiya T, Morooka T, Yazawa M, Kido K, Ogawa T, Ryu T, Ogata T, Tsuji S, Tokushima T, Matsuo S: Mental stress test is an effective inducer of vasospastic angina pectoris: comparison with cold pressor, hyperventilation and master two-step exercise test. Int J Cardiol 1999, 70:155-163.

156. Group JCSJW: Guidelines for diagnosis and treatment of patients with vasospastic angina (coronary spastic angina) (JCS 2008): digest version. Circ J 2010, 74:1745-1762.

157. Stein JD, Kim DS, Niziol LM, Talwar N, Nan B, Musch DC, Richards JE: Differences in rates of glaucoma among Asian Americans and other racial groups, and among various Asian ethnic groups. Ophthalmology 2011, 118:1031-1037.

158. Kothawade K, Bairey Merz CN: Microvascular coronary dysfunction in women: pathophysiology, diagnosis, and management. Curr Probl Cardiol 2011, 36:291-318.

159. Rosen SD, Paulesu E, Wise RJ, Camici PG: Central neural contribution to the perception of chest pain in cardiac syndrome X. Heart 2002, 87:513-519.

160. Kaiser HJ, Flammer J, Burckhardt D: Silent myocardial ischaemic in glaucoma patients. Ophthalmologica 1993, 207:6-7.

161. Waldmann E, Gasser P, Dubler B, Huber C, Flammer J: Silent myocardial ischaemic in glaucoma and cataract patients. Graefes Arch Clin Exp Ophthalmol 1996, 234:595-598.

162. Flammer AJ, Ruschitzka F: Psoriasis and atherosclerosis: two plaques, one syndrome? Eur Heart J 2012, 33:1989-1991.

163. Flammer J, Konieczka K, Bruno RM, Virdis A, Flammer AJ, Taddei S: The eye and the heart. Eur Heart J 2013, 34:1270-1278.

164. Anders D, Vollenweider S, Cann J, Hofstetter M, Flammer J, Orgul S, Krauchi K: Heart-rate variability in women during 40-hour prolonged wakefulness. Chronobiol Int 2010, 27:1609-1628.

165. Wierzbowska J, Wierzbowski R, Stankiewicz A, Siesky B, Harris A: Cardiac autonomic dysfunction in patients with normal tension glaucoma: 24-h heart rate and blood pressure variability analysis. $\mathrm{Br} J$ Ophthalmol 2012, 96:624-628.

166. Gugleta K, Orgul S, Hasler PW, Picornell T, Gherghel D, Flammer J: Choroidal vascular reaction to hand-grip stress in subjects with vasospasm and its relevance in glaucoma. Invest Ophthalmol Vis Sci 2003, 44:1573-1580.

167. Kistler A, Mariauzouls C, von Berlepsch K: Fingertip temperature as an indicator for sympathetic responses. Int J Psychophysiol 1998, 29:35-41.

168. Brandstrom H, Wiklund U, Karlsson M, Angquist KA, Grip H, Haney M: Autonomic nerve system responses for normal and slow rewarmers after hand cold provocation: effects of long-term cold climate training. Int Arch Occup Environ Health 2013, 86:357-365.

169. Na KS, Lee NY, Park SH, Park CK: Autonomic dysfunction in normal tension glaucoma: the short-term heart rate variability analysis. J Glaucoma 2010, 19:377-381.

170. Lee NY, Park HY, Na KS, Park SH, Park CK: Association between heart rate variability and systemic endothelin-1 concentration in normal-tension glaucoma. Curr Eye Res 2013, 38:516-519.

171. Silva $A Q$, Schreihofer AM: Altered sympathetic reflexes and vascular reactivity in rats after exposure to chronic intermittent hypoxia. J Physiol 2011, 589:1463-1476.

172. Krauchi $K$, Deboer $T$ : The interrelationship between sleep regulation and thermoregulation. Front Biosci 2010, 15:604-625.

173. Krauchi $K$ : The thermophysiological cascade leading to sleep initiation in relation to phase of entrainment. Sleep Med Rev 2007, 11:439-451.

174. Krauchi K, Cajochen C, Werth E, Wirz-Justice A: Warm feet promote the rapid onset of sleep. Nature 1999, 401:36-37.

175. Yeghiazaryan K, Flammer J, Orgul S, Wunderlich K, Golubnitschaja O: Vasospastic individuals demonstrate significant similarity to glaucoma patients as revealed by gene expression profiling in circulating leukocytes. Mol Vis 2009, 15:2339-2348.

176. Yeghiazaryan K, Flammer J, Golubnitschaja O: Predictive molecular profiling in blood of healthy vasospastic individuals: clue to targeted prevention as personalised medicine to effective costs. EPMA J 2010, 1:263-272.

177. Golubnitschaja O, Flammer J: What are the biomarkers for glaucoma? Surv Ophthalmol 2007, 52(Suppl 2):S155-161.
178. Golubnitschaja O, Yeghiazaryan K, Flammer J: Key molecular pathways affected by glaucoma pathology: is predictive diagnosis possible? EPMA J 2010, 1:237-244.

179. Moenkemann H, Flammer J, Wunderlich K, Breipohl W, Schild HH, Golubnitschaja O: Increased DNA breaks and up-regulation of both $G(1)$ and $\mathrm{G}(2)$ checkpoint genes $\mathrm{p} 21$ (WAF1/CIP1) and 14-3-3 sigma in circulating leukocytes of glaucoma patients and vasospastic individuals. Amino Acids 2005, 28:199-205.

180. Mozaffarieh M, Schoetzau A, Sauter M, Grieshaber M, Orgul S, Golubnitschaja O, Flammer J: Comet assay analysis of single-stranded DNA breaks in circulating leukocytes of glaucoma patients. Mol Vis 2008 14:1584-1588.

181. Osborne NN, Del Olmo-Aguado S: Maintenance of retinal ganglion cell mitochondrial functions as a neuroprotective strategy in glaucoma. Curr Opin Pharmacol 2013, 13:16-22

182. Gasser P, Flammer J: Influence of vasospasm on visual function. Doc Ophthalmol 1987, 66:3-18.

183. Guthauser U, Flammer J, Mahler F: The relationship between digital and ocular vasospasm. Graefes Arch Clin Exp Ophthalmol 1988, 226:224-226.

184. Bebie H, Flammer J, Bebie T: The cumulative defect curve: separation of local and diffuse components of visual field damage. Graefes Arch Clin Exp Ophthalmol 1989, 227:9-12.

185. Brandl H, Lachenmayr B: [Dependence of the sensitivity of the central visual field on hemoglobin-oxygen saturation]. Ophthalmologe 1994, 91:151-155.

186. Flammer J, Drance SM, Fankhauser F, Augustiny L: Differential light threshold in automated static perimetry. Factors influencing short-term fluctuation. Arch Ophthalmol 1984, 102:876-879.

187. Flammer J, Drance SM, Schulzer M: Covariates of the long-term fluctuation of the differential light threshold. Arch Ophthalmol 1984, 102:880-882.

188. Flammer J, Drance SM, Augustiny L, Funkhouser A: Quantification of glaucomatous visual field defects with automated perimetry. Invest Ophthalmol Vis Sci 1985, 26:176-181.

189. Mozaffarieh M, Flammer J: New insights in the pathogenesis and treatment of normal tension glaucoma. Curr Opin Pharmacol 2013, 13:43-49.

190. Traquair HM: Spasm of central artery of retina. Trans Ophthalmol Soc UK 1948, 68:259-264.

191. Cogan DG: Life events and visual symptoms of Adolf Hitler (with personal anecdotes). Doc Ophthalmol 1995, 89:9-13.

192. Flammer J, Guthauser U, Mahler F: Do ocular vasospasms help cause low tension glaucoma? Doc Ophthalmol Proc Series 1987, 49:397-399.

193. Flammer J, Guthauser U: Behandlung chorioidaler Vasospasmen mit Kalziumantagonisten. Klin Mbl Augenheilk 1987, 190:299-300.

194. Prunte C, Flammer J, Markstein R, Rudin M: Quantification of optic nerve blood flow changes using magnetic resonance imaging. Invest Ophthalmol Vis Sci 1995, 36:247-251.

195. Grieshaber MC, Flammer J: Blood flow in glaucoma. Curr Opin Ophthalmol 2005, 16:79-83.

196. Flammer J, Jenni A, Bebie H, Keller B: The Octopus Glaucoma G1 program. Glaucoma 1987, 9:67-72.

197. Gasser P, Flammer J, Mahler F: [The use of calcium antagonists in the treatment of ocular circulation symptoms in the framework of a vasospastic syndrome]. Schweiz Med Wochenschr 1988, 118:201-202.

198. Araie M, Mayama C: Use of calcium channel blockers for glaucoma. Prog Retin Eye Res 2011, 30:54-71.

199. Flammer J, Drance SM: Effect of acetazolamide on the differential threshold. Arch Ophthalmol 1983, 101:1378-1380.

200. Pillunat LE, Lang GK, Harris A: The visual response to increased ocular blood flow in normal pressure glaucoma. Surv Ophthalmol 1994, 38 Suppl:S139-147. discussion S147-138.

201. Boehm AG, Breidenbach KA, Pillunat LE, Bernd AS, Mueller MF, Koeller AU: Visual function and perfusion of the optic nerve head after application of centrally acting calcium-channel blockers. Graefes Arch Clin Exp Ophthalmol 2003, 241:34-38

202. Gherghel D, Orgul S, Gugleta K, Gekkieva M, Flammer J: Relationship between ocular perfusion pressure and retrobulbar blood flow in patients with glaucoma with progressive damage. Am J Ophthalmol 2000, 130:597-605.

203. Hasler PW, Orgul S, Gugleta K, Vogten H, Zhao X, Gherghel D, Flammer J: Vascular dysregulation in the choroid of subjects with acral vasospasm. Arch Ophthalmol 2002, 120:302-307. 
204. Flammer J, Mozaffarieh M: Autoregulation, a balancing act between supply and demand. Can J Ophthalmol 2008, 43:317-321.

205. Kothy P, Suveges I, Vargha P, Hollo G: Cold pressor test and retinal capillary perfusion in vasospastic subjects with and without capsular glaucoma (a preliminary study). Acta Physiol Hung 1999, 86:245-252.

206. Gherghel D, Orgul S, Dubler B, Lubeck P, Gugleta K, Flammer J: Is vascular regulation in the central retinal artery altered in persons with vasospasm? Arch Ophthalmol 1999, 117:1359-1362.

207. Emre M, Orgul S, Gugleta K, Flammer J: Ocular blood flow alteration in glaucoma is related to systemic vascular dysregulation. $\mathrm{Br} J$ Ophthalmol 2004, 88:662-666.

208. Kochkorov A, Gugleta K, Zawinka C, Katamay R, Flammer J, Orgul S: Short-term retinal vessel diameter variability in relation to the history of cold extremities. Invest Ophthalmol Vis Sci 2006, 47:4026-4033.

209. Kawasaki R, Wang JJ, Rochtchina E, Lee AJ, Wong TY, Mitchell P: Retinal vessel caliber is associated with the 10-year incidence of glaucoma: the Blue Mountains Eye Study. Ophthalmology 2013, 120:84-90.

210. Gugleta K, Kochkorov A, Katamay R, Zawinka C, Flammer J, Orgul S: On pulse-wave propagation in the ocular circulation. Invest Ophthalmol Vis Sci 2006, 47:4019-4025.

211. Oettli A, Gugleta K, Kochkorov A, Katamay R, Flammer J, Orgul S: Rigidity of retinal vessel in untreated eyes of normal tension primary open-angle glaucoma patients. J Glaucoma 2011, 20:303-306

212. Kaur C, Foulds WS, Ling EA: Blood-retinal barrier in hypoxic ischaemic conditions: basic concepts, clinical features and management. Prog Retin Eye Res 2008, 27:622-647

213. Jo SM, Ryu HJ, Kim JE, Yeo SI, Kim MJ, Choi HC, Song HK, Kang TC: Up-regulation of endothelial endothelin-1 expression prior to vasogenic edema formation in the rat piriform cortex following status epilepticus. Neurosci Lett 2011, 501:25-30.

214. Wang L, Cioffi GA, Cull G, Dong J, Fortune B: Immunohistologic evidence for retinal glial cell changes in human glaucoma. Invest Ophthalmol Vis Sci 2002, 43:1088-1094.

215. Graf T, Flammer J, Prunte C, Hendrickson P: Gliosis-like retinal alterations in glaucoma patients. J Glaucoma 1993, 2:257-259.

216. Grieshaber MC, Orgul S, Schoetzau A, Flammer J: Relationship between retinal glial cell activation in glaucoma and vascular dysregulation. J Glaucoma 2007, 16:215-219.

217. Grieshaber MC, Moramarco F, Schoetzau A, Flammer J, Orguel S: Detection of retinal glial cell activation in glaucoma by time domain optical coherence tomography. Klin Monbl Augenheilkd 2012, 229:314-318.

218. Mozaffarieh M, Osusky R, Schotzau A, Flammer J: Relationship between optic nerve head and finger blood flow. Eur J Ophthalmol 2010, 20:136-141.

219. Polunina A, Gugleta K, Kochkorov A, Katamay R, Flammer J, Orgul S: Relationship between peripheral blood flow in extremities and choroidal circulation. Klin Monbl Augenheilkd 2011, 228:302-305.

220. Gherghel D, Hosking SL, Cunliffe IA: Abnormal systemic and ocular vascular response to temperature provocation in primary open-angle glaucoma patients: a case for autonomic failure? Invest Ophthalmol Vis Sci 2004, 45:3546-3554.

221. Bohdanecka Z, Orgul S, Meyer AB, Prunte C, Flammer J: Relationship between blood flow velocities in retrobulbar vessels and laser Doppler flowmetry at the optic disk in glaucoma patients. Ophthalmologica 1999, 213:145-149.

222. Quaranta L, Katsanos A, Russo A, Riva I: 24-hour intraocular pressure and ocular perfusion pressure in glaucoma. Surv Ophthalmol 2013, 58:26-41.

223. Firsching R, Muller C, Pauli SU, Voellger B, Rohl FW, Behrens-Baumann W: Noninvasive assessment of intracranial pressure with venous ophthalmodynamometry. Clinical article. J Neurosurg 2011, 115:371-374

224. Harder B, Jonas JB: Frequency of spontaneous pulsations of the central retinal vein. $\mathrm{Br} J$ Ophthalmol 2007, 91:401-402

225. Abegao Pinto L, Vandewalle E, De Clerck E, Marques-Neves C, Stalmans I: Lack of spontaneous venous pulsation: possible risk indicator in normal tension glaucoma? Acta Ophthalmol 2012. http://onlinelibrary.wiley.com/doi/10.1111/ j.1755-3768.2012.02472.x/abstract;jsessionid=C459560F6BD0A3A35C191C7BFAF D9875.d02t04.

226. Begg IS, Drance SM, Sweeney VP: Haemorrhage on the disc-a sign of acute ischaemic optic neuropathy in chronic simple glaucoma. Can J Ophthalmol 1970, 5:321-330.

227. Kottler MS, Drance SM: Studies of hemorrhage on the optic disc. Can J Ophthalmol 1976, 11:102-105.
228. Begg IS, Drance SM: Progress of the glaucomatous process related to recurrent ischaemic changes at the optic disc. Exp Eye Res 1971, 11:141.

229. Suh MH, Park KH, Kim H, Kim TW, Kim SW, Kim SY, Kim DM: Glaucoma progression after the first-detected optic disc hemorrhage by optical coherence tomography. J Glaucoma 2012, 21:358-366.

230. Wang YX, Hu LN, Yang H, Jonas JB, Xu L: Frequency and associated factors of structural progression of open-angle glaucoma in the Beijing Eye Study. Br J Ophthalmol 2012, 96:811-815.

231. Park HY, Park SH, Oh YS, Park CK: Nail bed hemorrhage: a clinical marker of optic disc hemorrhage in patients with glaucoma. Arch Ophthalmol 2011, 129:1299-1304.

232. Healey PR, Mitchell P, Smith W, Wang JJ: Optic disc hemorrhages in a population with and without signs of glaucoma. Ophthalmology 1998, 105:216-223.

233. Grieshaber MC, Terhorst T, Flammer J: The pathogenesis of optic disc splinter haemorrhages: a new hypothesis. Acta Ophthalmol Scand 2006, 84:62-68.

234. Flammer J: The vascular concept of glaucoma. Surv Ophthalmol 1994, 38(Suppl):S3-6.

235. Asrani S, Zeimer R, Wilensky J, Gieser D, Vitale S, Lindenmuth K: Large diurnal fluctuations in intraocular pressure are an independent risk factor in patients with glaucoma. J Glaucoma 2000, 9:134-142.

236. Flammer J, Eppler E, Niesel P: [Quantitative perimetry in the glaucoma patient without local visual field defects]. Graefes Arch Clin Exp Ophthalmol 1982, 219:92-94.

237. Kaiser HJ, Flammer J: Systemic hypotension: a risk factor for glaucomatous damage? Ophthalmologica 1991, 203:105-108.

238. Kaiser HJ, Flammer J, Graf T, Stumpfig D: Systemic blood pressure in glaucoma patients. Graefes Arch Clin Exp Ophthalmol 1993, 231:677-680.

239. Bonomi L, Marchini G, Marraffa M, Bernardi P, Morbio R, Varotto A: Vascular risk factors for primary open angle glaucoma: the Egna-Neumarkt Study. Ophthalmology 2000, 107:1287-1293.

240. Sung KR, Lee S, Park SB, Choi J, Kim ST, Yun SC, Kang SY, Cho JW, Kook MS Twenty-four hour ocular perfusion pressure fluctuation and risk of normal-tension glaucoma progression. Invest Ophthalmol Vis Sci 2009, 50:5266-5274

241. Kaiser HJ, Schoetzau A, Stumpfig D, Flammer J: Blood-flow velocities of the extraocular vessels in patients with high-tension and normal-tension primary open-angle glaucoma. Am J Ophthalmol 1997, 123:320-327.

242. Schumann J, Orgul S, Gugleta K, Dubler B, Flammer J: Interocular difference in progression of glaucoma correlates with interocular differences in retrobulbar circulation. Am J Ophthalmol 2000, 129:728-733.

243. Satilmis M, Orgul S, Doubler B, Flammer J: Rate of progression of glaucoma correlates with retrobulbar circulation and intraocular pressure. Am J Ophthalmol 2003, 135:664-669.

244. Flammer J, Orgul S: Optic nerve blood-flow abnormalities in glaucoma. Prog Retin Eye Res 1998, 17:267-289.

245. Galassi F, Sodi A, Ucci F, Renieri G, Pieri B, Baccini M: Ocular hemodynamics and glaucoma prognosis: a color Doppler imaging study. Arch Ophthalmol 2003, 121:1711-1715.

246. Gasser P, Flammer J: Blood-cell velocity in the nailfold capillaries of patients with normal-tension and high-tension glaucoma. Am J Ophthalmol 1991, 111:585-588.

247. Sines D, Harris A, Siesky B, Januleviciene I, Haine CL, Yung CW, Catoira Y, Garzozi HJ: The response of retrobulbar vasculature to hypercapnia in primary open-angle glaucoma and ocular hypertension. Ophthalmic Res 2007, 39:76-80.

248. Venkataraman ST, Hudson C, Rachmiel R, Buys YM, Markowitz SN, Fisher JA Trope GE, Flanagan JG: Retinal arteriolar vascular reactivity in untreated and progressive primary open-angle glaucoma. Invest Ophthalmol Vis Sci 2010, 51:2043-2050.

249. Venkataraman ST, Flanagan JG, Hudson C: Vascular reactivity of optic nerve head and retinal blood vessels in glaucoma-a review. Microcirculation 2010, 17:568-581.

250. Henry E, Newby DE, Webb DJ, Hadoke PW, O'Brien CJ: Altered endothelin-1 vasoreactivity in patients with untreated normal-pressure glaucoma. Invest Ophthalmol Vis Sci 2006, 47:2528-2532.

251. Ghanem AA, Elewa AM, Arafa LF: Endothelin-1 and nitric oxide levels in patients with glaucoma. Ophthalmic Res 2011, 46:98-102. 
252. Osborne NN, Casson RJ, Wood JP, Chidlow G, Graham M, Melena J: Retinal ischaemic: mechanisms of damage and potential therapeutic strategies. Prog Retin Eye Res 2004, 23:91-147.

253. Pache M, Dubler B, Flammer J: Peripheral vasospasm and nocturnal blood pressure dipping-two distinct risk factors for glaucomatous damage? Eur J Ophthalmol 2003, 13:260-265.

254. Flammer J, Mozaffarieh M: What is the present pathogenetic concept of glaucomatous optic neuropathy? Surv Ophthalmol 2007, 52(Suppl 2):S162-173.

255. Mozaffarieh M, Flammer J: Ocular blood flow and glaucomatous optic neuropathy. 1st edition. Berlin/Heidelberg: Springer; 2009.

256. Ganesh A, Mitra S, Koul RL, Venugopalan P: Spontaneous ophthalmic artery occlusion in a child. J Pediatr Ophthalmol Strabismus 2001, 38:183-185.

257. Karth $P$, Singh R, Kim J, Costakos D: Bilateral central retinal artery occlusions in an infant with hyperhomocysteinemia. J AAPOS 2012, 16:398-400.

258. Gutteridge IF, McDonald RA, Plenderleith JG: Branch retinal artery occlusion during a migraine attack. Clin Exp Optom 2007, 90:371-375.

259. Pournaras JA, Nguyen C, Mameletzi E, Zografos L, Wolfensberger TJ: Successful treatment of longstanding vasospastic central retinal artery occlusion. Acta Ophthalmol 2010, 88:e34-35.

260. Messerli J, Flammer J: [Central vein thrombosis in younger patients]. Klin Monbl Augenheilkd 1996, 208:303-305.

261. Schatz $H$, Fong $A C$, McDonald $H R$, Johnson RN, Joffe L, Wilkinson CP, de Laey JJ, Yannuzzi LA, Wendel RT, Joondeph BC, Angioletti LV, Meredith TA: Cilioretinal artery occlusion in young adults with central retinal vein occlusion. Ophthalmology 1991, 98:594-601.

262. Catier A, Paques M, Gaudric A: Retinal vasospasm in a case of impending central retinal vein occlusion. Retina 2003, 23:415-417.

263. Tanano I, Nagaoka T, Sogawa K, Tani T, Omae T, Nakabayashi S, Ishibazawa A, Yoshida A: Impaired systemic vascular endothelial function in patients with branch retinal vein occlusion. Curr Eye Res 2013, 38:114-118.

264. Flammer J, Messerli J, Haefliger I: [Vision disorders to vascular dysregulation]. Ther Umsch 1996, 53:37-42.

265. Gaspar AZ, Flammer J, Hendrickson P: Influence of nifedipine on the visual fields of patients with optic-nerve-head diseases. Eur J Ophthalmol 1994, 4:24-28.

266. Kordic H, Flammer J, Mironow A, Killer HE: Perioperative posterior ischemic optic neuropathy as a rare complication of blepharoplasty. Ophthalmologica 2005, 219:185-188.

267. Killer HE, Huber A, Portman C, Forrer A, Flammer J: Bilateral non-arteritic anterior ischemic optic neuropathy in a patient with autoimmune thrombocytopenia. Eur J Ophthalmol 2000, 10:180-182.

268. Susac JO, Hardman JM, Selhorst JB: Microangiopathy of the brain and retina. Neurology 1979, 29:313-316

269. Adatia FA, Sheidow TG: Central retinal artery occlusion as the initial ophthalmic presentation of Susac's syndrome. Can J Ophthalmol 2004 39:288-291.

270. Magro CM, Poe JC, Lubow M, Susac JO: Susac syndrome: an organ-specific autoimmune endotheliopathy syndrome associated with anti-endothelial cell antibodies. Am J Clin Pathol 2011, 136:903-912.

271. Flammer J, Kaiser H, Haufschild T: Susac syndrome: a vasospastic disorder? Eur J Ophthalmol 2001, 11:175-179.

272. Killer HE, Laeng HR, Flammer J, Groscurth P: Architecture of arachnoid trabeculae, pillars, and septa in the subarachnoid space of the human optic nerve: anatomy and clinical considerations. Br J Ophthalmol 2003, 87:777-781.

273. Killer HE, Jaggi GP, Flammer J, Miller NR, Huber AR, Mironov A: Cerebrospinal fluid dynamics between the intracranial and the subarachnoid space of the optic nerve. Is it always bidirectional? Brain 2007, 130:514-520.

274. Killer HE, Jaggi GP, Flammer J, Miller NR, Huber AR: The optic nerve: a new window into cerebrospinal fluid composition? Brain 2006, 129:1027-1030.

275. Jaggi GP, Flammer J, Huber AR, Killer HE: Lipocalin-like prostaglandin D synthase in subretinal fluid of detached retinas in humans. Retina 2008, 28:858-863.

276. Jaggi GP, Miller NR, Flammer J, Weinreb RN, Remonda L, Killer HE: Optic nerve sheath diameter in normal-tension glaucoma patients. $\mathrm{Br} J$ Ophthalmol 2012, 96:53-56.

277. Killer HE, Flammer J, Miller NR: Glaucoma and cerebrospinal fluid pressure. Ophthalmology 2008, 115:2316-2317. author reply 2317 .

278. Killer HE, Jaggi GP, Flammer J, Miller NR: Is open-angle glaucoma caused by impaired cerebrospinal fluid circulation: around the optic nerve? Clin Experiment Ophthalmol 2008, 36:308-311.
279. Killer HE, Miller NR, Flammer J, Meyer P, Weinreb RN, Remonda L, Jaggi GP. Cerebrospinal fluid exchange in the optic nerve in normal-tension glaucoma. Br J Ophthalmol 2012, 96:544-548.

280. Killer HE, Mironov A, Flammer J: Optic neuritis with marked distension of the optic nerve sheath due to local fluid congestion. Br J Ophthalmol 2003, 87:249.

281. Xin X, Fan B, Flammer J, Miller NR, Jaggi GP, Killer HE, Meyer P, Neutzner A: Meningothelial cells react to elevated pressure and oxidative stress. PLoS One 2011, 6:e20142.

282. Xin X, Fan B, Killer HE, Neutzner A, Flammer J, Meyer P: Primary cell culture of meningothelial cells-a new model to study the arachnoid in glaucomatous optic neuropathy. Graefes Arch Clin Exp Ophthalmol 2010, 248:1273-1278.

283. Fan B, Bordigari G, Flammer J, Killer HE, Meyer P, Neutzner A: Meningothelial cells participate in immunological processes in the cerebrospinal fluid. J Neuroimmunol 2012, 244:45-50.

284. Xin X, Huber A, Meyer P, Flammer J, Neutzner A, Miller NR, Killer HE: L-PGDS (betatrace protein) inhibits astrocyte proliferation and mitochondrial ATP production in vitro. J Mol Neurosci 2009, 39:366-371.

285. Jaggi GP, Killer HE: Re: "D2-40 expression demonstrates lymphatic vessel characteristics in the dural portion of the optic nerve sheath". Ophthal Plast Reconstr Surg 2007, 23:504-505. author reply 505.

286. Killer HE, Jaggi GP, Miller NR, Flammer J, Meyer P: Does immunohistochemistry allow easy detection of lymphatics in the optic nerve sheath? J Histochem Cytochem 2008, 56:1087-1092.

287. Killer HE, Laeng HR, Groscurth P: Lymphatic capillaries in the meninges of the human optic nerve. J Neuroophthalmol 1999, 19:222-228.

288. Prunte C, Flammer J: Choroidal capillary and venous congestion in central serous chorioretinopathy. Am J Ophthalmol 1996, 121:26-34.

289. Grieshaber MC, Staub JJ, Flammer J: The potential role of testosterone in central serous chorioretinopathy. Br J Ophthalmol 2007, 91:118-119.

290. Yu-Wai-Man P, Griffiths PG, Chinnery PF: Mitochondrial optic neuropathies - disease mechanisms and therapeutic strategies. Prog Retin Eye Res 2011, 30:81-114.

291. Beretta S, Ferrarese C, Wood JP, Osborne NN, Carelli V: Pathogenesis of retinal ganglion cell death in Leber hereditary optic neuropathy (LHON): possible involvement of mitochondria, light and glutamate. Mitochondrion 2006, 6:102-103.

292. Opial D, Boehnke M, Tadesse S, Lietz-Partzsch A, Flammer J, Munier F, Mermoud A, Hirano M, Fluckiger F, Mojon DS: Leber's hereditary optic neuropathy mitochondrial DNA mutations in normal-tension glaucoma. Graefes Arch Clin Exp Ophthalmol 2001, 239:437-440.

293. Konieczka K, JF A, Todorova M, Meyer P, Flammer J: Retinitis pigmentosa and ocular blood flow. EPMA J 2012, 3:17.

294. del Olmo-Aguado S, Manso AG, Osborne NN: Light might directly affect retinal ganglion cell mitochondria to potentially influence function. Photochem Photobiol 2012, 88:1346-1355.

295. Osborne NN: Mitochondria: their role in ganglion cell death and survival in primary open angle glaucoma. Exp Eye Res 2010, 90:750-757.

296. Osborne NN, Li GY, Ji D, Mortiboys HJ, Jackson S: Light affects mitochondria to cause apoptosis to cultured cells: possible relevance to ganglion cell death in certain optic neuropathies. J Neurochem 2008, 105:2013-2028.

297. Kaiser HJ, Flammer J, Miller G: Chronic light damage to the macula of an endoscopist. Gastrointest Endosc 1992, 38:401-402.

298. Yoshida K, Ohguro I, Ohguro H: Black currant anthocyanins normalized abnormal levels of serum concentrations of endothelin- 1 in patients with glaucoma. J Ocul Pharmacol Ther 2013, 29:480-487.

299. Corti R, Flammer AJ, Hollenberg NK, Luscher TF: Cocoa and cardiovascular health. Circulation 2009, 119:1433-1441.

300. Badjatia N, Seres D, Carpenter A, Schmidt JM, Lee K, Mayer SA, Claassen J, Connolly ES, Elkind MS: Free Fatty acids and delayed cerebral ischaemic after subarachnoid hemorrhage. Stroke 2012, 43:691-696.

301. Zhang B, Rusciano D, Osborne NN: Orally administered epigallocatechin gallate attenuates retinal neuronal death in vivo and light-induced apoptosis in vitro. Brain Res 2008, 1198:141-152.

302. Pechere-Bertschi A, Nussberger J, Biollaz J, Fahti M, Grouzmann E, Morgan T, Brunner HR, Burnier M: Circadian variations of renal sodium handling in patients with orthostatic hypotension. Kidney Int 1998, 54:1276-1282.

303. Dettmann ES, Luscher TF, Flammer J, Haefliger IO: Modulation of endothelin-1-induced contractions by magnesium/calcium in porcine ciliary arteries. Graefes Arch Clin Exp Ophthalmol 1998, 236:47-51. 
304. Gaspar AZ, Gasser P, Flammer J: The influence of magnesium on visual field and peripheral vasospasm in glaucoma. Ophthalmologica 1995, 209:11-13.

305. Gasser P, Flammer J: Short- and long-term effect of nifedipine on the visual field in patients with presumed vasospasm. J Int Med Res 1990, 18:334-339.

306. Lang MG, Zhu P, Meyer P, Noll G, Haefliger IO, Flammer J, Luscher TF: Amlodipine and benazeprilat differently affect the responses to endothelin-1 and bradykinin in porcine ciliary arteries: effects of a low and high dose combination. Curr Eye Res 1997, 16:208-213.

307. Meyer P, Lang MG, Flammer J, Luscher TF: Effects of calcium channel blockers on the response to endothelin-1, bradykinin and sodium nitroprusside in porcine ciliary arteries. Exp Eye Res 1995, 60:505-510.

308. Gasser P: Reaction of capillary blood cell velocity in nailfold capillaries to nifedipine and ketanserin in patients with vasospastic disease. J Int Med Res 1991, 19:24-31.

309. Koseki N, Araie M, Tomidokoro A, Nagahara M, Hasegawa T, Tamaki Y, Yamamoto S: A placebo-controlled 3-year study of a calcium blocker on visual field and ocular circulation in glaucoma with low-normal pressure. Ophthalmology 2008, 115:2049-2057.

310. Grieshaber MC, Flammer J: Is the medication used to achieve the target intraocular pressure in glaucoma therapy of relevance?-an exemplary analysis on the basis of two beta-blockers. Prog Retin Eye Res 2010, 29:79-93.

311. Osborne NN, Wood JP, Cupido A, Melena J, Chidlow G: Topical flunarizine reduces IOP and protects the retina against ischaemic-excitotoxicity. Invest Ophthalmol Vis Sci 2002, 43:1456-1464.

312. Mozaffarieh M, Konieczka K, Flammer J: Calcium channel blockers: their use in normal tension glaucoma. Expert Rev Ophthalmol 2010, 5:617-625.

313. Krishnan U, Win W, Fisher M: First report of the successful use of bosentan in refractory vasospastic angina. Cardiology 2010, 116:26-28.

314. Shigeno T, Clozel M, Sakai S, Saito A, Goto K: The effect of bosentan, a new potent endothelin receptor antagonist, on the pathogenesis of cerebral vasospasm. Neurosurgery 1995, 37:87-90. discussion 90-81.

315. Pham I, Wuerzner G, Richalet JP, Peyrard S, Azizi M: Bosentan effects in hypoxic pulmonary vasoconstriction: preliminary study in subjects with or without high altitude pulmonary edema-history. Pulm Circ 2012, 2:28-33.

316. Resch H, Karl K, Weigert G, Wolzt M, Hommer A, Schmetterer L, Garhofer G: Effect of dual endothelin receptor blockade on ocular blood flow in patients with glaucoma and healthy subjects. Invest Ophthalmol Vis Sci 2009, 50:358-363.

317. Konieczka K, Meyer P, Schoetzau A, Neutzner A, Mozaffarieh M, Flammer J: Effect of avosentan (SPP-301) in porcine ciliary arteries. Curr Eye Res 2011, 36:118-124.

318. Syed H, Safa R, Chidlow G, Osborne NN: Sulfisoxazole, an endothelin receptor antagonist, protects retinal neurones from insults of ischaemic/ reperfusion or lipopolysaccharide. Neurochem Int 2006, 48:708-717.

319. Lanier JB, Mote MB, Clay EC: Evaluation and management of orthostatic hypotension. Am Fam Physician 2011, 84:527-536.

320. Gugleta K, Orgul S, Stumpfig D, Dubler B, Flammer J: Fludrocortisone in the treatment of systemic hypotension in primary open-angle glaucoma patients. Int Ophthalmol 1999, 23:25-30.

321. Paterson G: Effect of intravenous acetazolamide on relative arcuate scotomas and visual field in glaucoma simplex. Proc $R$ Soc Med 1970, 63:865-869.

322. Heilmann K: Intraocular pressure, blood pressure, and glaucoma damage. Comparative perimetric studies on the relationship between the increase of intraocular pressure, blood sedimentation, and visual-field disorders in primary glaucoma. Buch Augenarzt 1972, 61:1-82.

323. Flammer J, Drance SM: Reversibility of a glaucomatous visual field defect after acetazolamide therapy. Can J Ophthalmol 1983, 18:139-141.

324. Ohguro I, Ohguro $\mathrm{H}$ : The effects of a fixed combination of $0.5 \%$ timolol and $1 \%$ dorzolamide on optic nerve head blood circulation. J Ocul Pharmacol Ther 2012, 28:392-396

325. Cybulska-Heinrich AK, Mozaffarieh M, Flammer J: Ginkgo biloba: an adjuvant therapy for progressive normal and high tension glaucoma. Mol Vis 2012, 18:390-402

326. Kim DY, Silverman RH, Chan RV, Khanifar AA, Rondeau M, Lloyd H, Schlegel P, Coleman DJ: Measurement of choroidal perfusion and thickness following systemic sildenafil (Viagra ${ }^{\oplus}$ ). Acta Ophthalmol 2013, 91:183-188.
327. Pache M, Meyer P, Prunte C, Orgul S, Nuttli I, Flammer J: Sildenafil induces retinal vasodilatation in healthy subjects. Br J Ophthalmol 2002, 86:156-158.

328. Meyer P, Flammer J, Luscher TF: Effect of dipyridamole on vascular responses of porcine ciliary arteries. Curr Eye Res 1996, 15:387-393.

329. Kaiser HJ, Stumpfig D, Flammer J: Short-term effect of dipyridamole on blood flow velocities in the extraocular vessels. Int Ophthalmol 1995, 19:355-358

doi:10.1186/1878-5085-4-14

Cite this article as: Flammer et al:: The primary vascular dysregulation syndrome: implications for eye diseases. The EPMA Journal 2013 4:14.

\section{Submit your next manuscript to BioMed Central and take full advantage of:}

- Convenient online submission

- Thorough peer review

- No space constraints or color figure charges

- Immediate publication on acceptance

- Inclusion in PubMed, CAS, Scopus and Google Scholar

- Research which is freely available for redistribution

Submit your manuscript at www.biomedcentral.com/submit
C BioMed Central 